Métodos heurísticos para um problema de planejamento da produção em uma indústria química 
SERVIÇO DE PÓS-GRADUAÇÃO DO ICMC-USP

Data de Depósito:

Assinatura:

\title{
Métodos heurísticos para um problema de planejamento da produção em uma indústria química
}

\author{
Artur Lovato da Cunha
}

Orientadora: Profa. Dra. Maristela Oliveira dos Santos

Dissertação apresentada ao Instituto de Ciências Matemáticas e de Computação - ICMC-USP, como parte dos requisitos para obtenção do título de Mestre em Ciências - Ciências de Computação e Matemática Computacional. VERSÃO REVISADA 
Ficha catalográfica elaborada pela Biblioteca Prof. Achille Bassi e Seção Técnica de Informática, ICMC/USP, com os dados fornecidos pelo(a) autor(a)

\begin{tabular}{|c|c|}
\hline \multirow[t]{3}{*}{$\mathrm{C} 972 \mathrm{~m}$} & $\begin{array}{l}\text { Cunha, Artur Lovato } \\
\text { Métodos heurísticos para um problema de } \\
\text { planejamento da produção em uma indústria química / } \\
\text { Artur Lovato Cunha; orientadora Maristela oliveira } \\
\text { Santos. -- São Carlos, } 2013 \text {. } \\
\quad 94 \mathrm{p} \text {. }\end{array}$ \\
\hline & $\begin{array}{l}\text { Dissertação (Mestrado - Programa de Pós-Graduação } \\
\text { em Ciências de Computação e Matemática } \\
\text { Computacional) -- Instituto de Ciências Matemáticas } \\
\text { e de Computação, Universidade de São Paulo, } 2013 .\end{array}$ \\
\hline & $\begin{array}{l}\text { 1. Dimensionamento de Lotes. 2. Indústria } \\
\text { Química. 3. Heurísticas. 4. Otimização Combinatória. I } \\
\text { Santos, Maristela oliveira, orient. II. Título. }\end{array}$ \\
\hline
\end{tabular}




\section{AGRADECIMENTOS}

Em primeiro lugar gostaria de agradecer aos meus pais Luiz e Edir e a minha tia Goreti, por todo o apoio que recebi desde que entrei na faculdade.

À minha namorada Loriz pela ajuda nos momentos mais difíceis dessa etapa da minha vida.

À minha orientadora Maristela pela contribuição na minha formação e pela paciência e auxílio no decorrer deste trabalho.

Aos professores Alysson, Franklina e Marina por acrescentarem conteúdo aos meus conhecimentos de otimização.

À Pâmela pelos conselhos e pelo auxílio na correção deste trabalho.

Ao Luiz Henrique, Daniel (Pinguim) e Lucas pela ajuda com as disciplinas e pelas horas de descontração.

Aos membros da banca pelas sugestões de aprimoramento deste trabalho.

Ao CNPq pelo apoio financeiro parcial deste trabalho. 



\section{RESUMO}

Neste trabalho foi estudado um problema de dimensionamento de lotes em uma indústria química brasileira, cujo objetivo era determinar o tamanho dos lotes dos produtos para atender às demandas, minimizando os custos produtivos. Os itens podem ser produzidos em máquinas paralelas distintas, através de diferentes processos, e devem ser armazenados em taques cativos, exclusivos a um produto, ou multipropósitos, compartilhado entre produtos, desde que não simultaneamente. Foram propostos dois modelos matemáticos de programação inteira mista para representar o problema, o primeiro apresentava uma função objetivo compreendendo o preço das matérias-primas consumidas nas reações, os gastos com a estocagem de produtos e o custo de descarte de produtos quando os tanques de armazenamento não tiverem capacidade suficiente para armazená-los, já o segundo estendendo este modelo para considerar custos de preparação de máquina. Experimentos computacionais com os modelos propostos, utilizando instâncias geradas a partir dos dados fornecidos pela empresa, mostraram que o software de otimização empregado foi capaz de resolver poucas instâncias, após uma hora de processamento. Portanto, foram propostas heurísticas construtivas do tipo LP-and-fix e relax-and-fix, além de heurísticas de melhoria do tipo fix-and-optimize. Após serem realizados testes com essas heurísticas, constatou-se que algumas proporcionaram a obtenção de soluções factíveis de boa qualidade, quando comparadas às obtidas pelo software, sendo ainda capazes de resolver um maior número de instâncias.

Palavras-chave: Dimensionamento de Lotes, indústria química, heurísticas, otimização combinatória. 



\section{ABSTRACT}

In this dissertation the lot sizing problem in a chemical Brazilian industry was studied, with the goal to determine the products' lot size to satisfy the demands, minimizing the production costs. The items can be produced on distinct parallel machines through different processes and then must be stored in exclusive tanks, used by only one product, or multipurpose tanks, when more than one product can use the tank, but not simultaneously. Two models were proposed to represent the problem, the first one aiming to minimize the price of raw material consumed in the reactions, storage product spending and the cost of discarting products when the storage tanks do not have enough capacity to store them, and the second one considering setup cost either. Computational experiments using the proposed models, with instances were generated from the data provided by the company, showed that the used optimization software was able to solve only few instances after processing for one hour. In this dissertation we propose constructives heuristics such LP-and-fix and relax-and-fix, and improving heuristics like fix-and-optimize. After performing the tests with those heuristics, it was found that some of them provided feasible solutions with good quality, when compared to the ones obtained by the software, and they were also able to solve a larger number of instances.

KEYWORDS: Lot Sizing, chemical insdustry, heuristics, combinatorial optimization. 



\section{SUMÁRIO}

1 Introdução

p. 1

2 Revisão Bibliográfica $\quad$ p. 5

2.1 Dimensionamento de Lotes Monoestágio $\ldots \ldots \ldots \ldots$

2.2 Dimensionamento de Lotes Multiestágio . . . . . . . . . . . . . . p. 15

2.3 Problema com Máquinas Paralelas . . . . . . . . . . . . . . . . p. 22

2.4 Problema com Múltiplos Processos . . . . . . . . . . . . . . . p. 25

2.5 Problema de Dimensionamento de Lotes na Indústria Química . . . . . . . . p. 26

3 Definição do Problema e Modelagem Matemática $\quad$ p. 29

3.1 A Indústria Química . . . . . . . . . . . . . . . . . . . . p. 29

3.2 Descrição do Problema . . . . . . . . . . . . . . . p. 30

3.3 Modelagem Matemática . . . . . . . . . . . . . . p. 35

3.3 .1 Modelo Principal . . . . . . . . . . . . . p. 36

3.3.2 Modelo Considerando Custo de Setup . . . . . . . . . . . . . p. 38

3.4 Estudos de Modelos Matemáticos . . . . . . . . . . . . . . p. 39

4 Métodos de Solução $\quad$ p. 47 


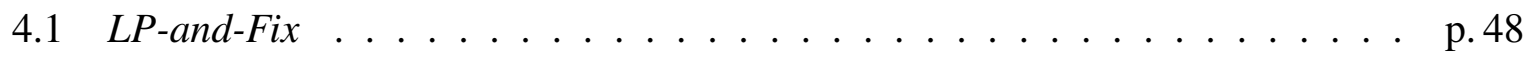

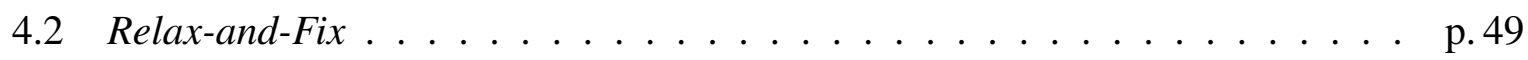

4.2.1 Estratégias de Particionamento . . . . . . . . . . . . . . p. 51

4.2.2 Estratégia para Selecionar Soluções . . . . . . . . . . . . p. 53

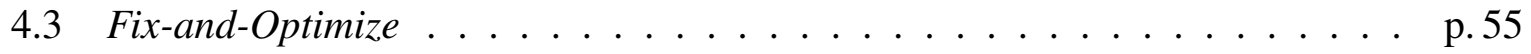

5 Geração das Instâncias $\quad$ p. 57

5.1 Introdução . . . . . . . . . . . . . . . . . . . . . p. 57

5.2 Tratamento Inicial dos Dados $\ldots \ldots \ldots \ldots \ldots \ldots \ldots$

5.3 Geração dos Dados . . . . . . . . . . . . . . . . . p. 58

5.4 Estruturas do Problema . . . . . . . . . . . . . . p. 63

$\begin{array}{llr}6 & \text { Testes Computacionais } & \text { p. } 67\end{array}$

6.1 Critérios de Parada . . . . . . . . . . . . . . . . . p. 68

6.2 Testes Iniciais $\ldots \ldots \ldots \ldots \ldots \ldots$

6.3 Definição de Parâmetros . . . . . . . . . . . . . . p. 71

6.3.1 Tempo Utilizado nos Experimentos . . . . . . . . . . . p.71

6.3.2 Tamanho do Pool de Soluções . . . . . . . . . . . . . . p. 75

6.3.3 Custo de Preparação de Máquinas . . . . . . . . . . . . . . p. p77

6.4 Testes Finais $\ldots \ldots \ldots \ldots \ldots \ldots \ldots \ldots \ldots \ldots$

6.4.1 Desempenho das Heurísticas Propostas . . . . . . . . . . p.78

6.4.2 Instâncias Similares ao Problema da Indústria . . . . . . . . . . . p. 81

6.4.3 Compartilhamento de Tanques Exclusivo a Produtos Intermediários p. 83

6.4.4 Modelo Considerando Custos de Preparação de Máquina . . . . . . . p. 83

7 Conclusões e Trabalhos Futuros p 85

$\begin{array}{lr}\text { Referências Bibliográficas } & \text { p. } 89\end{array}$ 


\section{LISTA DE TABELAS}

3.1 Parâmetros definidos pelo mercado. . . . . . . . . . . . . p. 41

3.2 Solução ótima para a função objetivo dada pela equação $(3.30)$. . . . . . . . p. p.43

3.3 Solução ótima para a função objetivo dada pela equação (3.1) . . . . . . . . . p.44

3.4 Solução ótima para a função objetivo dada pela equação $(3.10) \ldots \ldots$. . . . . p. 45

5.1 Estrutura dos Dados do Problema . . . . . . . . . . . . . . p. 63

6.1 GAPs relativos médios das heurísticas construtivas. . . . . . . . . . p. 70

6.2 Média dos GAPs relativos com divisão crescente do tempo entre as iterações . p.73

6.3 Média dos GAPs relativos com divisão decrescente do tempo entre as iterações p.73

6.4 Média dos GAPs relativos com divisão igualitária do tempo entre as iterações p.73

6.5 Média dos GAPs relativos com divisão igualitária do tempo entre as iterações p.74

6.6 Redução média do número de preparação de máquinas, utilizando a heurística

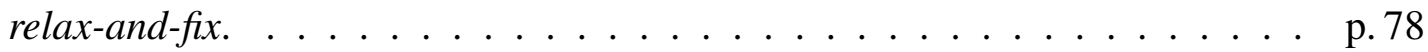

6.7 Resumo dos parâmetros determinados na Seção 6.3 . . . . . . . . . . . . p. 78

6.8 Variação do GAP médio para as heurísticas construtivas. $\quad \ldots \ldots$. . . . . . p. 79

6.9 Tempo de execução médio para as heurísticas construtivas. . . . . . . . p p. 80

6.10 Variação do GAP médio para as heurísticas de melhoria. . . . . . . . . . p. 81

6.11 Resultados obtidos pelas heurísticas para instâncias similares ao problema real. p. 82 
6.12 Resultados obtidos pelas heurísticas para instâncias com compartilhamento de tanques apenas pelos produtos intermediários. . . . . . . . . p. 83

6.13 Resultados obtidos pelas heurísticas considerando o custo de setup . . . . . . p. 84 


\section{LISTA DE FIGURAS}

2.1 Representação do modelo Economic Order Quantity (HARRIS, 1913). . . . . p.6

2.2 Estratégias de varredura propostas por Maes e Wassenhove (1986). . . . . . . p. 10

2.3 Partição do horizonte de planejamento de (MERCÉ; FONTAN, 2003). . . . . p. 14

2.4 Estruturas de produto: (a) Serial, (b) Paralelo, (c) Montagem e (d) Geral. . . . p. 15

3.1 Fluxograma resumido do processo produtivo da indústria em estudo. . . . . . p. 32

3.2 Processo produtivo detalhado de um item. . . . . . . . . . . . p. 33

3.3 Processo de embalagem dos produtos. . . . . . . . . . . . p. 34

3.4 Processo de transferência dos produtos entre as unidades produtivas. . . . . . p. 34

3.5 Estrutura de processos produtivos para fins didáticos. . . . . . . . . p. 39

3.6 Estrutura de produto simplificada. . . . . . . . . . . . p. 40

3.7 Concorrência dos reatores (a) e do tanque (b) pelos produtos P1 e P2. . . . . p. 40

4.1 Representação genérica de uma heurística $L P$-and-fix . . . . . . . . . . . . p. 48

4.2 Representação genérica de uma heurística relax-and-fix. . . . . . . . . p. 50

4.3 Relax-and-fix forward com partição por período. . . . . . . . . . p.51

4.4 Relax-and-fix com partição por itens. . . . . . . . . . . . . p. 52

4.5 Estrutura de produtos com três níveis. . . . . . . . . . . p. 53

4.6 Relax-and-fix com partição por níveis. . . . . . . . . . . . p. 53 
4.7 Relax-and-fix com partição por níveis. . . . . . . . . . . . p. 54

4.8 Representação genérica de uma heurística fix and optimize. . . . . . . . . . p. 55

5.1 Remoção de produto intermediário com demanda nula. Estrutura de quatro níveis (a), estrutura de três níveis $(b) \ldots \ldots$. . . . . . . . . . . . . p.59

5.2 Divisão da demanda entre processos para determinação da demanda total. . . p. 60

5.3 Contribuição de cada reação para determinação da capacidade dos reatores. p.61

5.4 Contribuição de cada reação para determinação da capacidade dos reatores. p. 62

5.5 Estrutura de produto completa da unidade produtiva em estudo. . . . . . . . p. 64

5.6 Compartilhamento dos reatores entre as estruturas de produtos. . . . . . . p. 65

5.7 Estrutura de relacionamento para a utilização dos reatores no processo produtivo. .............................. 66

6.1 Diferença média das soluções para a política de divisão igualitária de tempo entre as iterações. . . . . . . . . . . . . . . . . . . . p. 72

6.2 Variação das soluções para o compartilhamento médio de tanques utilizando a divisão de tempo igualitária do tempo de execução. . . . . . . . . . . p. 75

6.3 Redução do GAP médio para instâncias monoestágio com a variação do tamanho do pool de soluções. . . . . . . . . . . . . . . . . p. 75

6.4 Redução do GAP médio para instâncias multiestágio com a variação do tamanho do pool de soluções. . . . . . . . . . . . . . . . . p. 76

6.5 Redução do GAP médio para instâncias multiestágio, com compartilhamento mínimo de tanques, pela variação do tamanho do pool de soluções. . . . . . . p.77 


\section{CAPÍTULO 1}

\section{INTRODUÇÃO}

A partir da revolução industrial, em meados do século XVIII, constatou-se que a automação de processos produtivos proporciona vantagens econômicas sobre os processos manuais, dentre os quais podemos destacar o aumento da produtividade, a redução do tempo e do custo de processamento, assim como a diminuição do quadro de funcionários, o que contribuiu diretamente para a ampliação do lucro das indústrias.

Passados quase três séculos do início dessa revolução, o processo de industrialização foi disseminado por todos os setores da economia. Já nas últimas décadas, devido à expansão da economia mundial, observou-se uma acentuação na agressividade das decisões estratégicas das companhias, ocasionando um processo de fusão e aquisição de empresas que resultou em diversas multinacionais.

Esses fatores contribuíram para o atual cenário de elevada competitividade entre as empresas, o que torna indispensável a busca constante por processos mais eficientes em todos os seus setores, desde a aquisição de matérias-primas e da cadeia produtiva, até o marketing e o serviço de atendimento ao consumidor. Essas melhorias são fundamentais para a sobrevivência das empresas, tendo em vista que as multinacionais, além de competirem entre si, devem estar atentas ao crescimento das indústrias nacionais, e estas devem estar preparadas para não perderem espaço no mercado para outras empresas.

Para determinar as ações a serem seguidas, as empresas requerem uma série de decisões gerenciais que enquadram-se em três níveis: decisões estratégicas, de planejamento e de controle (CHOPRA; MEINDL, 2008): 
- Decisões Estratégicas (Longo Prazo): relacionadas à localização das fábricas, à ampliação da capacidade produtiva, ao lançamento de novos produtos, às instalações de armazenamento, aos meios de transporte e aos sistemas de informação utilizados;

- Decisões de Planejamento (Médio Prazo): relacionadas aos controles de estoque de produtos e matérias-primas, à terceirização da produção ou contração de horas extras e à dimensão das campanhas de marketing;

- Decisões Operacionais (Curto Prazo): relacionadas ao sequenciamento da produção para atender às datas de entrega dos períodos, à frequência de manutenções preventivas, à geração de inventário de estoque e à organização das entregas dos caminhões.

Um dos aspectos importantes para o sucesso de uma empresa está nas decisões relacionadas à sua linha produtiva, dentre as quais o planejamento e controle da produção (PCP) é fundamental, por ser uma atividade que consiste em determinar a aquisição de matérias-primas e a alocação de recursos, geralmente limitados, para a manufatura de produtos, visando atender à demanda dos clientes em um determinado horizonte de tempo, minimizando os custos produtivos.

Outra característica fundamental para a empresa é como sua linha produtiva foi planejada, pois durante as decisões estratégicas pode-se optar por uma linha de produção contínua, ou seja, monta-se uma linha para produzir um item por um longo período, ininterruptamente, ou então pode-se optar pela construção de linhas produtivas por batelada, as quais são amplamente utilizadas nas indústrias de corantes, farmacêuticas, de cosméticos, entre outras (MAUDERLI; RIPPIN, 1979). Essas indústrias utilizam equipamentos denominados reatores, nos quais ocorrem as reações químicas entre os insumos. O que diferencia reatores de meros tanques é o fato dos primeiros controlarem pressão, temperatura e fluxo da mistura entre os reagentes. Além disso, os materiais utilizados em seus núcleos são cuidadosamente analisados para não interferirem nem contaminarem as reações.

As indústrias que utilizam sistemas de produção por batelada apresentam maior flexibilidade do que as de produção contínua (MAUDERLI; RIPPIN, 1979), pois a atividade de encerrar um processo produtivo e, em seguida, iniciar a produção de um novo item é muito demorada para linhas de produção contínuas.

Analisando as operações de uma empresa, é natural que a demanda de produtos sofram variações no decorrer do ano devido a fatores como sazonalidade, surgimento de novas empresas, desenvolvimento de novos produtos, entre outros. Sendo assim, quando há presença de linhas produtivas com reatores de batelada, pode-se atender à demanda dos itens apenas alocando-se 
mais ou menos equipamentos para sua produção.

Apesar da flexibilidade proporcionada pelos sistemas de produção por batelada, estes apresentam um inconveniente que não é observado nos sistemas de produção contínua: a necessidade de decidir quais reatores devem produzir quais itens em cada período, garantindo a melhor utilização da planta. Esta atividade pode ser decomposta em duas etapas, uma que compreende o problema do dimensionamento de lotes (PDL) e outra correspondendo o problema de sequenciamento da produção.

O problema do dimensionamento de lotes (lot sizing problem) corresponde a uma atividade de médio prazo e será o foco de pesquisa desta dissertação. Cabe a esta atividade a responsabilidade por determinar o tamanho dos lotes que serão produzidos em cada reator. Dessa forma, quando o dimensionamento de lotes é efetuado em um sistema de produção por bateladas, origina-se um problema inteiro, visto que os reatores devem ser preenchidos completamente para que o processo ocorra de forma homogênea (HEUTS et al., 1992), ou seja, o tamanho dos lotes a serem produzidos são determinados através de múltiplos do volume de bateladas das reações.

O problema do dimensionamento de lotes foi amplamente estudado na literatura, porém, quando são acrescidas características como utilização de máquinas paralelas ou produtos que apresentam múltiplos processos, o problema é pouco explorado. Ao considerar as pesquisas voltadas para o planejamento da produção em indústrias químicas, constata-se que a grande maioria das pesquisa abordam o problema do sequenciamento da produção. Portanto, concluímos que novas pesquisas podem agregar conhecimento fundamental para melhoria do planejamento das indústrias desse setor.

Esta dissertação trata de um problema real enfrentado por uma indústria química brasileira que apresenta linhas produtivas com máquinas paralelas distintas e múltiplos processos produtivos (ALVARES, 2010), ou seja, as máquinas podem apresentar volumes de batelada distintos entre si para a produção de um mesmo produto. Para esse problema foram propostos dois modelos considerando a concorrência de tanques de armazenamento pelos produtos e as características descritas anteriormente, os quais diferem entre si pela inclusão do custo de preparação de máquina na função objetivo.

Foram propostas heurísticas construtivas do tipo LP-and-fix e relax-and-fix, além de heurísticas de melhoria do tipo fix-and-optimize, para tratar os problemas abordados nesta dissertação. A heurística $L P$-and-fix caracteriza-se por relaxar todas as variáveis inteiras e binárias do problema, resultando em um problema linear, o qual pode ser resolvido de forma eficiente. A partir do momento que o problema linear é resolvido, sua solução é utilizada como base para que um 
conjunto de variáveis do modelo inteiro misto seja fixada, auxiliando a obtenção de soluções factíveis mais rapidamente.

Já a heurística relax-and-fix caracteriza-se por relaxar e fixar partições de variáveis inteiras e binárias do problema. O procedimento geral dessa heurística utiliza apenas um pequeno subconjunto de variáveis inteiras e binárias a cada iteração, para que a resolução do subproblema possa ser rápida. Ao final de cada iteração, pelo menos uma parte dessas variáveis são fixadas, assumindo o valor encontrado na solução do subproblema, enquanto um subconjunto de variáveis relaxadas passam a ser inteiras e binárias. Este ciclo repete-se até que todas as variáveis estejam fixadas, configurando uma solução factível ao problema original, ou até que a heurística não seja mais capaz de fornecer soluções factíveis.

Por fim, a heurística fix-and-optimize caracteriza-se por iniciar com uma solução factível e buscar por soluções melhores, fixando todas as partições de variáveis inteiras e binárias, com exceção da que será otimizada, para que o problema resultante seja então resolvido. Esta heurística não torna o problema infactível, e pode ser aplicada recursivamente enquanto houver melhora da solução.

A organização desta dissertação está da seguinte forma: no Capítulo 2 é apresentada uma breve revisão da literatura sobre problemas de dimensionamento de lotes, no Capítulo 3 o problema em estudo é descrito e apresentam-se os modelos matemáticos a serem utilizados, no Capítulo 4 são descritas as abordagens de solução aplicadas no problema, no Capítulo 5 descrevese a forma que os dados foram gerados, a partir das informações fornecidas pela indústria, no Capítulo 6 são discutidos os resultados obtidos pelas heurísticas propostas e no Capítulo 7 encontram-se as conclusões e as perspectivas de trabalhos futuros. 


\section{CAPÍTULO 2}

\section{REVISÃO BIBLIOGRÁFICA}

Os estudos na área de dimensionamento de lotes iniciaram com a elaboração do modelo Economic Order Quantity (EOQ) proposto por Harris (1913). O objetivo deste modelo era determinar o tamanho do lote que minimizasse os custos produtivos de um item, levando em consideração o custo de preparação da máquina produtora, conhecido como custo de setup, e o custo de estocagem, composto por taxas de juros e desvalorização de moeda, conforme ilustrado pela Figura 2.1, segundo a qual o tamanho do lote ideal ocorre no ponto de intersecção das curvas que representam o custo de preparação de máquina e de estocagem.

Segundo (DREXL; KIMMS, 1997), a solução ótima do EOQ pode ser obtida facilmente. Porém, este modelo não retratava de forma abrangente as situações práticas enfrentadas pelas indústrias, pois considerava um único item com demanda estacionária (ou constante), horizonte de planejamento infinito com tempo contínuo e sem restrições de capacidade.

Estudos posteriores buscaram incluir novas características, presentes em problemas reais, ao modelo EOQ, originando modelos como o Economic Lot Sizing Problem (ELS) e o Economic Lot Scheduling Problem (ELSP). O modelo ELS estendeu o EOQ ao tratar demanda dinâmica, a qual varia no decorrer do tempo, e horizonte de planejamento finito e discreto, porém, ainda considera apenas um item e capacidade produtiva ilimitada (WAGNER; WHITIN, 1958), (MANNE, 1958). Já o modelo ELSP estendeu o EOQ passando a considerar múltiplos itens e restrições de capacidade, visto que geralmente os itens competem por recursos escassos, porém, ainda assumia demanda estacionária e horizonte de planejamento infinito com tempo contínuo (ELMAGHRABY, 1978). 


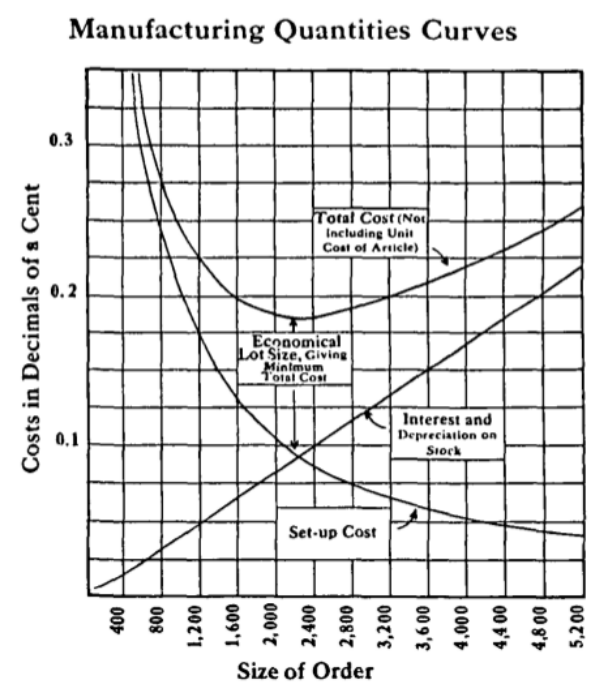

Figura 2.1: Representação do modelo Economic Order Quantity (HARRIS, 1913).

Outros modelos foram propostos combinando características como restrições de capacidade, demanda dinâmica, horizonte de planejamento finito, além de associar o sequenciamento da produção em alguns casos. Segundo (DREXL; KIMMS, 1997), esses novos modelos podem ser agrupados da seguinte forma:

- Capacited Lot Sizing Problem (CLSP): reúne características do ELS e do ELSP. Dessa forma, considera-se a produção de múltiplos itens com estrutura monoestágio, com restrições de capacidade, horizonte de planejamento finito e discreto, além de demanda dinâmica. Outra característica desse modelo é o tamanho das partições do horizonte de planejamento, ou simplesmente períodos, as quais são grandes o suficiente para permitir a produção de diversos produtos, caracterizando o modelo como big bucket.

- Discrete Lot Sizing and Scheduling Problem (DLSP): consiste no modelo CLSP com a divisão dos períodos (semanas ou dias) em microperíodos (turnos ou horas), nos quais apenas um item é produzido, ocupando todo o microperíodo, ou não há produção alguma (política do "tudo ou nada"). Esta limitação da quantidade de itens produzidos por período é responsável por caracterizar este modelo como small bucket.

- Continuous Setup Lot Sizing Problem (CSLP): equivalente ao DLSP, porém exclui a obrigatoriedade da produção "tudo ou nada", permitindo que um item seja produzido por um intervalo de tempo do período. Uma consequência desta modificação é que a preparação da máquina torna-se de fato contínua, ou seja, caso haja a produção de um item no período $t$, seguido de uma inatividade no período $t+1$ e da produção do mesmo item no período $t+2$, a função objetivo considera o custo de setup apenas para o período $t$. 
- Proportional Lot Sizing and Scheduling Problem (PLSP): semelhante ao CLSP, porém permite incorporar a produção de um segundo item durante os períodos. Esta particularidade é obtida ao ser permitido que o item produzido no período $t$ mantenha sua produção no início do período $t+1$, fazendo com que a produção do segundo item seja iniciada após o término do seu processamento.

- General Lot Sizing and Scheduling Problem (GLSP): similar ao CSLP, porém permite a produção de diversos itens por período, através de sua divisão em microperíodos de tamanho variável, nos quais apenas um item é produzido. Portanto, a obtenção de uma solução factível também proporciona o sequenciamento da produção. Este modelo possui um limite máximo de subperíodos por período, que se fosse definido como apenas um, tornaria este modelo equivalente ao CSLP.

De acordo com Florian et al. (1980), Salomon et al. (1991) e Fleischmann e Meyr (1997), a complexidade dos respectivos modelos CLSP, DLSP, GLSP faz com que eles sejam situados na classe de problemas NP. Enquanto é provável que os modelos CSLP e PLSP também pertençam a essa mesma classe, por apresentarem características comuns aos três modelos anteriores.

Como a maioria dos pesquisadores acreditam que problemas da classe NP provavelmente não possam ser resolvidos em tempo polinomial, apesar de ainda não existir uma prova formal (LEISERSON et al., 2002), o crescimento do esforço computacional necessário para encontrar a solução ótima, ou mesmo uma factível (MAES et al., 1991), deve aumentar exponencialmente enquanto o número de variáveis aumenta apenas linearmente.

Nem mesmo a constante evolução tecnológica é capaz de superar esta dificuldade, pois supondo que a capacidade de processamento dos computadores continuem seguindo a Lei de Moore $^{1}$, ela aumentará $2^{10}$ vezes nos próximos 15 anos. Porém, ao ser feita uma investigação exaustiva em todas as possíveis combinações de respostas para um problema que possua apenas variáveis binárias, cada variável adicional faz com que o espaço de soluções a ser investigado dobre. Sendo assim, caso um problema de dimensionamento de lotes fosse reduzido a um problema composto apenas por variáveis binárias, a evolução tecnológica de 15 anos seria equivalente à adição de um único item para um planejamento de 10 meses.

Ainda que exista essa provável limitação teórica, alguns métodos de resolução exata para esses problemas foram desenvolvidos, dentre os quais encontram-se: o Branch-and-Bound (LAND; DOIG, 1960), os planos de corte (BALAS, 1971), o Branch-and-Price (BARNHART et al., 1998) e o Branch-and-Cut (BELVAUX; WOLSEY, 2000).

\footnotetext{
${ }^{1}$ Segundo a lei de Moore, o número de componentes dos circuitos integrados dos microprocessadores dobra a cada 18 meses, portanto, a capacidade de processamento tem um crescimento exponencial.
} 
Entretanto, devido à grande complexidade, boa parte dos trabalhos realizados em dimensionamento de lotes focaram no desenvolvimento de heurísticas que visam a obtenção de boas aproximações em tempo de processamento viável. Algumas dessas heurísticas desenvolvidas podem ser agrupadas em heurísticas especialistas e em heurísticas baseadas em programação matemática (KARIMI et al., 2003).

As heurísticas especialistas geralmente caracterizam-se por apresentar três etapas distintas: determinação do tamanho dos lotes, factibilização e melhoria da solução (MAES; WASSENHOVE, 1986), (KARIMI et al., 2003). O objetivo na etapa de determinação do tamanho dos lotes é fragmentar a demanda total dos produtos através dos períodos, de forma que ela seja atendida completamente, desconsiderando ou relaxando as restrições de capacidade. Em seguida, inicia-se uma etapa de rearranjo do tamanho dos lotes para eliminar possíveis infactibilidades originadas na etapa anterior. Por último, são aplicados procedimentos que visam melhorar a solução factível conhecida.

Por outro lado, segundo Karimi et al. (2003), as heurísticas baseadas em programação matemática são mais gerais, permitindo extensões para diversos problemas, e geralmente são capazes de encontrar soluções de melhor qualidade, muitas vezes oferecendo limitantes para a solução ótima. Porém, usualmente essas heurísticas requerem maior esforço computacional, além de necessitarem de algum conhecimento teórico para sua implementação.

Idealizando uma revisão da literatura que facilite a compreensão dos estudos prévios, os problemas de dimensionamento de lotes foram considerados com as seguintes características: estruturas de produto monoestágio, estruturas de produto multiestágio, máquinas paralelas e múltiplos processos.

\subsection{Dimensionamento de Lotes Monoestágio}

Uma das principais características do dimensionamento de lotes monoestágio é apresentar independência entre os processos produtivos, ou seja, a fabricação de qualquer produto não requer a utilização de outros produtos, os quais são conhecidos como produtos intermediários ou componentes.

Problemas dessa natureza podem ser encontrados em indústrias nas quais o processo produtivo é contínuo, como nas indústrias de cimento, siderúrgica, petroquímica e alimentícia, além de servirem como subproblema de casos mais gerais, cuja decomposição em problemas monoestágio visa aumentar a eficiência da resolução em relação ao tempo e à qualidade da solução (ARAUJO; ARENALES, 2000). 
A seguir, apresenta-se o modelo matemático de Trigeiro et al. (1989) para o problema de dimensionamento de lotes monoestágio.

Índices:

$i=1, \ldots, N$ (número de itens);

$t=1, \ldots, T$ (número de períodos).

Parâmetros do problema:

$b_{i}$ : tempo de produção de uma unidade do item $i$;

$c_{i, t}$ : custo unitário para a produção do item $i$ no período $t$;

$d_{i, t}$ : demanda do item $i$ no período $t$;

$h_{i, t}$ : custo de estocagem do item $i$ no período $t$;

$p_{i, t}$ : custo de preparação da máquina para o item $i$ no período $t$;

$s_{i}$ : tempo de preparação da máquina para o item $i$;

$C A P_{t}$ : tempo total para utilização da máquina no período $t$;

$M$ : número suficientemente grande.

Variáveis do problema:

$X_{i, t}$ : quantidade produzidas do item $i$ no período $t$;

$Y_{i, t}$ : variável binária que indica se a máquina foi preparada para o item $i$ no período $t$;

$I_{i, t}$ : estoque do item $i$ ao final do período $t$.

$$
\begin{array}{rc}
\min \sum_{t=1}^{T} \sum_{i=1}^{N} h_{i, t} I_{i, t}+\sum_{t=1}^{T} \sum_{i=1}^{N} c_{i, t} X_{i, t}+\sum_{t=1}^{T} \sum_{i=1}^{N} p_{i, t} Y_{i, t} & \\
I_{i, t-1}+X_{i, t}=d_{i, t}+I_{i, t} & \forall i, t \\
\sum_{i=1}^{N} b_{i} X_{i, t}+\sum_{i=1}^{N} s_{i} Y_{i, t} \leq C A P_{t} & \forall t \\
X_{i, t} \leq M Y_{i, t} & \forall i, t \\
Y_{i, t} \in\{0,1\} & \forall i, t \\
X_{i, t}, I_{i, t} \geq 0 & \forall i, t \\
I_{i, 0}=0 & \forall i
\end{array}
$$

Neste modelo a função objetivo busca minimizar o custo de estocagem e de produção dos produtos, além do custo de preparação da máquina. As restrições (2.2) representam o balanço de estoque, nas quais o estoque de cada item ao final do período $t-1$ somado à sua produção no período $t$ devem ser iguais à sua demanda mais o seu estoque final no período $t$. Já as restrições 
(2.3) limitam a utilização da máquina em cada período, levando-se em consideração o tempo de processamento despendido para cada unidade produzida e o tempo de preparação de máquina em caso de mudança de produto. As restrições (2.4) indicam a ocorrência de preparação de máquina para os itens sempre que houver produção. Já as restrições (2.5) e (2.6) representam os domínios das variáveis. E, finalmente, as restrições (2.7) definem, sem perda de generalidade, que o estoque inicial de todos os itens é nulo.
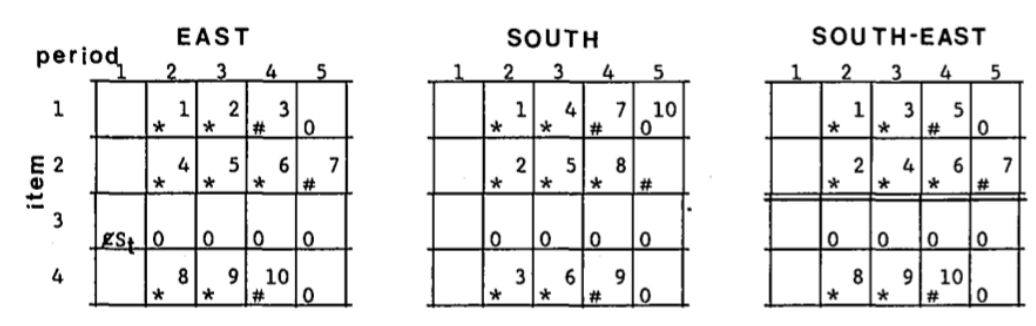

Figura 2.2: Estratégias de varredura propostas por Maes e Wassenhove (1986).

Em Maes e Wassenhove (1986) foi proposta uma heurística período a período, partindo do primeiro até o último, para resolver um problema CLSP com custo de setup, considerando a capacidade produtiva de cada período maior do que a sua demanda. Na etapa de dimensionamento de lotes considerou-se a produção das demandas em seus respectivos períodos e então foram testados quatro critérios para avaliar as antecipações da produção, utilizados por três estratégias de varredura: leste, sul e sudeste, como ilustrada na Figura 2.2, para a qual o símbolo “*” indica que houve verificação e antecipação da produção, “\#” indica verificação mas não antecipação e "0" indica que não houve verificação. Nesta figura ainda é possível notar a ordem de processamento através da sequência numérica, de 1 a 10, em cada estratégia. A varredura leste percorre todos os períodos de um produto antes de passar ao próximo, já a sul percorre todos os produtos de um período antes de iniciar o período seguinte e a sudeste seleciona conjuntos de produtos para aplicar a varredura sul. Somente produtos com custo de preparação de máquina são avaliados, portanto o produto 3 não foi considerado. A etapa de factibilização ocorre simultaneamente à etapa de dimensionamento de lotes, não sendo permitido qualquer antecipação que acarrete alguma infactibilidade. Por fim, dois processos de melhoria são aplicados, um buscando eliminar custos de preparação de máquina, através da antecipação da produção, e outro visando eliminar estoque, através da procrastinação da produção. Os resultados computacionais mostraram que a heurística é promissora, apresentando tempo de execução entre 10 e 30 vezes mais rápido do que o dos trabalhos anteriores com ganhos médios de 0.6 a $1.0 \%$ nas soluções obtidas, para a melhor variação testada.

Em Günther (1987) foi proposta uma heurística período a período para resolução de problemas CLSP com tempo e custo de setup. Inicialmente, a heurística determina o tamanho dos lotes necessários para atender à demanda de cada período, geralmente resultando em uma solução in- 
factível, em seguida, um processo busca determinar quais produtos proporcionariam maiores ganhos com sua antecipação e enquanto forem propícias, as antecipações serão efetuadas. Após esta etapa, busca-se antecipar a produção dos períodos com capacidade produtiva insuficiente para atender à sua produção, de forma que a infactibilidade do planejamento seja eliminada. Como resultado, os autores observaram que as soluções de sua heurística apresentaram um ganho muito pequeno em relação às soluções de Dixon e Silver (1981), porém conseguiram um melhor balanceamento de carga das máquinas.

Selen e Heuts (1989) observaram a afirmação de Günther (1987) sobre a antecipação da produção, segundo a qual não haveria modificação no valor da função objetivo se algum lote fosse deslocado para outro período em que o produto já estivesse sendo produzido. Porém, se toda a produção de um lote fosse antecipada, o custo de setup nesse caso deixaria de ser contabilizado, logo afetaria a função objetivo. Dessa forma, eles propuseram uma modificação na métrica de avaliação da antecipação. Porém, ao realizarem os testes computacionais observaram que não houve redução no custo de setup em nenhuma das instâncias, entretanto, os custos de estocagem foram menores ou iguais aos da heurística original. De forma geral, em $50 \%$ dos casos de testes a nova estratégia apresentou custos totais menores, enquanto a estratégia original foi superior em $30 \%$ dos casos. Sendo assim, os autores concluíram que ambas as versões poderiam ser incorporadas no processo de planejamento da produção.

Em Trigeiro et al. (1989) foi proposta uma heurística que aplica relaxação lagrangiana nas restrições de capacidade para a resolução de problemas CLSP com tempo e custo de setup. Como as restrições relaxadas eram responsáveis pelo relacionamento entre os produtos, o problema pode ser decomposto em subproblemas independentes com um item e sem restrições de capacidade, os quais podem ser resolvidos eficientemente por programação dinâmica (WAGNER; WHITIN, 1958). Caso a composição dessas solução forneça uma solução infactível ao problema original, calcula-se a utilização dos recursos em cada período e aplica-se um procedimento de deslocamento e partição dos lotes. Em seguida, os multiplicadores de Lagrange são atualizados com o método do subgradiente e os subproblemas são novamente resolvidos. Quando uma solução é encontrada, esta passa por um processo de rearranjo para que estoques desnecessários sejam eliminados. Durante a análise computacional comparou-se a heurística desenvolvida com o algoritmo de Billington et al. (1983), apesar deste ter sido projetado para problemas multiestágio, e observou-se que a nova heurística obteve, em média, soluções $4 \%$ melhores com tempo de processamento reduzido entre 20 a 56\%. Ainda foi possível notar que o aumento do número de itens reduziu o GAP de solução (diferença entre a menor solução factível e o maior limitante inferior), apesar de utilizar mais tempo de processamento. Os autores também observaram que modelos com tempo de setup não são uma mera extensão dos com 
custos de setup, pois a ação de verificar a existência de soluções factíveis passa de um problema trivial a um extremamente difícil.

Em Lozano et al. (1991) foram analisadas três heurísticas para resolver problemas CLSP com custo e tempo de setup: um método primal-dual (PDH), uma variação deste denominada ascendente máximo (MAH) e o algoritmo de Wagner-Whitin (WWH). Nos três casos foi aplicado um procedimento de factibilização da solução inicialmente obtida (LOZANO, 1987). Os autores compararam as heurísticas com outras da literatura, observando que o tempo computacional de PDH e MAH são algumas ordens de grandeza maiores que os das heurísticas especialistas, como WWH. As três heurísticas não foram capazes de encontrar soluções factíveis para todos os casos de teste, ao contrário das heurísticas da literatura, como a proposta por Lambrecht e Vanderveken (1979). Assim como em Trigeiro et al. (1989), os autores também observaram a redução dos GAPs em suas heurísticas à medida que o número de itens aumentava.

Em Diaby et al. (1992) foi tratado um problema CLSP através do método branch-andbound, cujos limitantes foram gerados por relaxação lagrangiana e método do subgradiente. $\mathrm{O}$ procedimento consiste em gerar uma solução inicial e determinar o seu GAP, com relação à relaxação lagrangiana do problema. Se após esse cálculo observa-se que a solução não é boa o suficiente, inicia-se um processo iterativo para encontrar novas soluções. Esse processo é composto por uma primeira etapa que consiste em um método branch-and-bound, cujas soluções encontradas são avaliadas através de seus GAPs. Caso essas soluções sejam boas o suficiente o método concentra-se apenas na etapa de branch-and-bound, caso contrário, uma nova etapa é encarregada de recalcular o limitante e voltar para a primeira etapa. Para encontrar a solução inicial foram utilizados três métodos: um baseado em heurística gulosa, outro em relaxações lineares e o último em relaxações lagrangianas. Caso nenhum método seja bem sucedido, são executados outros dois métodos apresentados por Diaby (1987). Os autores observaram que em termos de qualidade da solução final, o procedimento baseado em relaxações lagrangianas foi superior ao baseado em relaxações lineares que por sua vez foi superior à heurística gulosa. Já com relação ao tempo de execução, o método com heurística gulosa destacou-se, sendo seguido pelo de relaxações lagrangianas, e por fim, o baseado em relaxações lineares.

Em Kirca e Kökten (1994) foi proposta uma heurística que utiliza uma estratégia item por item para resolver problemas CLSP, a qual consiste em particionar os itens em conjuntos e determinar suas produções iterativamente. Durante este processo, aplica-se uma regra que seleciona os itens, um a um, do conjunto considerado para que seus limitantes superiores de produção e de estocagem sejam determinados para cada período. Em seguida, o subproblema é resolvido, determinando-se a produção do item e, em seguida, atualizando a capacidade disponível por 
período e o valor da função objetivo. Durante os testes, notou-se que os itens iniciais utilizavam grande parte da capacidade produtiva de alguns períodos, resultando em custos elevados para os itens finais. Assim, foi proposta uma fórmula para calcular um valor mínimo de estoque entre períodos, dispersando a utilização das máquinas. Com esta correção, a heurística proposta apresentou, em média, soluções $4 \%$ melhores do que as obtidas com o algoritmo de Cattrysse et al. (1990), heurística da literatura que apresentou melhor desempenho nos testes, para problemas com poucos itens e muitos períodos. Ao analisar todos os casos de teste, a heurística proposta sempre obteve soluções com diferença menor do que 5\% para as melhores soluções encontradas por outras heurísticas.

Em Armentano et al. (1999) o problema CLSP com tempo e custo de preparação foi representado como um problema de fluxo de redes após a relaxação linear das variáveis binárias, sendo então resolvido por um método branch-and-bound. Inicialmente, buscou-se fixar algumas variáveis binárias de setup para reduzir o tamanho do problema. Em seguida, utilizou-se a heurística proposta por Trigeiro et al. (1989) para encontrar uma solução factível inicial e, caso esta solução não apresente a qualidade desejada, inicia-se o processo de enumeração dos nós, ou branch-and-bound. Os autores avaliaram a influência de variações nos parâmetros do problema, concluindo que a redução das folgas de capacidade e a ampliação do número de períodos provoca um aumento nos GAPs e na quantidade de soluções infactíveis, e por outro lado, o aumento do custo de setup e do número de itens provoca a redução dos GAPs e do número de soluções infactíveis.

Araujo e Arenales (2000) revisaram o artigo de Trigeiro et al. (1989), propondo uma modificação na etapa de rearranjo da solução, a qual baseou-se nas condições de otimalidade de Geoffrion (1974). O modelo original de Trigeiro et al. (1989) buscava atender a condição $I_{i, t-1} X_{i, t}=0(\forall i, t)$, na qual $I$ representa as unidades estocadas e $X$ as unidades produzidas, porém, como o custo produtivo pode variar entre períodos, é possível que ocorra transferência da produção para um período com maior custo produtivo, aumentando o valor da função objetivo. Diante dos resultados computacionais, observou-se que a heurística modificada obteve desempenho superior à original, na maioria dos testes, principalmente quando considerou-se maior número de itens. Porém, os autores concluíram que o processo de factibilização original é eficiente, visto que o ganho proporcionado pela etapa de rearranjo tanto utilizando a heurística original como a modificada foi muito pequeno, em termos percentuais, ao ser comparado com os resultados obtidos pelo algoritmo de resolução de Trigeiro et al. (1989).

Mercé e Fontan (2003) consideraram um problema CLSP com lotes mínimos de produção, possibilidade de atraso nas entregas e tempo de preparação de máquina. A heurística 
proposta baseia-se na estratégia relax-and-fix orientada a períodos, dividindo o horizonte de planejamento em três subconjuntos de variáveis: o primeiro (seção inicial) com variáveis que passaram por um processo de fixação, o segundo (seção central) com variáveis inteiras e binárias, como no modelo original, e o último (seção final) contendo as variáveis que passaram por um processo de simplificação. Através da Figura 2.3 é possível notar que entre as iterações k e k+1, algumas variáveis passaram pelo procedimento de fixação, o qual pode utilizar duas estratégias, uma em que todas as variáveis de decisão que deixam a seção central são fixadas e outra que apenas as variáveis de setup são fixadas. Por fim, o procedimento de simplificação fixa as variáveis de setup em zero, ou seja, ignora o processo produtivo dos períodos. Os autores utilizaram diferentes configurações de tamanho da seção central e do número de variáveis fixadas por iteração, concluindo que a estratégia de fixação apenas para as variáveis de setup com a seção central pequena em relação ao horizonte de planejamento, em geral, proporciona bons resultados com um tempo de processamento menor do que a resolução do problema em sua forma geral.

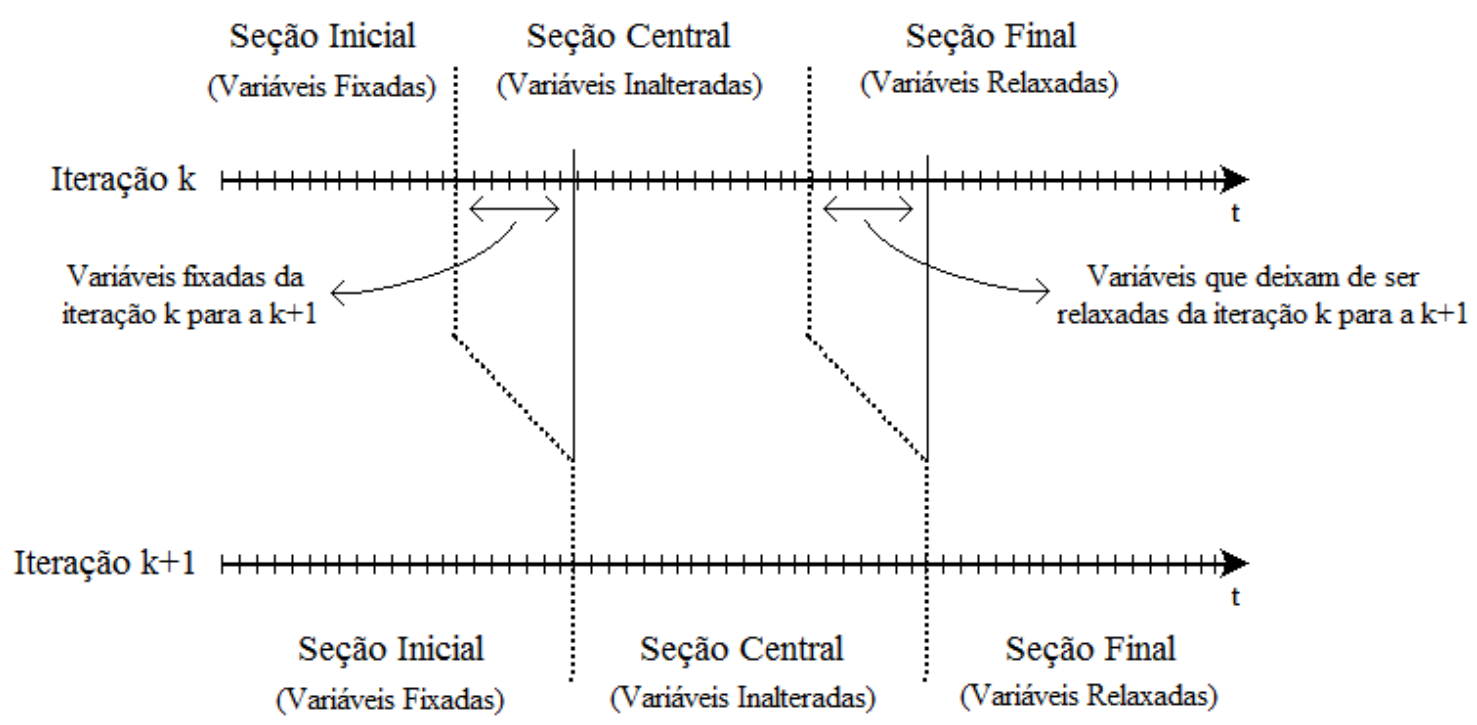

Figura 2.3: Partição do horizonte de planejamento de (MERCÉ; FONTAN, 2003).

Federgruen et al. (2007) consideraram duas variações do problema CLSP: na primeira o custo de setup refere-se apenas ao período como um todo, já na segunda considera-se o setup na forma tradicional, valendo para cada preparação de máquina em cada período. Para resolver os modelos foram propostas duas heurísticas semelhantes à relax-and-fix, uma chamada strict partitioning (SP) e a outra denominada expanding horizon (EH), as quais consistem em selecionar um subconjunto de variáveis com relação aos períodos, a cada iteração, para que o subproblema resultante possa ser resolvido e essas variáveis sejam então fixadas. A diferença entre elas ocorre pelo fato da heurística SP também fixar as variáveis lineares, além das inteiras. Os autores observaram que a heurística EH pode ser utilizada em problemas com até 25 produtos e 
50 períodos, fornecendo soluções próximas às obtidas pelo CPLEX 7.1, com tempo de resposta menor. Com relação aos problemas que apresentam custo de setup apenas para os períodos, ao serem definidas algumas condições, ambas as heurísticas são capazes de encontrar soluções próximas às ótimas, quando limitadas assintoticamente por um $\varepsilon$, em tempo polinomial.

\subsection{Dimensionamento de Lotes Multiestágio}

O dimensionamento de lotes multiestágio caracteriza-se por representar cadeias produtivas em que a fabricação de um produto requer a utilização de pelo menos um outro produto. Sendo assim, surge a denominação demanda interna ou dependente, a qual denota a quantidade necessária do produto intermediário para atender a produção de quem o utiliza. Por outro lado, a denominação demanda externa ou independente é empregada para representar a quantidade de produto requisitada pelos clientes.

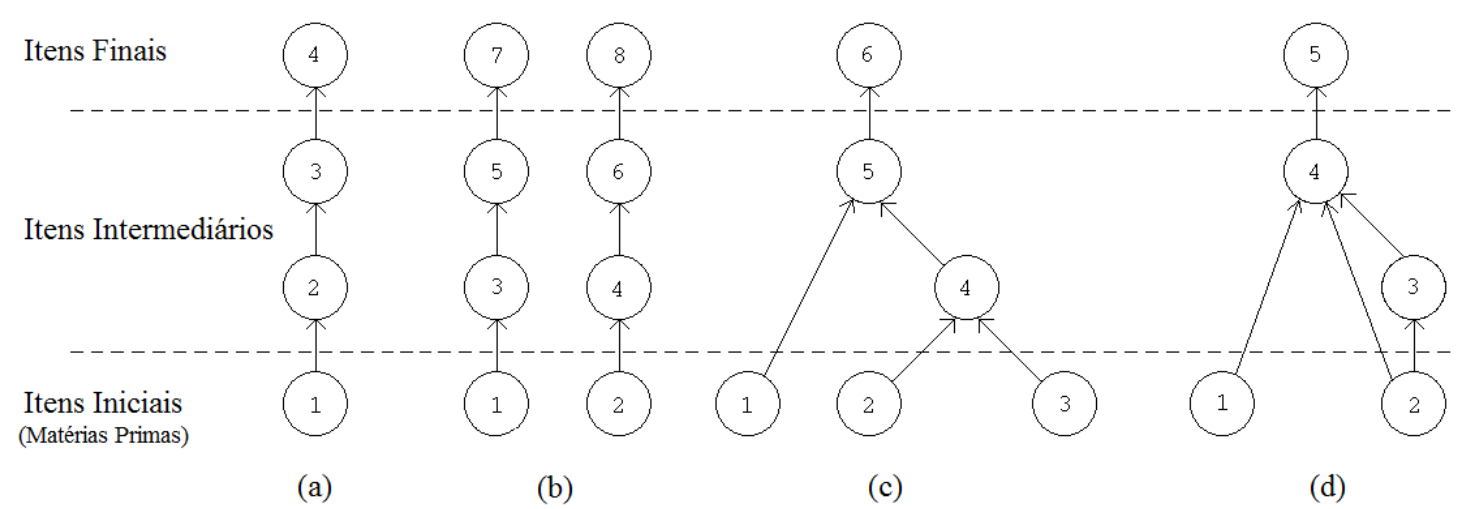

Figura 2.4: Estruturas de produto: (a) Serial, (b) Paralelo, (c) Montagem e (d) Geral.

A estrutura de produção multiestágio pode ser compreendida através da estrutura de produto (BILLINGTON et al., 1983), como exibido pela Figura 2.4, na qual a produção pode ser:

- serial: possui apenas um item predecessor e um sucessor, com exceção do item inicial e do final, Figura 2.4 (a);

- paralelo: vários itens são produzidos simultaneamente através dos mesmos passos produtivos, Figura 2.4 (b);

- montagem: o item pode possuir mais de um item predecessor, com exceção dos itens iniciais, porém possuem apenas um item sucessor, com exceção dos itens finais, Figura 2.4 (c);

- geral: não há definição para o número de itens predecessores nem para itens sucessores, Figura $2.4(\mathrm{~d})$. 
A seguir, é apresentado o modelo matemático de Maes et al. (1991) para o dimensionamento de lotes multiestágio com restrições de capacidade ou Multi-Level CLSP (MLCLSP), juntamente com seus índices, parâmetros e variáveis.

Índices:

$i=1, \ldots, N$ (número de itens);

$k=1, \ldots, K$ (número de máquinas);

$t=1, \ldots, T$ (número de períodos).

Parâmetros do problema:

$b_{i, k}$ : tempo de produção de uma unidade do item $i$ na máquina $k$;

$d_{i, t}$ : demanda externa do item $i$ no período $t$;

$h_{i}$ : custo de estocagem do item $i$;

$p_{i}$ : custo de preparação de máquina para o item $i$;

$r_{i j}$ : quantidade do item $i$ utilizada na produção de um item $j$;

$s_{i, k}$ : tempo de preparação da máquina $k$ para o item $i$;

$C A P_{k, t}:$ tempo total para utilização da máquina $k$ no período $t$;

$M$ : número suficientemente grande;

$S(i)$ : conjunto de sucessores do item $i(S(i)=\varnothing$ se $i$ é um item final).

Variáveis do problema:

$X_{i, t}$ : quantidade produzidas do item $i$ no período $t$;

$Y_{i, t}$ : variável binária que indica se a máquina foi preparada para o item $i$ no período $t$;

$I_{i, t}$ : estoque do item $i$ ao final do período $t$.

$$
\begin{aligned}
\min \sum_{i=1}^{N} \sum_{t=1}^{T} p_{i} Y_{i, t}+\sum_{i=1}^{N} \sum_{t=1}^{T} h_{i} I_{i, t} & \\
I_{i, t-1}+X_{i, t}=d_{i, t}+\sum_{j \in S(i)} r_{i, j} X_{j, t}+I_{i, t}, & \forall i, t \\
\sum_{i=1}^{N}\left(b_{i, k} x_{i, t}+s_{i, k} Y_{i, t}\right) \leq C A P_{k, t}, & \forall k, t \\
X_{i, t} \leq M Y_{i, t}, & \forall i, t \\
Y_{i, t} \in\{0,1\} & \forall i, t \\
X_{i, t}, I_{i, t} \geq 0, & \forall i, t \\
I_{i, 0}=0 & \forall i
\end{aligned}
$$


Neste modelo a função objetivo visa minimizar o custo de preparação das máquinas e o custo de estocagem dos itens. As restrições (2.9) representam o balanço de estoque, ou seja, a produção dos itens em um período, somado ao estoque proveniente do período anterior, deve ser igual à soma de sua demanda externa, de sua demanda interna e do estoque ao final deste período. Já as restrições (2.10) limitam a utilização das máquinas pelos itens a cada período levando-se em consideração o tempo de processamento de cada unidade além do tempo de setup gasto para cada item em cada máquina. As restrições (2.11) indicam a ocorrência de preparação de máquina para os itens sempre que houver produção, as restrições (2.12) e (2.13) representam os domínios das variáveis e as restrições (2.14) foram incluídas neste modelo para indicar a ausência de estoque inicial dos produtos.

Billington et al. (1983) foram um dos pioneiros na abordagem de problemas MLCLSP, considerando ainda lead times ${ }^{2}$. Os autores propuseram um procedimento para compressão do problema sem perda da otimalidade, cujo objetivo é eliminar produtos que utilizam máquinas com capacidade ociosa considerável, ou seja, as restrições de capacidade dessas máquinas foram desconsideradas.

Em Blackburn e Millen (1984) foi considerado o MLCLSP com estrutura de linha de montagem com um único item final. Os autores integraram as restrições de capacidade produtiva com o planejamento da produção para sistemas MRP (Material Requirements Planning) e apresentaram alguns procedimentos para ajuste dos custos de preparação de máquina e de estocagem dos produtos, os quais foram testados para horizonte de planejamento infinito com demanda constante e horizonte de planejamento finito com demanda variável.

Em Billington et al. (1986) o problema MLCLSP foi tratado com um método branch-andbound que utiliza relaxações semelhantes à lagrangiana para eliminar as restrições de capacidade e de balanço de massa. Os subproblemas resultantes foram resolvidos item a item e um processo responsável pela factibilização encontrava uma solução factível, que era utilizada para excluir nós não promissores da árvore de soluções do branch-and-bound. Os resultados computacionais mostraram que instâncias com um item final eram resolvidas, em média, após 40.6 segundos e as soluções estavam a menos de $1 \%$ das soluções ótimas, as quais foram calculadas pelo software LINDO. Este mesmo software foi utilizado para resolver uma instância com três itens finais, mas após 2 horas de execução ele ainda não havia encontrado a solução ótima, e sua solução incumbente era $7 \%$ melhor do que a encontrada pela heurística, a qual utilizou, em média, 154.0 segundos para resolver esse conjunto de instâncias.

\footnotetext{
${ }^{2}$ Tempo necessário para um produto estar disponível após sua requisição
} 
Em Maes et al. (1991) foi proposta uma heurística baseada em relaxação linear, através da qual os valores da solução eram arredondados e fixados para que uma solução inteira fosse obtida. Dois métodos de arredondamento foram utilizados, um de passo simples, no qual apenas uma variável é fixada por iteração, e o outro de decisão múltipla, que pode fixar mais de uma variável. Os autores ainda propuseram uma segunda heurística que consistia em relaxar o problema linearmente e, após sua resolução, todas as variáveis inteiras eram fixadas para que tivesse início um procedimento de brach-and-bound. Apesar da possibilidade dessa heurística eliminar a solução ótima, ela obteve soluções melhores do que a anterior, porém o tempo de processamento foi apenas de 2 a 4 vezes mais rápido do que a resolução do modelo inteiro. Já a primeira heurística, com o método de decisão múltipla, obteve soluções, em média, 1\% piores do que a da segunda heurística, mas com tempo de processamento entre 4 e 70 vezes menor. Por fim, os autores ainda mostraram que ao ser considerado o tempo de preparação de máquina no modelo, a simples tarefa de verificação da factibilidade torna-se um problema um problema NP-Completo.

Em Tempelmeier e Helber (1994) foi proposta uma heurística para um problema MLCLSP, que consistia em utilizar os custos de setup e de estocagem como nos parâmetros originais ou então atualizá-los de acordo com o procedimento proposto por Heinrich (1987 (in german)). O procedimento ordenava os produtos por nível, de forma que os itens finais ficassem no nível zero, seus predecessores no nível um e assim sucessivamente. Em seguida, era resolvida uma sequência de problemas CLSP, baseados em Dixon e Silver (1981), para antecipar a produção dos itens para um único período, enquanto houvesse redução no custo médio por período. Os experimentos computacionais mostraram que o GAP da solução, com relação ao limitante inferior, variou de $2 \%$ e $26 \%$, para instâncias com 40 itens e 16 períodos, com tempo de processamento médio de 8 segundos. Já as instâncias com 80 itens e 16 períodos foram resolvidas em, no máximo, um minuto.

Em Clark e Armentano (1995) foi proposta uma heurística de planos de corte para um problema MLCLSP com tempo de preparação de máquina e lead times. O procedimento correspondia em resolver o problema relaxado linearmente para determinar planos de corte (adição de restrições) que eliminassem sucessivamente as soluções ótimas do problema relaxado, sem eliminar nenhuma solução inteira. Portanto, o algoritmo buscava aproximar-se cada vez mais do envoltório convexo ao redor da solução do problema inteiro, pois nesse caso a solução de ambos coincidiriam. Caso não fosse possível encontrar novos cortes válidos, iniciava-se uma busca do tipo branch-and-bound. Os autores observaram que os cortes proporcionaram melhorias tanto no limitante inferior como nas soluções factíveis obtidas pelo branch-and-bound. 
Em Helber (1995) foi proposto um modelo alternativo ao MLCLSP tradicional, segundo o qual as máquinas foram dividas em dois conjuntos, um crítico (com tempo e/ou custo de preparação altos) e outro não crítico, cujos períodos foram divididos em microperíodos. Para este novo modelo, foram aplicadas diversas heurísticas conhecidas como: Decomposition Approach (DA), baseada na heurística de Dixon e Silver (1981), Busca Local, entre as quais estavam Simulated Annealing (SA), Tabu Search (TS), Genetic Algorithm (GA) e Evolution Strategies (ES), e Lagrangean Based Procedure (TD), baseado em Tempelmeier e Derstroff (1993) e no trabalho que posteriormente originou Tempelmeier e Derstroff (1996). Os experimentos computacionais mostraram que para a classe de testes mais simples, o GA não obteve bom desempenho com relação à qualidade da solução nem ao tempo de processamento, enquanto o SA apresentou apenas soluções de boa qualidade. Portanto, ambos não foram considerados na segunda classe testes, na qual destacaram-se o DA e o TD, resolvendo todas as instâncias em tempo computacional viável. Já para a terceira classe a heurística TD foi superior à DA, tanto pela qualidade da solução como pelo tempo de execução. Porém, deve-se ressaltar que os autores não utilizaram a mesma linguagem de programação para todas as heurísticas, sendo DA e TD implementadas em Fortan 5.0 e as demais, em Turbo Pascal 6.0, a qual é menos eficiente para cálculos do que a anterior.

Em Tempelmeier e Derstroff (1996) foi proposta uma heurística baseada na relaxação lagrangiana das restrições de capacidade e balanço de massa para problemas MLCLSP com tempo de preparação de máquina. Após a relaxação lagrangiana, o problema foi decomposto em diversos subproblemas similares ao tratado por Wagner e Whitin (1958), para o qual existem algoritmos eficientes para resolução. Porém, essas soluções não garantem a composição de uma solução válida para o problema original. Portanto, inicialmente buscou-se garantir o balanço de massa do sistema, resolvendo os subproblemas dos itens finais e propagando a quantidade utilizada dos itens imediatamente predecessores (itens componentes) para que suas demandas fossem atualizadas e, a partir desse momento, o processo de resolução dos subproblemas era retomado, com as novas demandas. Ao final deste processo, as restrições de capacidade eram avaliadas para que parte da produção de períodos sobrecarregados fosse deslocada para períodos com capacidade produtiva ociosa.

Em Katok et al. (1998) foi considerado um problema MLCLSP com tempo e custo de preparação de máquina, para o qual foi proposto uma heurística que estende o algoritmo CMH (HARRISON; LEWIS, 1996). Como o modelo matemático relaciona as variáveis binárias de setup com as variáveis contínuas de produção, caso as variáveis binárias estivessem fixadas, o problema resultante seria de otimização linear, portanto, esta abordagem visava modificar os coeficientes de utilização das máquinas e de custo de produção para simularem o impacto das 
variáveis de setup no modelo, já que elas seriam fixadas. Experimentos computacionais mostraram que para instâncias pequenas aproximadamente $90 \%$ das soluções obtidas pela heurística estavam a menos de $10.2 \%$ da solução ótima, enquanto que para instâncias grandes a heurística foi capaz de encontrar soluções, em média, $25.6 \%$ melhores do que as obtidas pelo software OSL 1.2, da IBM.

Em Xie e Dong (2002) foi proposto um algoritmo genético para o problema MLCLSP, com uma versão em que era permitida a expansão da capacidade produtiva (overtime) e outra em que não era permitida. A base genética para esse algoritmo era formada pelas variáveis binárias, e o seu "processo reprodutivo" ocorre após a seleção de duas soluções, com probabilidade de escolha dada por uma função de avaliação (fitness), e da aplicação de mutações genéticas em ambas (de acordo com uma probabilidade predefinida a variável binária altera seu valor), para então iniciar o crossover, no qual cada variável é selecionada aleatoriamente de algum dos indivíduos. Com as variáveis de setup definidas, determinam-se as variáveis de produção para, em seguida, aplicar um processo de factibilização no qual parte da produção de períodos sobrecarregados é deslocada para períodos que apresentam ociosidade. Quando considerou-se a expansão de capacidade, antes de iniciar o processo de factibilização, verificou-se a possibilidade da capacidade adicional das máquinas ser suficiente para eliminar as infactibilidades. Experimentos computacionais mostraram que para instâncias pequenas, com até 10 produtos, a heurística sem overtime é competitiva, em termos de qualidade, com a heurística de relaxação lagrangiana proposta por Billington et al. (1986) e superior às heurísticas de simulated annealing e tabu search, propostas por Kuik et al. (1993), porém, ela utiliza mais tempo de processamento. Já para os testes com overtime, os autores afirmam que a heurística obteve soluções aceitáveis, sem entrarem em maiores detalhes.

Em Berretta e Rodrigues (2004) foi desenvolvido um método baseado em metaheurística evolucionária, memetic algorithm, para um problema MLCLSP com tempo e custo de preparação de máquina. O método assemelha-se ao algoritmo genético, por considerar agentes populacionais, porém não precisa apresentar todas suas "características biológicas". Definiu-se a população com 13 agentes, distribuídos em uma árvore ternária (um nó raiz com 3 filhos e cada um desses com mais 3 filhos), os quais armazenam a solução atual e sua melhor solução até o momento, a qual é replicada aos nós pai de forma que o nó raiz sempre contenha a solução incumbente. A população inicial é determinada com a resolução de diversos problemas como o de Wagner e Whitin (1958), seguida de um processo de factibilização, mas para que haja variabilidade entre os agentes, os custos de preparação de máquina sofre uma variação aleatórias para cada um deles. Durante as iterações, ocorre o crossover entre a solução incumbente dos nós com a do nó raiz, porém, após algumas iterações a população é reiniciada, mantendo-se 
apenas a solução incumbente do nó raiz. Para instâncias pequenas, com até 10 itens, o algoritmos obteve soluções a $0.2 \%$ das soluções ótimas, e quando comparado às heurísticas propostas por França et al. (1997) e Tempelmeier e Derstroff (1996), ele foi capaz de encontrar soluções melhores, em média.

Em Akartunali e Miller (2009) foi desenvolvida uma heurística que utiliza LP-and-Fix e relax-and-fix para o problema MLCLSP com tempo e custo de preparação de máquinas, que consiste em relaxar e resolver o problema linearmente, para que as variáveis inteiras da solução possam ser fixadas (LP-and-Fix). Em seguida, tem início a resolução de subproblemas pelo relax-and-fix com janela deslizante, cujas variáveis internas são consideradas inteiras, como no modelo, as variáveis que ainda não entraram na janela são consideradas contínuas e as que já saíram estão fixas. Caso essas iterações terminem antes do tempo limite, o procedimento LP-and-Fix é executado novamente, para o subproblema resultante a fim de encontrar soluções factíveis que serão utilizadas como limitantes. Os experimentos computacionais mostraram que a heurística proposta obteve soluções de boa qualidade ao serem comparadas às obtidas com a resolução do modelo completo pelo software Xpress Mosel, o qual foi superior em apenas 10 das 194 instâncias. Ao ser comparada com a heurística de Stadtler (2003), os resultados mostram que a nova heurística é competitiva, além de apresentar mais flexibilidade e facilidade de implementação.

Em Sahling et al. (2009) foi desenvolvido uma heurística baseada em fix-and-optimize para problemas MLCLSP com tempo e custo de setup, além de sua propagação entre períodos ( $s e$ tup carry-over). A ideia básica apresentada consiste em acrescentar variáveis de overtime para resolver o problema com todas as variáveis de setup fixadas em 1, garantindo a factibilidade inicial da solução. Em seguida, inicia-se o algoritmo fix-and-optimize, percorrendo uma a uma as partições de variáveis do modelo, liberando-as individualmente para a otimização, o que resulta em subproblemas com um número menor de variáveis inteiras. Durante os experimentos computacionais, observou-se que para instâncias com até 40 produtos, 16 períodos e 6 recursos, a estratégia que considerou a decomposição das variáveis inicialmente com relação aos produtos, em seguida aos recursos e, por fim, aos processos encontrou soluções com desvio médio de $0.5 \%$ em relação aos limitantes inferiores conhecidos, com tempo de execução de 21.4 segundos, no máximo. Os autores observaram que uma boa estratégia de decomposição das variáveis é fundamental para a eficiência dessa heurística.

Helber e Sahling (2010) ainda modificaram o trabalho de Sahling et al. (2009) para considerar lead time de forma explícita, visto que anteriormente essa característica correspondia a exatamente um período, e desconsideraram o setup carry-over. Assim como anteriormente, a 
heurística que combina a decomposição por produtos, recursos e processos destacou-se ao ser mais eficiente do que a heurística proposta por Tempelmeier e Derstroff (1996), mas apenas em termos de qualidade de solução.

\subsection{Problema com Máquinas Paralelas}

Indústrias que necessitam de maior flexibilidade em sua cadeia produtiva, geralmente optam por linhas produtivas em paralelo, o que possibilita os produtos serem fabricados em diversas máquinas. Apesar da flexibilidade proporcionada, a complexidade do problema aumenta, pois além das características descritas anteriormente, surge a questão de alocação das máquinas aos produtos, o que aumenta o espaço de busca de soluções.

A partir da década de 90 houve um aumento nos trabalhos relacionados a este problema, mas a maior parte foi direcionada para o problema do sequenciamento da produção com máquinas paralelas idênticas, ou seja, todas as máquinas possuem características semelhantes, como as mesmas capacidades produtivas, os mesmos tempos de setup, até processando o mesmo conjunto de produtos.

Como o problema da indústria química em questão considera apenas o planejamento da produção em máquinas paralelas distintas, não há um grande número de trabalhos sobre esse assunto na literatura.

A seguir é apresentado o modelo matemático de Toledo e Armentano (2006) para este tipo de problema, assim como seus índices, parâmetros e variáveis.

Índices:

$i=1, \ldots, N$ (número de itens);

$j=1, \ldots, K$ (número de máquinas);

$t=1, \ldots, T$ (número de períodos).

Parâmetros do problema:

$b_{i, k}$ : tempo de produção de uma unidade do item $i$ na máquina $k$;

$c_{i, k}$ : custo unitário para a produção do item $i$ na máquina $k$;

$d_{i, t}:$ demanda do item $i$ no período $t$;

$h_{i}$ : custo de estocagem do item $i$;

$p_{i, k}$ : custo de preparação da máquina $k$ para o item $i$;

$s_{i, k}$ : tempo de preparação da máquina $k$ para o item $i$;

$C A P_{k}$ : tempo total para utilização da máquina $k$ 
$M$ : número suficientemente grande.

Variáveis do problema:

$X_{i, k, t}:$ quantidade do item $i$ produzida na máquina $k$ no período $t$;

$Y_{i, k, t}$ : variável binária que indica se a máquina $k$ foi preparada para o item $i$ no período $t$; $I_{i, t}$ : estoque do item $i$ ao final do período $t$.

$$
\begin{aligned}
\min \sum_{t=1}^{T} \sum_{k=1}^{K} \sum_{i=1}^{N}\left(p_{i, k} Y_{i, k, t}+c_{i, k} X_{i, k, t}\right)+\sum_{t=1}^{T} \sum_{i=1}^{N} h_{i} I_{i, t} & \\
\sum_{k=1}^{K} X_{i, k, t}+I_{i, t-1}=d_{i, t}+I_{i, t} & \forall i, t \\
\sum_{i=1}^{N}\left(b_{i, k} X_{i, k, t}+s_{i, k} Y_{i, k, t}\right) \leq C A P_{k} & \forall k, t \\
X_{i, k, t} \leq M Y_{i, k, t} & \forall i, k, t \\
Y_{i, k, t} \in\{0,1\} & \forall i, k, t \\
X_{i, k, t}, I_{i, t} \geq 0 & \forall i, k, t \\
I_{i, 0}=0 & \forall i
\end{aligned}
$$

Neste modelo a função objetivo visa minimizar o custo de preparação das máquinas, o custo produtivo e o de estocagem dos itens. O conjunto de restrições (2.16) é responsável pelo balanço de estoque. As restrições (2.17) são responsáveis por limitar a capacidade produtiva das máquinas. O conjunto de restrições (2.18) indicam a existência de setup quando houver produção dos itens. Já as restrições (2.19) e (2.20) representam os domínios da variáveis e as restrições (2.21) foram incluídas neste modelo para indicar que não há estoque inicial.

Em Carreno (1990) foi proposto um procedimento para tratar problemas com máquinas paralelas idênticas com restrições de capacidade, tempo de setup, custo de estocagem e demanda constante para um horizonte de planejamento infinito. Assumiu-se ainda que a produção de um item deveria restringir-se a apenas uma máquina em cada período, e que ela não poderia ser retomada enquanto houvesse estoque do item. O procedimento desenvolvido aloca a produção nas máquinas, sem que suas capacidades produtivas sejam excedidas, atendendo às demandas dos produtos para obter uma solução factível inicial. Em seguida inicia-se uma etapa de melhoria da solução que é encerrada quando não for possível encontrar soluções melhores. Os experimentos computacionais mostraram que a heurística obteve soluções, em média, com desvio de 5\% dos limitantes inferiores, para problemas com até 100 produtos e 10 máquinas, adotando um limite de processamento de 50 segundos. 
Em Sabbag (1993) foi desenvolvido uma heurística para o problema CLSP com máquinas paralelas distintas com tempo e custo de setup que é composta por três etapas: obtenção de uma solução inicial, factibilização desta solução e melhoria da solução factível. Para a primeira etapa são utilizados dois procedimentos, um baseado no algoritmo de Wagner-Whitin e outro baseado em relaxação linear. O processo de factibilização é necessário caso a primeira etapa não encontre uma solução factível, logo são necessárias transferências de lotes entre períodos para satisfazer as restrições de capacidade. Inicialmente foi utilizado um passo regressivo de transferência de lotes que garante a factibilidade em todos os períodos, exceto no primeiro, e caso a solução continuasse infactível, seria utilizado um passo progressivo para a transferência de lotes. A etapa de melhoria consistia em aplicar os mesmos procedimentos que a etapa anterior, porém, sem que houvesse perda de factibilidade. Os experimentos computacionais mostraram que a heurística que utiliza programação linear foi capaz de resolver praticamente todas as instâncias, 99.4\%, mas com GAP aproximadamente três vezes pior do que ao ser utilizado o algoritmo de Wagner-Whitin, para o qual foi possível resolver aproximadamente $76.7 \%$ das instâncias.

Em Toledo (1998) foram propostos dois métodos exatos para resolução do problema de dimensionamento de lotes monoestágio com máquinas paralelas distintas sem restrições de capacidade, baseadas na modificação do algoritmo de Wagner-Whitin e do proposto por Wagelmans et al. (1992). Também foram propostos dois métodos branch-and-bound para resolver o CLSP com máquinas paralelas distintas, tempo e custo de setup, uma baseada em relaxação lagrangiana, utilizando as heurísticas inicialmente propostas, e outra baseada em relaxação linear, resolvendo um problema de fluxo mínimo em rede generalizada, proposto por Jensen e Barnes (1980), para cada nó do algoritmo. Ambas os métodos resolveram 99\% das instâncias, porém o que utilizou relaxação lagrangiana obteve solução ótima em $72 \%$ dos testes, enquanto o com relaxação linear, em $78 \%$. Por fim, foram sugeridas melhorias nos passos progressivos e regressivos da heurística proposta por Sabbag (1993), observando-se uma redução média de $1 \%$ e $8 \%$ do GAP e um aumento de $3 \%$ e $7 \%$ no número de soluções factíveis para instâncias com baixo e alto custo de setup, respectivamente.

Em Toledo e Armentano (2006) foi proposta uma heurística de relaxação lagrangiana para o problema CLSP com máquinas paralelas distintas, tempo e custo de setup. A heurística consiste em aplicar relaxação lagrangiana nas restrições de capacidade e resolver o novo problema. Caso a solução obtida não seja factível, inicia-se uma fase de factibilização, segundo a qual busca-se deslocar a produção entre períodos e entre máquinas, além de considerar uma capacidade adicional ao problema. Se a solução resultante dessa fase ainda for infactível, aplica-se novamente a etapa de factibilização, porém, considerando novamente as capacidades originais. Por fim, a 
fase de melhoria inicia com uma solução factível e busca por novas soluções factíveis com custo menor. Os resultados computacionais mostraram que para instâncias com duas máquinas, as soluções da heurística ficaram no máximo a $4.8 \%$ da soluções ótimas, determinadas pelo software CPLEX 7.5.0, apesar do GAP de dualidade ter chegado até a 36.5\%. Para instâncias maiores, o GAP de dualidade comportou-se de forma semelhante, apenas instâncias com pouca folga de capacidade produtiva e alto custo de setup tiveram uma redução significativa. Uma análise geral mostrou que a classe com pior desempenho encontrou soluções factíveis para $95 \%$ das instâncias com tempo médio de 14.4 segundos e tempo máximo inferior a 11 minutos. Portanto, os autores concluíram que a heurística é rápida e capaz de encontrar soluções de boa qualidade.

\subsection{Problema com Múltiplos Processos}

Algumas situações possuem uma característica particular não abordada até agora, segundo a qual vários processos produtos distintos obtêm um mesmo produto. Sendo assim, o problema de dimensionamento de lotes nesses casos também deve investigar qual a escolha ideal de processos para encontrar a solução ótima.

Existem poucos trabalhos que consideram problemas com multiprocessos explicitamente, apenas para o dimensionamento de lotes. Segundo o nosso conhecimento, podemos citar Alvares (2010), o qual inspirou esta dissertação, e Luche et al. (2009).

Em Luche et al. (2009), foi tratado um problema real de planejamento e controle da produção de grãos eletrofundidos, em uma indústria brasileira que enfrenta dificuldades práticas para a obtenção de um planejamento factível, devido ao curto prazo de entrega e a pedidos adicionais que ocorrem semanal ou quinzenalmente. A esses fatores acrescentam-se o longo tempo de preparação de máquinas, permitidos apenas ao final do expediente diário, e uma característica própria do problema desta empresa, em que cada processo resulta em quantidades distintas de diversos produtos, os quais são diferenciados pela granulosidade dos grãos eletrofundidos. Devido à complexidade do problema, a equipe de planejamento da produção não é capaz de atender toda a demanda, havendo necessidade de renegociação de prazos de entrega, portanto, o objetivo da empresa é minimizar o atraso na entrega dos produtos.

Nesse trabalho, foram propostos dois modelos que minimizam a escassez de produto, um considerando e outro desconsiderando o tempo de preparação de máquina, os quais foram resolvidos utilizando GAMS/CPLEX. Os experimentos computacionais com dados simulados, mostraram que foi possível atender $95 \%$ da demanda mensal com o modelo que desconsidera a preparação de máquinas, enquanto o outro modelo obteve o mesmo resultado ao ser permitido 
a utilização de mais de um processo em alguns períodos. Nos experimentos com dados reais, o número de processos totais inviabilizou a consideração completa dos dados, logo foram selecionados apenas os 140 processos utilizados com mais frequência, porém, a solução obtida foi aproximadamente $315 \%$ inferior à apresentada pela indústria. Deve-se levar em consideração o fato da indústria ter utilizado 19 processos que não haviam sido considerados nos testes, portanto, ao incluir esses 19 processos em uma nova execução, obteve-se uma solução $22 \%$ melhor do que a da empresa, após 26 segundos de processamento, enquanto a equipe de planejamento e controle da produção necessita de horas ou até dias para determinar os planejamentos.

Os autores ainda propuseram uma heurística construtiva, que percorre do primeiro ao último período, avaliando as soluções através de uma função que considera um peso maior para os períodos mais próximos ao qual está sendo otimizado. Com esta heurística foi possível obter uma solução aproximadamente $17 \%$ superior à encontrada pela indústria, com apenas 9.5 segundos de processamento, ao ser considerado os 159 processos.

\subsection{Problema de Dimensionamento de Lotes na Indústria Quí- mica}

A maior parte das pesquisas voltadas ao planejamento e controle da produção em indústrias químicas tiveram como objetivo o sequenciamento da produção, também conhecido como planejamento a curto prazo. Maiores informações sobre esse tema podem ser encontradas nas revisões Kallrath (2002) e Méndez et al. (2006). Alguns estudos ainda consideraram em conjunto os problemas de dimensionamento de lotes e sequenciamento da produção.

Em Selen e Heuts (1990) foi desenvolvida uma heurística baseada no algoritmo do caixeiro viajante, sem backtraking, para o planejamento da produção de processos químicos. O problema possui características como a produção por batelada, uma única máquina com restrição de capacidade, tempo de preparação de máquina e tanques de armazenamento com restrições de capacidade. A heurística proposta baseia-se em determinar a produção lote por lote até que seja atingido um período infactível, quando um procedimento de factibilização é iniciado, tentando deslocar a produção para períodos anteriores com capacidade disponível. Os autores relataram que foi possível obter bons resultados para instâncias com 15 produtos e 20 períodos, com pouca capacidade excedente.

Em Sahinidis e Grossmann (1991) foram propostas reformulações que exploravam técnicas de desacoplamento de variáveis de acordo com subestruturas do problema para modelos de dimensionamento de lotes com produção por bateladas de um único produto, apresentando 
demanda dinâmica, custos de preparação de máquina e custos de estocagem. Após a aplicação das reformulações, o modelo resultante apresentava mais variáveis e restrições do que o original, porém, os limitantes obtidos com as relaxações eram melhores. Como consequência, um número maior de nós não promissores eram eliminados do procedimento de resolução branch-and-bound, tornando a resolução das instâncias uma ordem de magnitude mais rápidas.

Em Burkard et al. (1997) foram desenvolvidas diversas estratégias do tipo LP-and-Fix para tratar problemas de dimensionamento de lotes e sequenciamento da produção, utilizando como base o software CPLEX. As características consideradas pelo modelo englobavam múltiplos itens, estrutura de produtos multiestágio com dois tipos de produtos intermediários (um em que era permitida a estocagem e outro cujo consumo era imediato), múltiplas máquinas, quantidade das bateladas limitadas por produção mínima e máxima, contudo, não foram consideradas restrições de capacidade. Durante os experimentos computacionais, observou-se que instâncias com três produtos finais e até 75 períodos eram resolvidas em menos de 16 minutos, enquanto instâncias com até 120 períodos eram resolvidas em menos de 2 horas de processamento.

Em Grunow et al. (2002) foi proposto um novo modelo hierárquico para o planejamento da produção de múltiplos itens com estrutura multiestágio e processamento em bateladas, considerando ainda máquinas paralelas, custo de preparação de máquinas e custo de estocagem de produtos. O primeiro estágio era responsável por determinar o tamanho dos lotes, o tempo de processamento, as matérias-primas e os equipamentos utilizados. No segundo estágio ocorria a alocação dos equipamentos determinados no estágio anterior. Por fim, o último estágio realizava o processo de factibilização, eliminando violações de lotes mínimos e tempo de preparação de máquina, caso fossem considerados. Durante os experimentos computacionais foram utilizadas instâncias compostas por 3 produtos finais com horizonte de planejamento de até 30 períodos e variações de instâncias combinando lotes mínimos e preparação de máquina, para as quais empregou-se o software CPLEX 7.0 na resolução dos três estágios do modelo, sendo necessário pouco mais de dois minutos de processamento para a obtenção das soluções.

Em Susarla e Karimi (2010) foi desenvolvido um modelo de dimensionamento de lotes e sequenciamento da produção para tratar problemas com múltiplos itens, produção de batelada, lotes mínimos e preparação de máquina dependente do sequenciamento. Para avaliar o desempenho do modelo, foi utilizado um estudo de caso em uma indústria de lubrificantes, sendo utilizados vários cenários de mercado para um horizonte de planejamento de dois anos. Os autores concluíram que o modelo é útil por obter rapidamente bons planos de produção.

Em Baumann e Trautmann (2013) foi proposto um novo modelo inteiro misto para o sequenciamento da produção e empacotamento de produtos considerando tempo de preparação de 
máquina dependente da sequência e tanques de armazenamento multipropósito com restrição de capacidade. Para os experimentos computacionais foram avaliadas algumas variações do modelo, formuladas na linguagem AMPL e resolvidas pelo software Gurobi 4.52, e a heurística proposta por Fündeling e Trautmann (2006) para tratar 20 instâncias com 20 produtos cada. A melhor variação do modelo encontrou soluções factíveis em $90 \%$ das instâncias, das quais $65 \%$ eram soluções ótimas, com tempo médio de processamento de 1444.9 segundos, enquanto que a heurística encontrou soluções factíveis para todas as instâncias, das quais 30\% eram soluções ótimas, com tempo médio de processamento de 981.0 segundos. 


\section{CAPÍTULO 3}

\section{DEFINIÇÃO DO PROBLEMA E MODELAGEM MATEMÁTICA}

\subsection{A Indústria Química}

Os indicadores da indústria química mundial revelam que ela corresponde a um dos maiores setores industriais na atualidade, com faturamento competindo diretamente com a indústria de semicondutores, equipamentos e materiais de tecnologia de informação (GALEMBECK et al., 2007). Em 2005, a movimentação financeira do setor químico já superava a marca de um trilhão de dólares, sendo o mercado dos Estados Unidos responsável por US\$549 bilhões, enquanto os da Alemanha e do Japão correspondiam por US\$189 bilhões e US\$122 bilhões, respectivamente (GALEMBECK et al., 2007).

No Brasil, a indústria química é considerada um dos setores mais importantes e dinâmicos da economia. Segundo Associação Brasileira da Indústria Química (ABQUIM ${ }^{1}$ ), este segmento movimentou 2,4\% do PIB brasileiro em 2010, aproximadamente US\$ 130,2 bilhões, o que faz dele o quarto maior do mercado nacional, ficando atrás apenas das indústrias alimentícia, do petróleo $^{2}$ e automobilística. Com este faturamento, a indústria química brasileira ocupava a

\footnotetext{
${ }^{1}$ http://www.abiquim.org.br, último acesso em 26 de março de 2013.

${ }^{2} \mathrm{~A}$ classificação de indústria química e seus segmentos originou várias discussões, por exemplo, como no caso da indústria de refinamento do petróleo. Visando eliminar prováveis divergências, a ONU providenciou uma classificação internacional para a indústria química, que foi incluída na ISIC (International Standard Industry Classification). Segundo essa classificação, a indústria do refino do petróleo é considerada independente da indústria química.
} 
sétima posição mundial, ficando atrás apenas da Chinesa, Norte Americana, Japonesa, Alemã, Sul Coreana e Francesa.

A grandeza deste setor pode ser mensurada com uma análise da amplitude do emprego de seus produtos em elementos cotidianos, como por exemplo:

- Sistemas de tratamento de água e esgoto: cloro e dióxido de cloro (oxidam detritos e destroem micro-organismos), cloreto de ferro e sulfato de alumínio (absorvem e precipitam a sujeira), carvão ativo (retém micropoluentes e detergentes), e hidróxido de sódio (neutraliza a acidez da água);

- Agricultura: fertilizantes (repõem nitrogênio, cálcio, fósforo, potássio, entre outros) e defensivos químicos (aumentam a produtividade e evitam a disseminação de doenças);

- Pecuária: medicamentos e alimentação animal;

- Construção Civil: resinas acrílicas, caixas d'água, tintas e vernizes, tubos e conexões, argamassas e concretos;

- Automóveis: óleos lubrificantes, baterias, pastilha e lonas para freio, pneus, para-choques e painéis;

- Informática: resinas para os gabinetes, componentes eletrônicos em geral, fios e cabos, entre outros.

A partir de dados preliminares de projetos de investimento, a ABQUIM divulgou que durante o período de 2010 a 2015, a indústria química nacional deverá receber um aporte financeiro em torno de US\$26,1 bilhões, dos quais US\$ 3,9 bilhões seriam aplicados em manutenção, melhorias de processo, segurança, meio ambiente e troca de equipamentos, o que torna esse setor muito atrativo para pesquisas na área do planejamento e controle da produção.

\subsection{Descrição do Problema}

O problema em estudo considera o planejamento da produção de uma grande indústria química brasileira, com atuação em diversos países, distribuídos pelos cinco continentes mundiais. Porém, o foco deste trabalho é nas plantas brasileiras, das quais duas são responsáveis pela fabricação da família de produtos de interesse deste estudo, os Etoxilados. Esse problema foi inicialmente considerado por Alvares (2010), em um trabalho de conclusão de curso. 
De modo geral, grande parte dos produtos da família dos etoxilados é obtida após álcoois ou fenóis reagirem com óxido de etileno ${ }^{3}$, o que resulta em produtos como desinfetantes, detergentes multiuso, lava-roupas e lava-louças, ceras líquidas, polidores para couro, solubilizantes de fragrâncias e controladores eficazes de espuma a antiespuma.

Os principais ativos em uma indústria química são os tanques e os reatores. A principal diferença entre eles é que os tanques são responsáveis por armazenar matérias-primas e produtos, enquanto os reatores são responsáveis por controlarem os processos produtivos através de parâmetros como pressão, temperatura e fluxo da mistura entre os reagentes, além de possuírem núcleos projetados com materiais cuidadosamente analisados para não interferirem nem contaminarem as reações.

Os reatores utilizados em grande parte das indústrias químicas podem ser classificados, segundo Russell et al. (2008), como:

- Reatores de batelada: não há fluxo de entrada nem de saída de materiais durante a reação. Os reagentes são adicionados antes do processo iniciar e a mistura é mantida no reator até que o produto desejado seja obtido e então removido do equipamento. Este é o tipo de reator utilizado nas reações deste trabalho;

- Reatores de semibatelada: não há fluxo de saída durante a reação. Alguns reagentes são adicionados no início do processo, enquanto outros são acrescentados com o decorrer do tempo, e ao final, o produto em questão é obtido;

- Reatores contínuos: o fluxo de entrada dos reagentes é igual ao fluxo de saída do produto. A conversão das matérias-primas em produto é controlada através do tempo médio de reação, determinada pela velocidade do fluxo da matéria no interior do reator. Estes são os mais utilizados na indústria química por produzir maiores quantidades de produto com equipamentos menores, porém, são mais difíceis de iniciar e parar seus processos produtivos (SCHMIDT, 1998).

A incorporação das propriedades de controle das reações e a utilização de materiais inertes, responsáveis por diferenciar os reatores dos tanques de armazenamento, contribuem para o alto custo desses equipamentos. Dessa forma, deve-se evitar ao máximo a subutilização desses equipamentos, através da elaboração de planejamentos de produção eficazes, para que um dos principais ativos da indústria química não fique ocioso.

\footnotetext{
${ }^{3}$ http://www.portaleducacao.com.br/farmacia/artigos/15347/alcoois-graxos-etoxilados-e-alquil-fenoisetoxilados
} 
Durante a etapa de planejamento da produção, deve-se considerar o fato dos reatores possuírem capacidades distintas, portanto, a fabricação de um mesmo produto em reatores distintos pode resultar em diferentes volumes finais. Como cada um desses processos consomem quantidades predeterminadas de reagentes e produzem um volume final conhecido, em cada uma de suas reações, eles são classificados como produção por batelada. Sendo assim, a etapa de planejamento deve considerar apenas produções múltiplas do volume de batelada das reações. Esta característica faz com que seja necessário considerar variáveis discretas para a modelagem matemática deste problema, resultando em um problema inteiro misto (MIP).

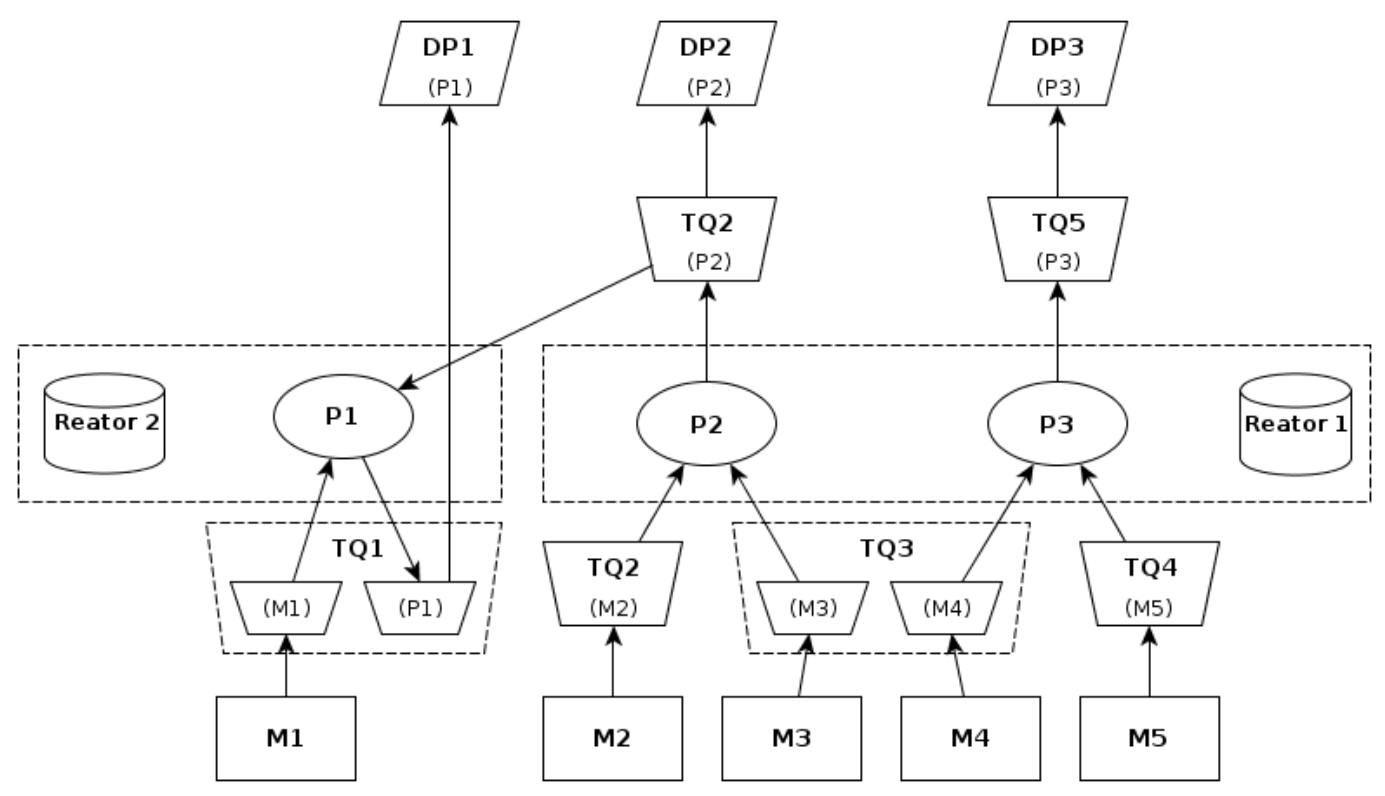

Figura 3.1: Fluxograma resumido do processo produtivo da indústria em estudo.

Outro aspecto relevante neste caso é o compartilhamento dos reatores por diversos processos, ou seja, a existência de concorrência para utilização dos recursos. Um resultado direto dessa característica é o fato do sequenciamento da produção influenciar o percentual de utilização desses equipamentos, visto que algumas reações poderiam contaminar-se com resíduos de reações anteriores e, portanto, seria necessário efetuar a limpeza dos reatores entre processos consecutivos, acarretando em tempo de preparação dos equipamentos e reduzindo o tempo total disponível para processamento.

O fluxo de produção da indústria em questão é representado de forma simplificada pela Figura 3.1, na qual os retângulos representam as matérias-primas $\left(\mathrm{MX}^{4}\right)$ que ao serem adquiridas devem ser estocadas em tanques (TQX), representados por trapézios. É importante destacar que as restrições de capacidade para armazenamento começam a partir da recepção das matériasprimas, pois estas competem pelos tanques com outras matérias-primas e com produtos, como

\footnotetext{
${ }^{4}$ Para esta nomenclatura, supõe-se que $X \in \mathbb{Z}$. Portanto, para a Figura 3.1, $M X \in\{M 1, M 2, M 3, M 4, M 5\}$, $P X \in\{P 1, P 2, P 3\}$ e assim por diante.
} 
pode ser observado nos tanques TQ1 e TQ3 da Figura 3.1, sendo compartilhados por M1 e P1 e por M3 e M4, respectivamente. Esses tanques são denominados tanques multipropósitos, enquanto os demais são denominados cativos, já que são utilizados exclusivamente por uma matéria-prima ou por um produto. Dessa forma, o planejamento da compra dos insumos está diretamente relacionado com a disponibilidade de seus respectivos tanques.

A partir do momento que as matérias-primas estiverem disponíveis, pode-se iniciar o processo de fabricação dos produtos nos reatores, representados na Figura 3.1 em forma de elipses, desde que ocorram individualmente em cada reator, adicionando-se quantidades predeterminadas dos reagentes e deixando-os reagirem por tempo suficiente.

Os reatores são representados pelos cilindros, na Figura 3.1, e os retângulos tracejados englobam os processos produtivos que podem ocorrer em cada um deles, tornando possível observar a concorrência dos processos na utilização desses recursos, como ocorre na produção de P2 e P3, que competem pela utilização do reator 1. Ao final do processamento, os produtos são armazenados em seus respectivos tanques para posteriormente serem enviados aos depósitos, representados por DPX.

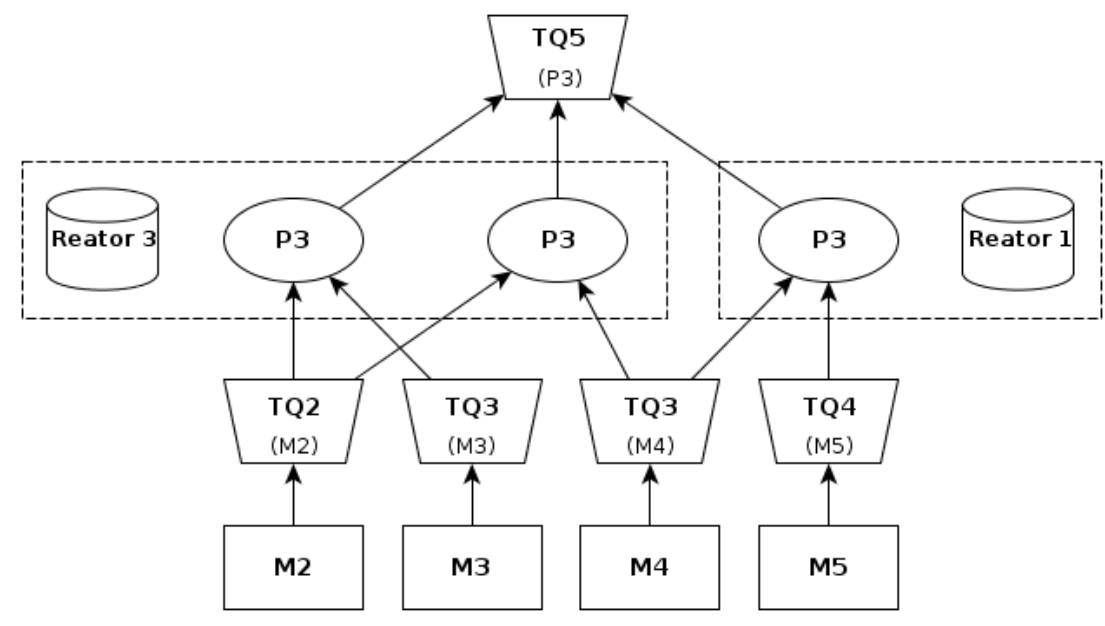

Figura 3.2: Processo produtivo detalhado de um item.

Analisando a estrutura dos produtos, P3 é considerado um produto de primeiro nível, pois seu processo produtivo não utiliza outros produtos e possui demanda exclusivamente externa. $\mathrm{O}$ produto $\mathrm{P} 2$ também pertence ao primeiro nível, porém sua demanda é composta por um percentual externo e outro interno, sendo assim, este é considerado um produto intermediário. Por último, P1 caracteriza um produto com estrutura multiestágio, já que ao menos um produto intermediário é utilizado em sua reação, representado por P2, na Figura 3.1. Como o produto intermediário em questão pertence ao primeiro nível, P1 é classificado como de segundo nível.

Os processos produtivos ainda podem ser descritos com maiores detalhes, conforme ilus- 
trado pela Figura 3.2. Nesta representação, o produto P3 apresenta três processos produtivos distintos, dos quais dois ocorrem no reator 3 (um utilizando as matérias-primas M2 e M3 e o outro, M2 e M4) e um ocorre no reator 1 (utilizando M4 e M5). Na estrutura da indústria encontram-se produtos com até 12 processos produtivos distintos.

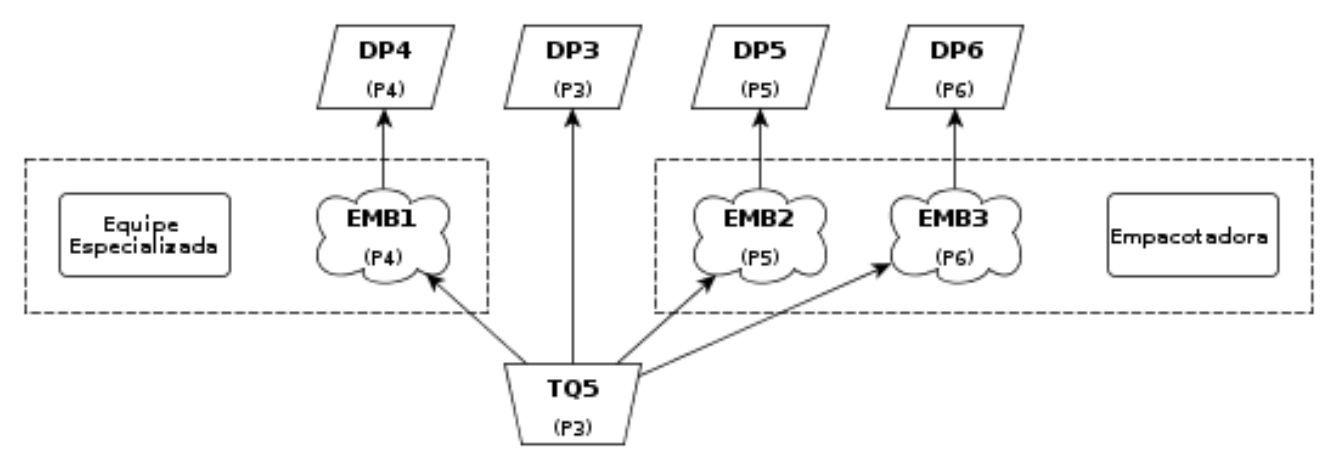

Figura 3.3: Processo de embalagem dos produtos.

Assim que a fase produtiva é finalizada, os produtos estão aptos a serem comercializados através da venda a granel ${ }^{5}$ ou após serem embalados. Este último processo é ilustrado na Figura 3.3, sendo possível observar duas formas distintas de embalagem: por máquina empacotadora ou por equipe especializada. Com a máquina empacotadora, é possível embalar os produtos em caixas de papelão e sacos, porém este processo apresenta capacidade de operação limitada. Já a equipe especializada embala os produtos em barris, sendo possível expandir a capacidade operacional mediante a contratação de horas extras dos operários.

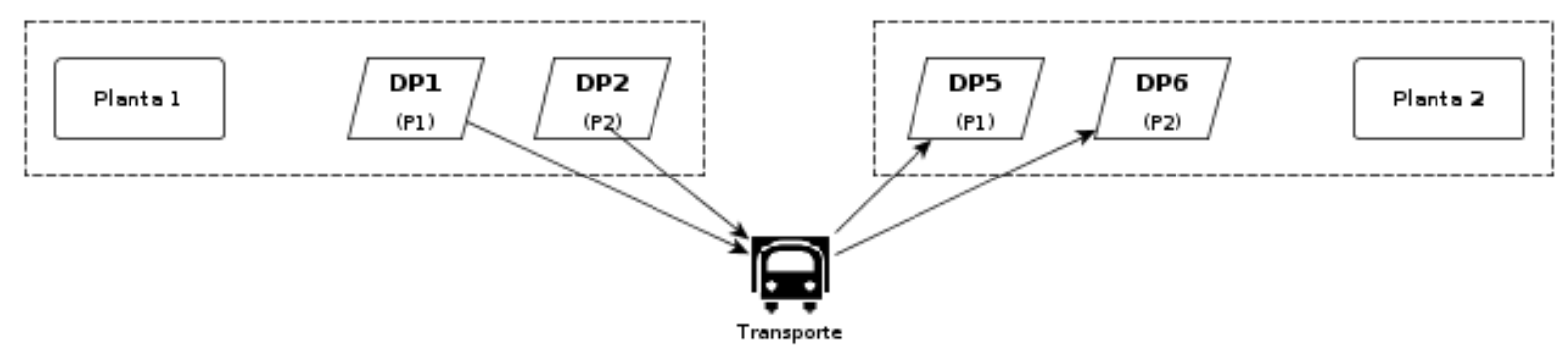

Figura 3.4: Processo de transferência dos produtos entre as unidades produtivas.

Uma última particularidade encontrada na empresa é a possibilidade de transferência de produtos entre as plantas produtivas, como ilustrado na Figura 3.4. Este procedimento pode ser necessário devido à insuficiência de capacidade produtiva em alguma planta, para um determinado período, ou devido à escassez de matérias-primas por atrasos de fornecedores ou

\footnotetext{
${ }^{5}$ De acordo com o dicionário on-line Priberam: sem embalagem ou sem acondicionamento.
} 
mesmo por decisão operacional, como por exemplo quando houver manutenção de equipamentos, reforma ou ampliação de linhas produtivas, ou ainda se a demanda for pequena a ponto de inviabilizar a produção em uma planta.

Esta descrição do problema representa de forma razoável as etapas produtivas que ocorrem nas plantas da indústria em questão, dessa forma, o cenário retratado agrupa características que corroboram sua classificação como um problema de dimensionamento de lotes com itens multiestágio de estrutura geral, restrições de capacidade produtiva e de armazenamento, tempo e custo de preparação dos equipamentos, máquinas paralelas distintas, múltiplos processos e múltiplas plantas com transferência interna de produtos.

\subsection{Modelagem Matemática}

Nesta etapa foram consideradas algumas simplificações do problema descrito na Seção 3.2, dentre as quais destacam-se a desconsideração do armazenamento de matérias-prima, da etapa de embalagem, da utilização de tempos de preparação de máquina e da transferência de produtos entre plantas.

O custo de estocagem de matéria-prima não foi considerado no modelo, pois a capacidade de aquisição durante os períodos era suficiente para atender à demanda e as variações do preço de compra entre os períodos era muito pequena, chegando a ser constante em muitos casos, durante o horizonte de planejamento, conforme informações obtidas com a indústria.

A etapa de embalagem não foi incluída no modelo por não afetar diretamente o fluxo produtivo, visto que ela utiliza mão de obra e equipamentos distintos, portanto, essa etapa foi considerada um novo problema, o qual não foi abordado neste trabalho. Por esse motivo, apesar da empresa diferenciar produtos finais ${ }^{6}$ pelas embalagens, as quais podem ser compostas pelo mesmo conteúdo, neste estudo foi considerado a somatória dessas demandas, de forma que um produto fosse identificado pelos seus processos produtivos e não pela sua embalagem. Uma abordagem semelhante foi utilizada em Baumann e Trautmann (2013).

Os tempos de preparação dos reatores e as transferências entre plantas foram desconsiderados, tanto por não apresentarem informações completas dos dados fornecidos, como para reduzir a complexidade do modelo. No caso da preparação, a única informação disponível era o percentual médio de utilização dos reatores, baseados em históricos operacionais, a partir do qual seria necessário inferir os tempos médios de preparação. Já com relação às transferências entre plantas, era conhecido apenas o custo médio de transporte de cada produto, não havendo

\footnotetext{
${ }^{6} \mathrm{~A}$ venda de um produto pode ser a granel, ensacada ou em caixa.
} 
qualquer referência às quantidades limites de transferência.

\subsubsection{Modelo Principal}

Com base nas considerações anteriores, o modelo proposto para abordar o problema enfrentado pela indústria é apresentado a seguir.

Índices:

$i=1, \ldots, \mathrm{N}$ (número de itens);

$p=1, \ldots, \mathrm{P}$ (número de processos);

$k=1, \ldots, \mathrm{K}$ (número de máquinas);

$m=1, \ldots, \mathrm{M}$ (número de matérias-primas);

$t=1, \ldots, \mathrm{T}$ (número de períodos);

$q=1, \ldots, \mathrm{Q}$ (número de tanques).

Parâmetros do problema:

$a_{q}$ : capacidade de armazenamento do tanque $q$;

$b_{i, k, p}$ : tempo de produção de uma batelada do item $i$ na máquina $k$ pelo processo $p$;

$c_{m, t}$ : custo unitário da matéria-prima $m$ no período $t$;

$d_{i, t}:$ demanda externa do item $i$ no período $t$;

$e_{m, i, p}$ : quantidade da matéria-prima $m$ consumida na produção de uma batelada do item $i$ pelo processo $p$;

$f_{i, p}$ : quantidade do item $i$ produzida por batelada, pelo processo $p$;

$g_{i, t}:$ custo de descarte do item $i$ no período $t$;

$h_{i, t}$ : custo de estocagem do item $i$ no período $t$;

$r_{i, j, p}$ : quantidade do item $i$ utilizada na produção de uma batelada do item $j$ pelo processo $p$;

$C A P_{k, t}:$ tempo total para utilização da máquina $k$ no período $t$;

$Q(i)$ : conjunto de tanques utilizáveis pelo item $i$;

$R(q)$ : conjunto de itens que podem utilizar o tanque $q$.

Variáveis do problema:

$X_{i, p, t}$ : quantidade produzida do item $i$ pelo processo $p$ no período $t$, em bateladas;

$I_{i, t}$ : estoque do item $i$ no período $t$;

$W_{i, t}$ : quantidade descartada do item $i$ no período $t$;

$Z_{q, i, t}$ : variável binária que indica se o tanque $q$ é ocupado pelo item $i$ ao final do período $t$.

$$
\min \sum_{i=1}^{N} \sum_{p=1}^{P} \sum_{t=1}^{T} \sum_{m=1}^{M}\left(e_{m, i, p} * c_{m, t} * X_{i, p, t}\right)+\sum_{i=1}^{N} \sum_{t=1}^{T}\left(g_{i, t} W_{i, t}+h_{i, t} I_{i, t}\right)
$$


sujeito a:

$$
\begin{array}{rc}
\sum_{i=1}^{N} \sum_{p=1}^{P}\left(b_{i, k, p} * X_{i, p, t}\right) \leq C A P_{k, t} & \forall t, k \\
I_{i, t-1}+\sum_{p=1}^{P}\left(f_{i, p} * X_{i, p, t}\right)=d_{i, t}+\sum_{p=1}^{P} \sum_{j=1}^{N}\left(r_{i, j, p} * X_{j, p, t}\right)+W_{i, t}+I_{i, t}, & \forall i, t \\
I_{i, t} \leq \sum_{q \in Q(i)} a_{q} * Z_{q, i, t}, & \forall t, i \\
\sum_{i \in R(q)} Z_{q, i, t} \leq 1, & \forall q, t \\
I_{i, 0}=0, & \forall i \\
I_{i, t}, W_{i, t} \geq 0, & \forall i, t \\
Z_{q, i, t} \in\{0,1\}, & \forall q, i, t \\
X_{i, p, t} \geq 0 \text { e inteiro, } & \forall i, t, p
\end{array}
$$

A função objetivo (3.1) visa minimizar os custos produtivos da indústria. Para isso, é analisada a relação de compromisso, ou trade-off, entre a escolha dos processos que reduzem o custo das matérias-primas empregadas nas reações, a perda com o descarte de produtos quando não houver capacidade de armazenamento suficiente para a produção excedente, e o custo de estocagem dos produtos após a demanda do período ser atendida.

No processo produtivo dos itens multiestágio, o cálculo dos custos referentes aos itens componentes acontece apenas durante a produção destes itens, ou seja, quando um item componente é utilizado em alguma reação, sua contribuição na função objetivo ocorre apenas pelo incremento de seu custo produtivo em relação à sua demanda, por isso, a primeira parcela da função objetivo considera somente matérias-primas.

O conjunto de inequações (3.2) limitam a utilização das máquinas pelos processos, assegurando que suas capacidades operacionais não sejam excedidas. Já em (3.3) ocorre o balanço de estoque do sistema, ou seja, a produção dos itens em um período, somado ao estoque proveniente do período anterior, deve ser igual à soma de sua demanda externa, de sua demanda interna, do estoque ao final deste período e ao seu descarte, caso não haja capacidade suficiente de armazenamento.

As restrições (3.4) indicam que o estoque dos produtos pode ser distribuído entre vários tanques, desde que a quantidade de cada produto armazenado não exceda a somatória das capacidades dos tanques que podem ser utilizados por eles, os quais limitam-se ao conjunto $Q(i)$. Já as restrições (3.5) garantem que ao final dos períodos cada tanque pode ser ocupado por no má- 
ximo um produto, caso este pertença ao conjunto de itens representado por $R(q)$. Em (3.6) são representados, sem perda de generalidade, os estoques dos produtos no início do horizonte de planejamento, $t=0$. Finalmente, em (3.7), (3.8) e (3.9) são definidos os domínios das variáveis.

\subsubsection{Modelo Considerando Custo de Setup}

O problema considerando custos de preparação de máquina não é o foco desta dissertação, mas devido à natureza do problema em estudo, com a redução do número de preparações de máquina, os processos produtivos dos itens tenderiam a concentrar maior volume, resultando em uma solução mais próxima à realidade da empresa.

Portanto, o emprego desta característica no momento do planejamento da produção é interessante, pois caso seja verificada a necessidade de agrupar a produção de cada produto em um número reduzido de processos, no momento em que o sequenciamento da produção estiver sendo definido, é possível que a nova configuração dos processos altere o consumo de matériasprimas a ponto de tornar o planejamento de sua aquisição inadequado.

Parâmetros acrescentados ao modelo principal:

$\lambda_{i, p, t}$ : custo de preparação de máquina para o processo $p$ do item $i$ no período $t$;

$M$ : número suficientemente grande.

Variável acrescentada ao modelo principal:

$Y_{i, p, t}$ : variável binária que indica se houve produção do item $i$ pelo processo $p$ no período $t$.

$$
\min \sum_{i=1}^{N} \sum_{p=1}^{P} \sum_{t=1}^{T}\left[\lambda_{i, p, t} * Y_{i, p, t}+\sum_{m=1}^{M}\left(e_{m, i, p} * c_{m, t} * X_{i, p, t}\right)\right]+\sum_{i=1}^{N} \sum_{t=1}^{T}\left(g_{i, t} W_{i, t}+h_{i, t} I_{i, t}\right)
$$

sujeito a:

$$
\begin{array}{r}
\sum_{i=1}^{N} \sum_{p=1}^{P}\left(b_{i, k, p} * X_{i, p, t}\right) \leq C A P_{k, t} \quad \\
I_{i, t-1}+\sum_{p=1}^{P}\left(f_{i, p} * X_{i, p, t}\right)=d_{i, t}+\sum_{p=1}^{P} \sum_{j=1}^{N}\left(r_{i, j, p} * X_{j, p, t}\right)+W_{i, t}+I_{i, t}, \quad \\
I_{i, t} \leq \sum_{q \in Q(i)} a_{q} * Z_{q, i, t}, \quad \\
\sum_{i \in R(q)} Z_{q, i, t} \leq 1, \quad \forall t, i \\
X_{i, p, t} \leq M Y_{i, p, t} \\
\forall q, t
\end{array}
$$




$$
\begin{aligned}
I_{i, 0}=0, & \forall i \\
I_{i, t}, W_{i, t} \geq 0, & \forall i, t \\
Z_{q, i, t}, Y_{i, p, t} \in\{0,1\}, & \forall q, i, t \\
X_{i, p, t} \geq 0 \text { e inteiro, } & \forall i, t, p
\end{aligned}
$$

A função objetivo (3.10) visa minimizar os custos produtivos, de descarte e de estocagem, além de penalizar a preparação das máquinas. O conjunto de inequações (3.11) limitam a utilização das máquinas pelos processos. Já em (3.12) ocorre o balanço de estoque do sistema.

As restrições (3.13) indicam que o estoque dos produtos pode ser distribuído entre vários tanques, desde que a quantidade de cada produto armazenado não exceda a somatória das capacidades dos tanques que podem ser utilizados por eles, os quais limitam-se ao conjunto $Q(i)$. Já as restrições (3.14) garantem que ao final dos períodos cada tanque pode ser ocupado por no máximo um produto, caso este pertença ao conjunto de itens representado por $R(q)$.

O conjunto de inequações (3.15) garante que a solução considera preparação de máquina para um processo produtivo sempre que este apresentar produção. Em (3.16) são representados, sem perda de generalidade, os estoques dos produtos no início do horizonte de planejamento, $t=0$. Finalmente, em (3.17), (3.18) e (3.19) são definidos os domínios das variáveis.

\subsection{Estudos de Modelos Matemáticos}

Esta seção tem como objetivo o estudo do comportamento dos modelos propostos na Seção 3.3, utilizando um exemplo reduzido para analisar as características das soluções perante algumas modificações.

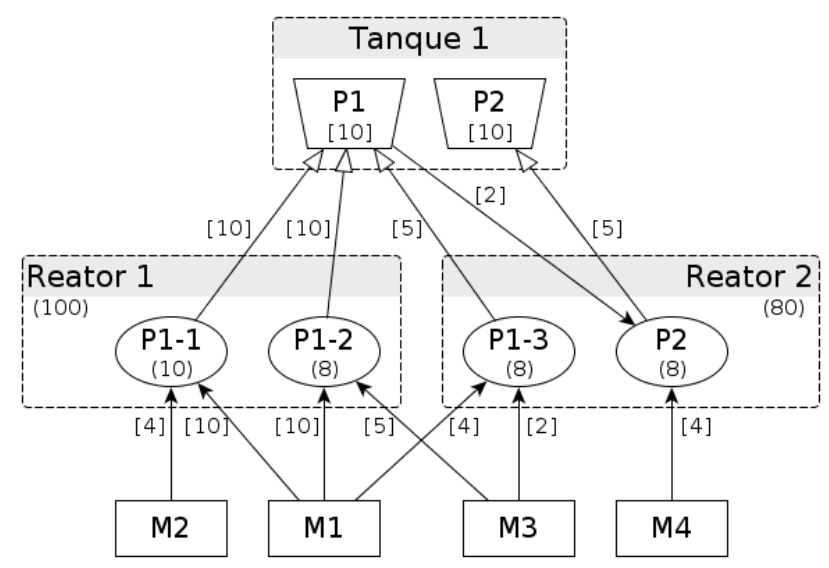

Figura 3.5: Estrutura de processos produtivos para fins didáticos. 
A estrutura do problema utilizado para os estudos desta seção é ilustrada de forma sucinta pela Figura 3.5, na qual observa-se quatro matérias-primas, dois reatores, dois produtos e um tanque de armazenamento. O produto P1 apresenta três formas distintas de produção, das quais duas ocorrem no reator 1 e uma no reator 2. Em seu primeiro processo, denominado P1-1, são adicionados quatro toneladas $^{7}$ da matéria-prima M2 e dez toneladas da matéria-prima M1 no reator 1 , as quais devem reagir por dez minutos ${ }^{8}$, resultando em dez toneladas do produto. $\mathrm{O}$ processo P1-2 também ocorre no reator 1, mas ao invés da matéria-prima M2, são adicionadas cinco toneladas da matéria-prima M3, e o tempo de processamento para essa reação é de oito minutos. Já o processo P1-3 ocorre no reator 2, consumindo os mesmos insumos que P1-2. Por fim, o único processo produtivo de P2 é efetuado no reator 2, sendo utilizado a matéria-prima M4 e o produto P1, dessa forma, P2 caracteriza-se como um produto de segundo nível, como pode ser visto na Figura 3.6.

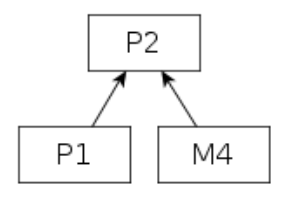

Figura 3.6: Estrutura de produto simplificada.

Simplificando a estrutura dos processos produtivos, pode-se representar a concorrência dos produtos pela utilização dos reatores 1 e 2, Figura 3.7 (a), cujas capacidades produtivas são de 100 e 80 minutos por período, respectivamente. Após os processos serem finalizados, iniciase a competição pela utilização do tanque de armazenamento, Figura 3.7 (b), o qual possui capacidade de 10 toneladas, podendo ser utilizado por ambos os produtos, não simultaneamente.

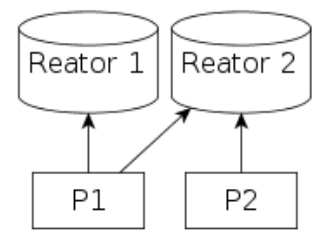

(a)

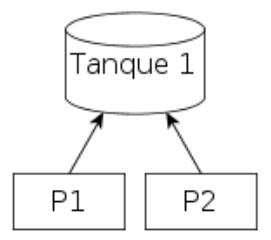

(b)

Figura 3.7: Concorrência dos reatores (a) e do tanque (b) pelos produtos P1 e P2.

Com a estrutura dos produtos definida, falta apenas a determinação de alguns parâmetros como preço de compra das matérias-primas, demanda e preço de venda dos produtos para caracterizar o exemplo. Estes dados são descritos na Tabela 3.1.

\footnotetext{
${ }^{7}$ Números entre colchetes possuem a mesma unidade de medida para matéria, neste caso, tonelada.

${ }^{8}$ Números entre parênteses apresentam a mesma unidade temporal, neste caso, minuto.
} 
Tabela 3.1: Parâmetros definidos pelo mercado.

\begin{tabular}{c|ccc}
\hline Parâmetro & Período 1 & Período 2 & Período 3 \\
\hline Custo M1 (\$/ton) & 30 & 29 & 30 \\
Custo M2 (\$/ton) & 40 & 40 & 41 \\
Custo M3 (\$/ton) & 44 & 45 & 45 \\
Custo M4 (\$/ton) & 75 & 73 & 74 \\
\hline Preço P1 (\$/ton) & 100 & 100 & 100 \\
Preço P2 (\$/ton) & 250 & 250 & 250 \\
\hline Demanda P1 (ton) & 59 & 90 & 56 \\
Demanda P2 (ton) & 42 & 38 & 58
\end{tabular}

Analisando somente a estrutura de produto e os custos das matérias-primas, pode-se determinar o custo dos produtos de acordo com a equação (3.20). Observa-se que a produção de P1 através do processo 3 (P1-3) apresenta a menor relação custo por tonelada, sempre menor ou igual 42 \$/ton, visto que os maiores custos das matérias-primas utilizadas, M1 e M3, são \$30 e $\$ 45$, respectivamente. Dessa forma custo $P 1-3 \leq \frac{4 * 30+2 * 45}{5}=42 \frac{\$}{\text { ton }}$.

$$
\text { Custo }_{P}=\frac{\sum_{M} \text { Preço }_{M} * \text { Volume }_{M}}{\text { Volume }_{P}}
$$

De forma análoga, pode-se observar que P1-2 corresponde ao processo produtivo mais caro para o produto tem questão, sendo sempre maior ou igual a 51 \$/ton. Porém, como esta análise não considera o contexto do problema, não é possível afirmar que o processo produtivo P1-3 será de fato utilizado, portanto, a seguir serão analisadas quatro situações distintas.

\section{SITUAÇÃO 1}

A partir do modelo principal foram realizadas simplificações que resultaram no modelo descrito a seguir:

$$
\min \sum_{i=1}^{N} \sum_{p=1}^{P} \sum_{t=1}^{T} \sum_{m=1}^{M}\left(e_{m, i, p} * c_{m, t} * X_{i, p, t}\right)
$$

sujeito a:

$$
\begin{array}{r}
\sum_{i=1}^{N} \sum_{p=1}^{P}\left(b_{i, k, p} * X_{i, p, t}\right) \leq C A P_{k, t} \quad \forall t, k \\
I_{i, t-1}+\sum_{p=1}^{P}\left(f_{i, p} * X_{i, p, t}\right)=d_{i, t}+\sum_{p=1}^{P} \sum_{j=1}^{N}\left(r_{i, j, p} * X_{j, p, t}\right)+I_{i, t}, \quad \forall i, t
\end{array}
$$




$$
\begin{aligned}
I_{i, t} \leq \sum_{q \in Q(i)} a_{q} * Z_{q, i, t}, & \forall t, i \\
\sum_{i \in R(q)} Z_{q, i, t} \leq 1, & \forall q, t \\
I_{i, 0}=0, & \forall i \\
I_{i, t} \geq 0, & \forall i, t \\
Z_{q, i, t} \in\{0,1\}, & \forall q, i, t \\
X_{i, p, t} \geq 0 \text { e inteiro, } & \forall i, t, p
\end{aligned}
$$

A função objetivo (3.21) visa minimizar apenas os custos dos processos produtivos da indústria. As restrições (3.23) representam o balanço de estoque do sistema, sem levar em consideração o descarte de produtos. As demais restrições são semelhantes às do modelo principal.

Porém, uma análise simples neste modelo é suficiente para concluir que não existe solução factível para este problema. Avaliando o primeiro período, constata-se que para atender à demanda de P2 seria necessário produzir 9 ou 10 lotes, para que seu volume final fosse de 45 ou 50 toneladas, respectivamente. Como P2 é um produto de segundo nível, que utiliza P1 em sua reação, conclui-se que para atender sua demanda no período em questão seria necessário consumir 18 ou 20 toneladas de P1.

Sendo assim, como a demanda externa de P1 no primeiro período é de 59 toneladas, ao considerar sua demanda interna, a demanda total resultante seria de 77 ou 79 toneladas. Mas nesses dois casos, a demanda total não é múltipla do volume produzido por nenhuma das combinações de seus processos. Portanto, qualquer processo selecionado para P1 e P2 induziria estoque ao final do primeiro período para os dois produtos, o que violaria as restrições (3.24) e (3.25), por existir apenas um tanque de armazenamento que não pode ser compartilhado simultaneamente entre ambos os produtos.

\section{SITUAÇÃO 2}

Para evitar que o fato apresentado na primeira situação inviabilize o estudo do problema enfrentado pela indústria, um novo conjunto de variáveis, $W_{i, t}$, foi considerado no modelo, representando o descarte de produtos quando seu estoque tornar as soluções infactíveis. Sendo assim, o novo modelo é representado a seguir:

Variável acrescentada ao modelo anterior:

$W_{i, t}$ : quantidade descartada do item $i$ no período $t$. 


$$
\min \sum_{i=1}^{N} \sum_{p=1}^{P} \sum_{t=1}^{T} \sum_{m=1}^{M}\left(e_{m, i, p} * c_{m, t} * X_{i, p, t}\right)+\sum_{i=1}^{N} \sum_{t=1}^{T} g_{i, t} W_{i, t}
$$

sujeito a:

A função objetivo (3.30) visa minimizar os custos dos processos produtivos da indústria e o descarte dos produtos.

Apesar de necessário para a factibilização do problema, o descarte de produtos deve ser evitado sempre que possível. Por essa razão, o parâmetro $g_{i, t}$ equivale a uma penalização com o próprio valor no qual o produto é comercializado.

Tabela 3.2: Solução ótima para a função objetivo dada pela equação (3.30)

\begin{tabular}{c|ccc}
\hline Variável & Período 1 & Período 2 & Período 3 \\
\hline P1-1 (ton) & 80 & 100 & 80 \\
P1-2 (ton) & 0 & 0 & 0 \\
P1-3 (ton) & 0 & 10 & 0 \\
P2 (ton) & 50 & 40 & 50 \\
\hline Descarte P1 (ton) & 1 & 4 & 4 \\
Descarte P2 (ton) & 0 & 0 & 0 \\
\hline Estoque P1 (ton) & 0 & 0 & 0 \\
Estoque P2 (ton) & 8 & 10 & 2 \\
\hline Consumo R1 (\%) & 80 & 100 & 80 \\
Consumo R2 (\%) & 100 & 100 & 100
\end{tabular}

A solução ótima obtida neste caso, é apresentada na Tabela 3.2, na qual encontram-se as quantidades produzidas, descartadas e estocadas, além do percentual de consumo dos reatores a cada período.

\section{SITUAÇÃO 3}

A abordagem anterior é suficiente para lidar com problemas semelhantes ao encontrado na indústria em estudo, porém, a inclusão de penalização para o estoque dos produtos tornaria o modelo mais próximo da realidade, pois estaria representando fatores como, por exemplo, gastos para evitar a deterioração dos produtos e ausência de lucratividade do capital empregado no estoque. Este modelo é descrito na Subseção 3.3.1, segundo a qual sua função objetivo é representada portanto:

$$
\min \sum_{i=1}^{N} \sum_{p=1}^{P} \sum_{t=1}^{T} \sum_{m=1}^{M}\left(e_{m, i, p} * c_{m, t} * X_{i, p, t}\right)+\sum_{i=1}^{N} \sum_{t=1}^{T}\left(g_{i, t} W_{i, t}+h_{i, t} I_{i, t}\right.
$$

A Tabela 3.3 apresenta as soluções ótimas deste modelo ao considerar $h_{i, t}=\beta * v_{i, t}$, para o 
qual $v_{i t}$ representa o preço de venda dos produtos e $\beta$ é um percentual desse valor que assume os valores 0,5 e 0,05 , para esta situação.

É possível verificar que ao diminuir o parâmetro $\beta$, a solução ótima tende a utilizar os processos com menor custo e que contribuam para minimizar o descarte de produtos, aproximandose cada vez mais da função objetivo (3.30).

Tabela 3.3: Solução ótima para a função objetivo dada pela equação (3.1)

\begin{tabular}{c|ccc|ccc}
\hline Parâmetro & \multicolumn{3}{|c|}{ Teste 1 } & \multicolumn{3}{c}{ Teste 2 } \\
\hline$\beta$ & \multicolumn{3}{|c|}{0,5} & & \multicolumn{3}{c}{05} \\
\hline \hline Variável & Período 1 & Período 2 & Período 3 & Período 1 & Período 2 & Período 3 \\
\hline P1-1 (ton) & 80 & 60 & 80 & 80 & 100 & 80 \\
P1-2 (ton) & 0 & 50 & 0 & 0 & 0 & 0 \\
P1-3 (ton) & 0 & 0 & 0 & 0 & 10 & 0 \\
P2 (ton) & 45 & 45 & 50 & 50 & 40 & 50 \\
\hline Descarte P1 (ton) & 3 & 2 & 0 & 1 & 4 & 4 \\
Descarte P2 (ton) & 2 & 0 & 0 & 0 & 0 & 0 \\
\hline Estoque P1 (ton) & 0 & 0 & 4 & 0 & 0 & 0 \\
Estoque P2 (ton) & 1 & 8 & 0 & 8 & 10 & 2 \\
\hline Consumo R1 (\%) & 80 & 100 & 80 & 80 & 100 & 80 \\
Consumo R2 (\%) & 90 & 90 & 100 & 100 & 100 & 100
\end{tabular}

Caso fossem considerados os custos de preparação dos reatores, a solução para $\beta$ valendo 0,05 poderia não ser ótima, pois no segundo período há uma produção de 10 toneladas de P1 no reator 2, mas para que isso ocorra, é necessário arcar com custo de preparação do reator para a produção de $\mathrm{P} 1 \mathrm{e}$, posteriormente, com um novo custo para a produção de $\mathrm{P} 2$ no terceiro período.

\section{SITUAÇÃO 4}

Ao efetuar uma variação do modelo abordado na situação anterior, na qual busca-se reduzir o número de preparações de máquina no planejamento da produção, além de minimizar o custo produtivo da indústria, o descarte dos produtos e a quantidade de estoque entre os períodos, obtém-se o modelo proposto na Subseção 3.3.2.

Considerando que a capacidade do reator 2 seja expandida de 80 para 88 minutos, as soluções ótimas para $\lambda_{i, p, t}$ igual a 4 vezes o preço de venda dos produtos $\left(v_{i t}\right)$ e para $\lambda_{i, p, t}$ igual a 16 vezes o preço de venda do produto são apresentadas na Tabela 3.4.

Analisando os dados da Tabela 3.4 é possível observar que ao aumentar o coeficiente de penalização dos setups de 4 para 16 vezes o valor do preço de venda, o número de setups é reduzido em $16,67 \%$ (de 7 para 6), mediante a um aumento de $6,81 \%$ da função objetivo (3.1). 
Tabela 3.4: Solução ótima para a função objetivo dada pela equação (3.10)

\begin{tabular}{c|ccc|ccc}
\hline Parâmetro & \multicolumn{3}{|c|}{ Teste 1 } & \multicolumn{3}{c}{ Teste 2 } \\
\hline$\lambda_{i, p, t}$ & \multicolumn{3}{|c|}{$4 * v_{i t}$} & & \multicolumn{3}{c}{$16 v_{i t}$} \\
\hline \hline Variável & Período 1 & Período 2 & Período 3 & Período 1 & Período 2 & Período 3 \\
\hline P1-1 (ton) & 80 & 90 & 80 & 80 & 0 & 80 \\
P1-2 (ton) & 0 & 0 & 0 & 0 & 110 & 0 \\
P1-3 (ton) & 0 & 15 & 0 & 0 & 0 & 0 \\
P2 (ton) & 50 & 35 & 55 & 45 & 40 & 55 \\
\hline Descarte P1 (ton) & 1 & 1 & 2 & 3 & 4 & 2 \\
Descarte P2 (ton) & 0 & 0 & 0 & 0 & 0 & 0 \\
\hline Estoque P1 (ton) & 0 & 0 & 0 & 0 & 0 & 0 \\
Estoque P2 (ton) & 8 & 5 & 2 & 3 & 5 & 2 \\
\hline Consumo R1 (\%) & 80 & 90 & 80 & 80 & 88 & 80 \\
Consumo R2 (\%) & 91 & 91 & 100 & 82 & 73 & 100 \\
\hline \hline Função Objetivo & \multicolumn{7}{c|}{} & & & $22.374,00$ \\
\hline (3.1) & \multicolumn{7}{|c|}{$20.947,50$} & & & $39.174,00$ &
\end{tabular}

O emprego desta função tem a finalidade de minimizar a influência dos coeficientes adotados.

Nesta dissertação serão considerados os modelo representado pela Situação 3, por adequarse às necessidades da empresa em questão, e pela Situação 4, por visar a redução do número de preparações de máquina, tornando o planejamento da produção mais robusto. 


\section{CAPÍTULO 4}

\section{MÉTODOS DE SOLUÇÃO}

Este trabalho tem como objetivo estudar o dimensionamento de lotes com restrições de capacidade, cujo problema de encontrar soluções ótimas pertence à classe de complexidade NP-Hard (FLORIAN et al., 1980), com uma característica adicional que representa a produção multiestágio, tornando sua resolução ainda mais difícil.

Os problemas pertencentes à classe NP apresentam um crescimento exponencial no espaço de busca de soluções à medida que as variáveis do problema apresentam apenas crescimento linear, como foi explicado no Capítulo 2. Portanto, caso as variáveis binárias $\left(Z_{q, i, t}\right)$ do modelo proposto na Seção 3.3 fossem modificadas, de forma que 140 produtos compartilhassem 70 tanques, dois a dois, durante os 4 períodos, seria possível representá-las através de 280 variáveis (cada estado da variável binária representaria o produto que teria direito a utilizar cada um dos 70 tanques a cada período), resultando em $2^{280}$ possíveis combinações para as soluções.

Recentemente foi divulgado que o cluster de processamento da Unicamp ${ }^{1}$ é capaz de realizar 4,5 trilhões de operações aritméticas por segundos, portanto, caso a verificação de cada uma dessas soluções necessitasse de apenas uma operação aritmética, ainda seriam necessários mais de $10^{71}$ segundos para uma análise completa desse conjunto soluções ${ }^{2}$.

Portanto, apesar dos esforços empregados para o desenvolvimento de métodos exatos de resolução para os elementos dessa classe (LAND; DOIG, 1960), (BALAS, 1971), (BARNHART

\footnotetext{
${ }^{1}$ http://agencia.fapesp.br/17251

${ }^{2}$ Como parâmetro de comparação para o tempo de processamento restante, a idade do universo é menor do que $5 \times 10^{17}$ segundos.
} 
et al., 1998) e (BELVAUX; WOLSEY, 2000)), as dimensões e características do problema são fundamentais e podem restringir a aplicação desses métodos em modelos que visam descrever detalhadamente situações reais.

Até mesmo com a utilização de pacotes de otimização modernos, como o CPLEX 12.4, que tentam agregar diversas estratégias para resolução desses problemas, não há garantias de que a solução ótima possa ser obtida após um tempo razoável de processamento. Na realidade, testes preliminares mostraram que este software foi incapaz de ao menos encontrar uma solução factível para algumas instâncias que possuíam características descritas na Seção 3.3.

Sendo assim, o estudo de heurísticas para tratar problemas como este é de extrema importância, principalmente quando nota-se que diversas heurísticas são capazes de encontrar soluções factíveis após pouco tempo de processamento.

Neste capítulo serão descritas as heurísticas que foram utilizadas neste trabalho, as quais podem ser agrupadas em construtivas, como no caso das heurísticas LP-and-fix e relax-and-fix, e de melhoramento, para as heurísticas fix-and-optimize.

\subsection{LP-and-Fix}

As heurísticas $L P$-and-fix foram previamente utilizadas na resolução de problemas de dimensionamento de lotes, sendo associadas a procedimentos branch-and-bound para resolução de problemas com múltiplos itens, restrições de capacidade, tempo de setup e com estrutura monoestágio (DENIZEL; SÜRAL, 2006) ou multiestágio (MAES et al., 1991) e a procedimentos relax-and-fix para estrutura multiestágio (AKARTUNALI; MILLER, 2009).

A lógica utilizada por essas heurísticas é simples, consistindo basicamente em relaxar todas as variáveis inteiras e binárias do $\mathrm{MIP}^{3}$ para que em seu lugar seja resolvido um problema linear, o qual demanda um esforço computacional consideravelmente menor.

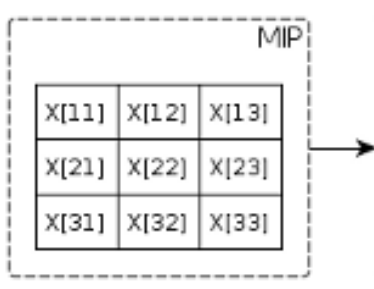

(a)

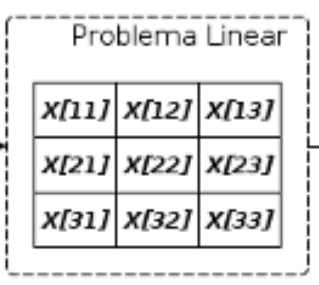

(b)

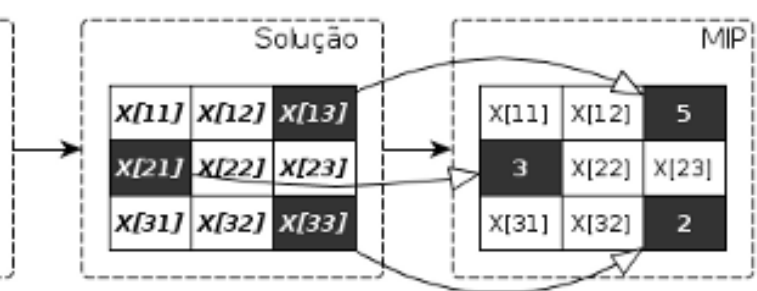

(c) (d)

Figura 4.1: Representação genérica de uma heurística $L P$-and-fix.

\footnotetext{
${ }^{3}$ Mixed Integer Problem ou problema inteiro misto.
} 
O problema inteiro misto, Figura 4.1 (a), é relaxado linearmente, resultando no problema representado pela Figura 4.1 (b), o qual é resolvido para que sua solução ótima seja encontrada, Figura 4.1 (c). Neste ponto, um procedimento de fixação é aplicado, determinando as variáveis que serão fixadas em valores inteiros, destacadas em preto nos casos (c) e (d). Dessa forma, espera-se que para a execução do novo MIP, representado pela Figura 4.1 (d), haja redução suficiente do número de variáveis, possibilitando a sua resolução em tempo menor do que o problema original.

Neste trabalho foram consideradas três estratégias de fixação das variáveis:

1. A primeira, que será denominada por LP-I, busca fixar os valores inteiros, presentes na solução ótima do problema linear para a composição do MIP resultante. Por exemplo, considerando a Figura 4.1, a solução ótima da situação (c) apresentaria os valores 5, 3 e 2 para as variáveis $x[13], x[21]$ e $x[33]$, respectivamente, as quais encontram-se fixadas na situação $(\mathrm{d})$.

2. A segunda estratégia, denominada LP-NN, visa fixar apenas variáveis cuja solução do problema linear seja inteira não nula. Portanto, continuando com a análise da Figura 4.1, caso a solução ótima do problema linear apresentasse as variáveis $x[11], x[13], x[21] \mathrm{e}$ $x$ [33] com os valores $0,5,3$ e 2, respectivamente, apenas a variável $x[11]$ não seria fixada para a situação (d). Essa variação é necessária quando a solução ótima do problema linear contém diversas variáveis com valor zero, portanto, a fixação desses valores nulos pode reduzir excessivamente o número de soluções factíveis, podendo inclusive eliminá-las em sua totalidade.

3. A terceira, denominada LP-RNN, consiste em arredondar e fixar variáveis cuja solução do problema linear estejam próximos o suficiente de um inteiro não nulo, desde que o arredondamento sempre aumente o valores das variáveis. Dessa forma, seriam arredondadas apenas as variáveis que satisfaçam a condição $\lceil x\rceil-x \leq \varepsilon$. Portanto, considerando $\varepsilon=0,1$, caso a solução para a situação (c) da Figura 4.1 apresentasse $x[12]=0,1$; $x[13]=5 ; x[21]=2,9 ; x[22]=2,05 ; x[31]=3,8$ e $x[33]=1,95$, apenas as variáveis $x[13], x[21]$ e $x[33]$ seriam fixadas.

\subsection{Relax-and-Fix}

Heurísticas do tipo relax-and-fix foram empregadas na resolução de problemas de dimensionamento de lotes com múltiplos itens, restrições de capacidade, tempo de setup e com estrutura de produtos monoestágio (MERCÉ; FONTAN, 2003) ou multiestágio (AKARTUNALI; 
MILLER, 2009). Também é possível encontrar esta heurística em aplicações reais, como por exemplo na indústria de bebidas (FERREIRA et al., 2010), na de fundição (ARAUJO et al., 2008) e papel e celulose (SANTOS; ALMADA-LOBO, 2012).

De forma geral, essas heurísticas caracterizam-se por particionarem o conjunto de variáveis inteiras do problema em três grupos: um contendo somente variáveis inteiras, como definido originalmente no problema, um segundo contendo variáveis relaxadas, que apesar de serem inicialmente inteiras, passaram por um processo de simplificação (linearização), e o último com variáveis fixadas, que já assumiram valores finais para comporem a solução factível, caso esta seja encontrada ao final do processamento.

(a)

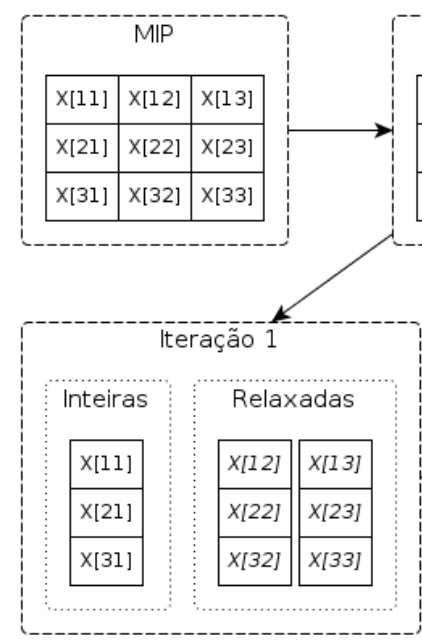

(c) (b)

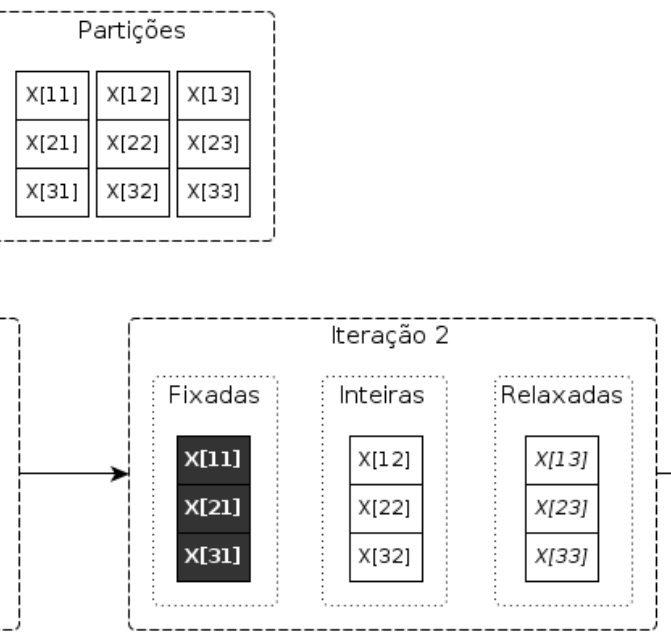

(d) (f)

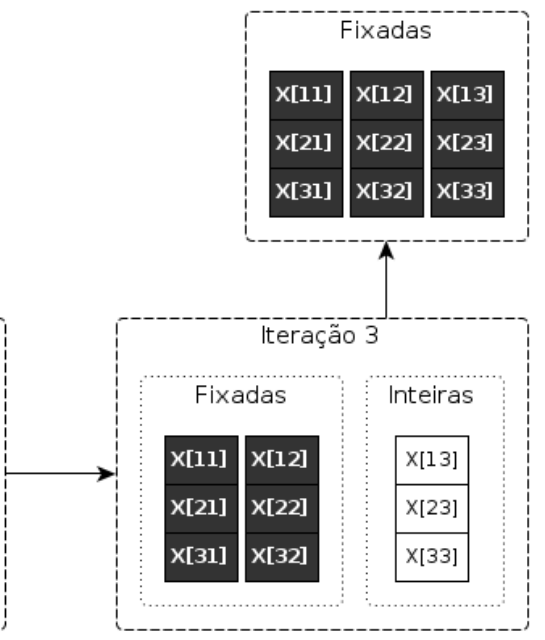

(e)

Figura 4.2: Representação genérica de uma heurística relax-and-fix.

O comportamento clássico dessa heurística é ilustrado pela Figura 4.2, consistindo em dividir as variáveis inteiras e binárias do MIP em diversas partições, neste exemplo, representadas por três colunas de variáveis, Figura 4.2 (b). A cada iteração, uma partição ingressa no conjunto de variáveis inteiras e, caso uma solução factível seja encontrada, um subconjunto dessas variáveis é fixado, ou seja, integram-se ao terceiro grupo de variáveis, as quais estão destacadas em preto, como na Figura 4.2 (d).

Ao final do processo, espera-se que todas as variáveis estejam fixadas, o que representa uma solução factível para o MIP original. Porém, a heurística deve ser interrompida caso alguma iteração não seja capaz de encontrar uma solução factível, pois considerando as variáveis fixadas previamente, não haveria possibilidade de encontrar uma solução factível para o problema utilizando esta heurística, mesmo que a existência dessa solução fosse conhecida, caso os critérios de parada fossem mantidos. 
Através da Figura 4.2, é possível concluir que o número de iterações necessárias para a resolução do problema é determinado através da quantidade de partições criadas inicialmente. Apesar desta abordagem resolver diversos (sub)problemas, ao invés de apenas um, como ocorre na resolução do MIP original, a redução do esforço computacional, proporcionada pela diminuição do número de variáveis inteiras, indica a possibilidade dessa heurística apresentar resultados promissores.

\subsubsection{Estratégias de Particionamento}

Um dos fatores fundamentais para a eficiência do método relax-and-fix está no particionamento de suas variáveis, portanto, foram avaliadas três maneiras distintas de efetuar esta operação: agrupamento por períodos, agrupamento por itens e agrupamento por níveis.

\section{Agrupamento por Períodos}

A primeira forma de particionamento utiliza o agrupamento das variáveis em períodos, como ilustrado na Figura 4.3. A cada iteração, as variáveis relacionadas a um determinado período são consideradas inteiras (retângulos com linhas pontilhadas), enquanto as outras variáveis encontram-se no conjunto de variáveis fixadas (retângulos na cor preta) ou no conjunto das que estão relaxadas (demais variáveis).

\begin{tabular}{|c|c|c|c|c|c|c|c|c|c|c|c|c|c|c|c|}
\hline & $\mathrm{tl}$ & t2 & t3 & & tl & t2 & t3 & & $\mathrm{tl}$ & t2 & t3 & & $\mathrm{tl}$ & t2 & t3 \\
\hline II & $x[11]$ & $\mathrm{X}[12]$ & $x[13]$ & II & $x[11]$ & $x[12]$ & $X[13]$ & II & $x[11]$ & $x[12]$ & $x[13]$ & 11 & $x[11]$ & $x$ [12] & X[13] \\
\hline 12 & $x[21]$ & $X[22]$ & $X[23]$ & 12 & $x[21]$ & $x[22]$ & $X[23]$ & 12 & $X[21]$ & $x[22]$ & $x[23]$ & 12 & $X[21]$ & $x[22]$ & $x[23]$ \\
\hline 13 & $x[31]$ & $\mathrm{X}$ [32] & $x[33]$ & 13 & $x[31]$ & $x[32]$ & $\mathrm{X}$ [33] & 13 & $x[31]$ & $x[32]$ & $x[33]$ & 13 & $X[31]$ & $x[32]$ & X[33] \\
\hline 14 & $x[41]$ & $\mathrm{X}$ [42] & $x[43]$ & 14 & $x[41]$ & $x[42]$ & X[43] & 14 & $X[41]$ & $X[42]$ & $x[43]$ & 14 & $X[41]$ & $X[42]$ & $X[43]$ \\
\hline 15 & $x[51]$ & $X[52]$ & $x[53]$ & 15 & $x[51]$ & $x[52]$ & $\mathrm{X}[53]$ & 15 & $x[51]$ & $x[52]$ & $x[53]$ & 15 & $X[51]$ & $x[52]$ & $x[53]$ \\
\hline 16 & $x[61]$ & $\mathrm{X}[62]$ & $\mathrm{X}[63]$ & 16 & $X[61]$ & $x[62]$ & $\mathrm{X}[63]$ & 16 & $X[61]$ & $X[62]$ & $x[63]$ & 16 & $\mathrm{X}[61]$ & $X[62]$ & $X[63]$ \\
\hline
\end{tabular}

Figura 4.3: Relax-and-fix forward com partição por período.

Durante o processamento, quando uma solução factível é encontrada, todas as variáveis referentes ao período em questão passam pelo processo de fixação, e uma nova iteração é iniciada a partir do período seguinte. Além desta estratégia, conhecida como relax-and-fix forward com decomposição orientada a períodos (RF-FP), também foi utilizada uma outra cuja execução ocorre no sentido inverso, ou seja, inicia pelo último período $(\mathrm{T})$ e termina no primeiro período, a qual é denominada relax-and-fix backward (RF-BP). 


\section{Agrupamento por Itens}

No agrupamento anterior, apenas as variáveis de um único período são consideradas inteiras, a cada iteração. Portanto, as variáveis de um determinado produto, que serão fixadas ao final da iteração, interagem apenas com variáveis relaxadas deste mesmo produto, no restante do horizonte de planejamento, o que pode afetar a qualidade do planejamento com relação aos níveis de estoque.

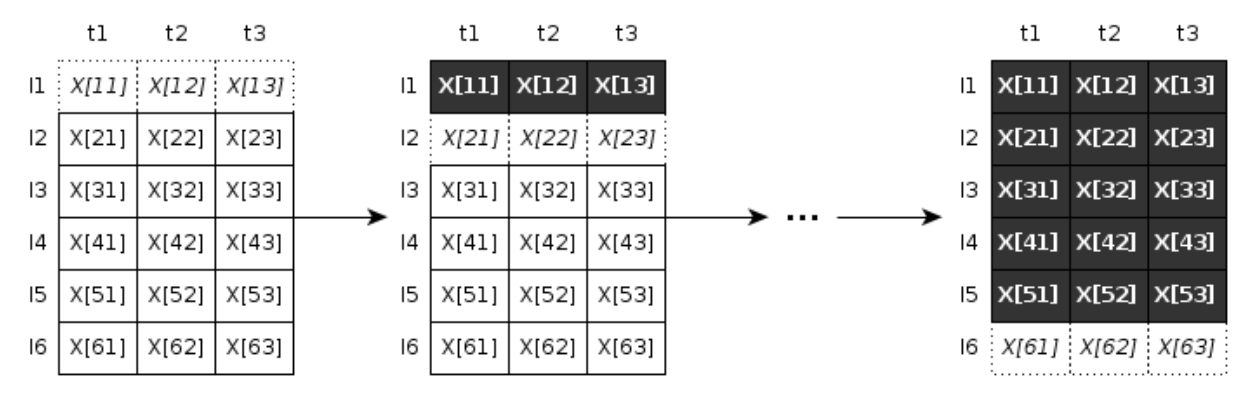

Figura 4.4: Relax-and-fix com partição por itens.

Por esse motivo, as variáveis foram agrupadas com relação aos itens, de forma que cada partição contivesse apenas as variáveis de um único produto para todo o horizonte de planejamento. Esta heurística denominada relax-and-fix com decomposição por itens (RF-I) pode ser observada na Figura 4.4, na qual as variáveis inteiras estão representadas pelas linha pontilhadas, as que foram fixadas estão ilustradas em preto e as demais correspondem às variáveis relaxadas.

Considerando as dimensões do problema em estudo, na qual número de itens (281) é significativamente superior ao de períodos (4), esta abordagem requer a resolução de uma quantidade maior de subproblemas, quando comparadas à anterior. Porém, utilizando uma quantidade menor de variáveis inteiras, há uma nova redução de esforço computacional e, consequentemente, diminuição do tempo de processamento.

\section{Agrupamento por Níveis}

Este último agrupamento levou em consideração a estrutura multiestágio do problema, portanto, as variáveis foram agrupadas de acordo com a hierarquia dos produtos às quais elas pertencem, sendo nomeado relax-and-fix com decomposição orientada a níveis (RF-L). A Figura 4.5 representa uma estrutura de três níveis, para a qual seriam criadas 3 partições de variáveis.

Para que essa estratégia seja eficiente, é necessário seguir uma ordem específica de exe- 


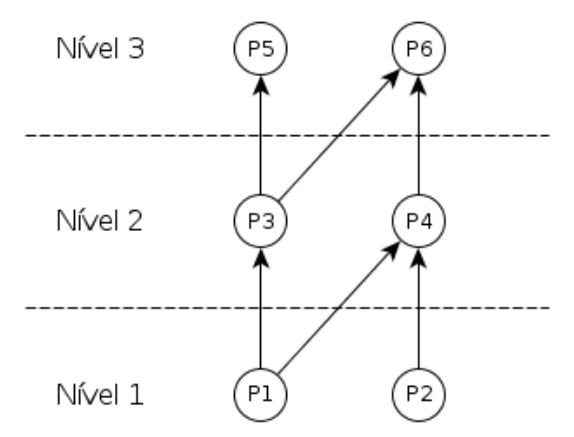

Figura 4.5: Estrutura de produtos com três níveis.

cução, iniciando pelo conjunto de variáveis do último nível e terminando após a execução do primeiro nível, como pode ser observado na Figura 4.6.

Esta sequência de processamento é necessária para lidar com a propagação de demanda interna, que é causada pela utilização de itens intermediários. Portanto, seguindo este critério, a partir do momento que os processos produtivos dos itens do último nível são determinados, a demanda de seus itens componentes pode ser definida. Caso os itens componentes também apresentem demanda externa, suas demandas são somadas. Por outro lado, se a ordem de processamento fosse invertida, não seria possível garantir a propagação correta das demandas internas, visto que a produção dos itens componentes seriam determinadas quando a produção dos itens consumidores estivesse relaxada. Logo, a partir do momento que estas fossem integralizadas, poderia haver falta de estoque de itens componentes.

\begin{tabular}{|c|c|c|c|c|c|c|c|c|c|c|c|c|c|c|c|c|}
\hline & & $\mathrm{tl}$ & t2 & t3 & & t1 & t2 & t3 & & $\mathrm{tl}$ & t2 & t3 & & t1 & t2 & t3 \\
\hline \multirow{2}{*}{ Nível 3} & 11 & $x[11]$ & $x[12]$ & $x[13]$ & 11 & $x[11]$ & $x[12]$ & $x[13]$ & II & $x[11]$ & $x[12]$ & $x[13]$ & II & $x[11]$ & $x[12]$ & $x[13]$ \\
\hline & 12 & $x[21]$ & $x[22]$ & $x[23]$ & 12 & $\mathrm{X}[21]$ & $X[22]$ & $x[23]$ & 12 & $\mathrm{X}[21]$ & $X[22]$ & $x[23]$ & 12 & $\mathrm{X}[21]$ & $X[22]$ & $x[23]$ \\
\hline \multirow{2}{*}{ Nível 2} & 13 & $\mathrm{x}[31]$ & $x[32]$ & $\mathrm{x}[33]$ & 13 & $x[31]$ & $x[32]$ & $x[33]$ & 13 & $\mathrm{X}[31]$ & $\mathrm{X}[32]$ & X[33] & 13 & $x[31]$ & $x[32]$ & X[33] \\
\hline & 14 & $\mathrm{X}[41]$ & $\mathrm{X}[42]$ & $\mathrm{X}[43]$ & 14 & $x[41]$ & $x[42]$ & $x[43]$ & 14 & $X[41]$ & $x[42]$ & $X[43]$ & 14 & $X[41]$ & $X[42]$ & $X[43]$ \\
\hline \multirow{2}{*}{ Nível 1} & 15 & $\mathrm{x}[51]$ & $\mathrm{X}[52]$ & $\mathrm{x}[53]$ & 15 & $\mathrm{x}[51]$ & $x[52]$ & $x[53]$ & 15 & $x[51]$ & $x[52]$ & $x[53]$ & 15 & $x[51]$ & $X[52]$ & $x[53]$ \\
\hline & 16 & $\mathrm{X}[61]$ & $x[62]$ & $\mathrm{x}[63]$ & 16 & $\mathrm{X}[61]$ & $x[62]$ & $x[63]$ & 16 & $x[61]$ & $x[62]$ & $x[63]$ & 16 & $X[61]$ & $X[62]$ & $X[63]$ \\
\hline
\end{tabular}

Figura 4.6: Relax-and-fix com partição por níveis.

\subsubsection{Estratégia para Selecionar Soluções}

A heurística relax-and-fix tradicional fixa uma partição de variáveis ao final de cada iteração, impedindo que seus valores possam ser alterados posteriormente. Porém, este procedimento para resolver os subproblemas pode eliminar a solução ótima do problema inicial, visto que as variáveis fixadas a cada iteração correspondem, no melhor caso, apenas à solução ótima do subproblema. Sendo assim, é provável que as variáveis fixadas a cada iteração não corres- 
pondam aos valores presentes na solução ótima do problema original.

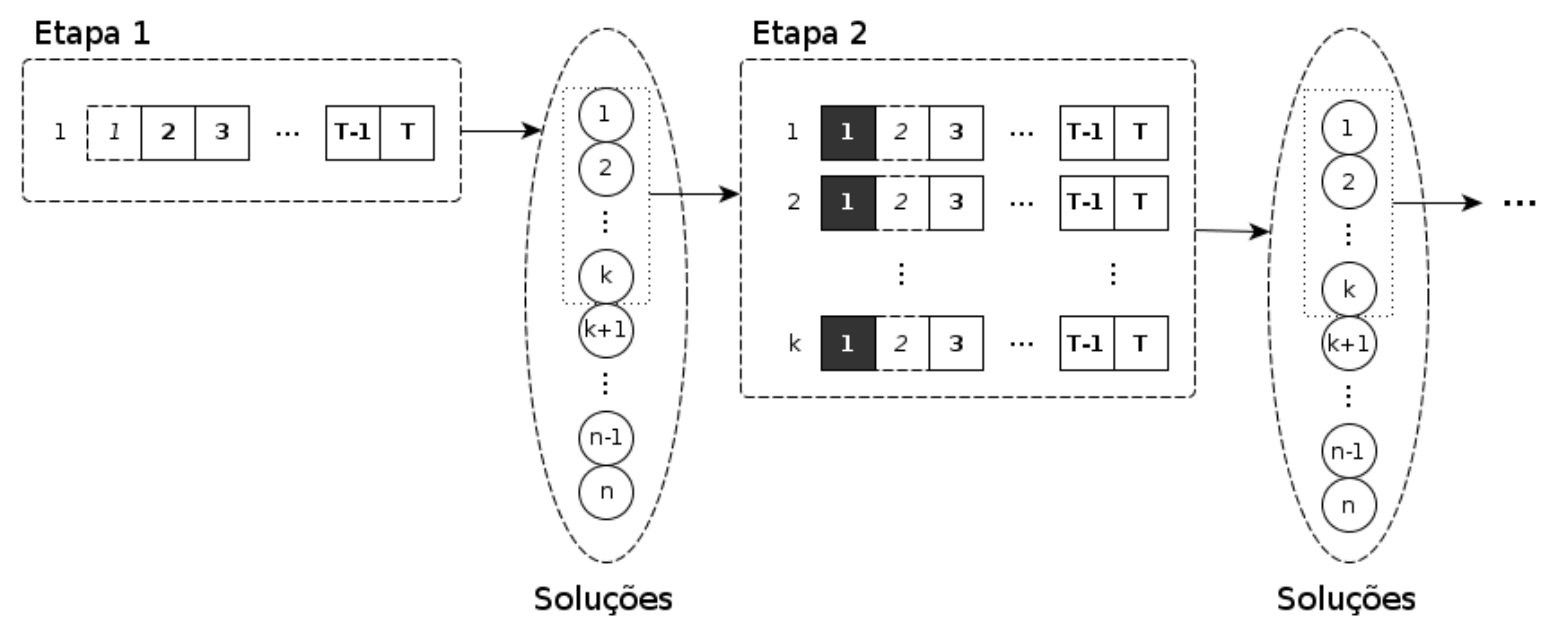

Figura 4.7: Relax-and-fix com partição por níveis.

Visando reduzir esta imposição com relação às variáveis das partições que já foram otimizadas, foi proposta uma estratégia que seleciona um conjunto com as soluções mais promissoras ${ }^{4}$ encontradas a cada iteração, o qual é denominado pool de soluções, portanto, esta heurística foi chamada relax-and-fix forward orientada a períodos com pool de soluções (RF-FPSP). Porém, é necessário controlar este pool para evitar um crescimento exponencial, o que inviabilizaria a utilização desse procedimento.

Segundo a Figura 4.7 é possível notar que a primeira iteração é semelhante à do relaxand-fix tradicional, exceto por armazenar no pool de soluções todas as soluções encontradas para esse subproblema. Ao final desta iteração, apenas as $k$ melhores soluções passam para a próxima etapa da heurística.

A partir da segunda iteração, para cada uma das $k$ soluções mais promissoras, provenientes da iteração anterior, é executado um relax-and-fix tradicional, mas armazenando todas as soluções factíveis encontradas em um novo pool de soluções comum entre elas, do qual também são selecionadas $k$ soluções para o processamento da partição seguinte.

Assim como no relax-and-fix tradicional, esta estratégia termina quando todas as partições são resolvidas ou quando algum critério de parada é atingido sem uma solução factível. Porém, espera-se que na última etapa de processamento, alguma das $k$ soluções proporcione à heurística a obtenção de uma solução factível melhor do que a obtida pelo relax-and-fix tradicional.

\footnotetext{
${ }^{4}$ As soluções mais promissoras são as que apresentam as melhores soluções para a execução do último subproblema.
} 


\subsection{Fix-and-Optimize}

Uma heurística do tipo fix-and-optimize basicamente consiste em partir de uma solução inicial, conhecida a priori, e buscar por novas soluções factíveis de melhor qualidade. Inicialmente, esta heurística foi proposta em Pochet e Wolsey (2006), com o nome exchange, sendo posteriormente referenciada como fix-and-optimize por Sahling et al. (2009).

Essas heurísticas foram empregadas na resolução de problemas de dimensionamento de lotes com múltiplos itens, restrições de capacidade e tempo de setup para estrutura de produtos monoestágio com máquinas paralelas (JAMES; ALMADA-LOBO, 2011), para estrutura de produtos monoestágio com sequenciamento da produção (LANG; SHEN, 2011) e para estruturas multiestágio com setup carry-over (SAHLING et al., 2009) ou com lead time (HELBER; SAHLING, 2010).

A forma geral de seu processamento é ilustrada pela Figura 4.8, segundo a qual nota-se uma etapa de particionamento das variáveis, como nas heurísticas relax-and-fix, para posteriormente iniciar uma etapa em que um processo iterativo busca por novas soluções.

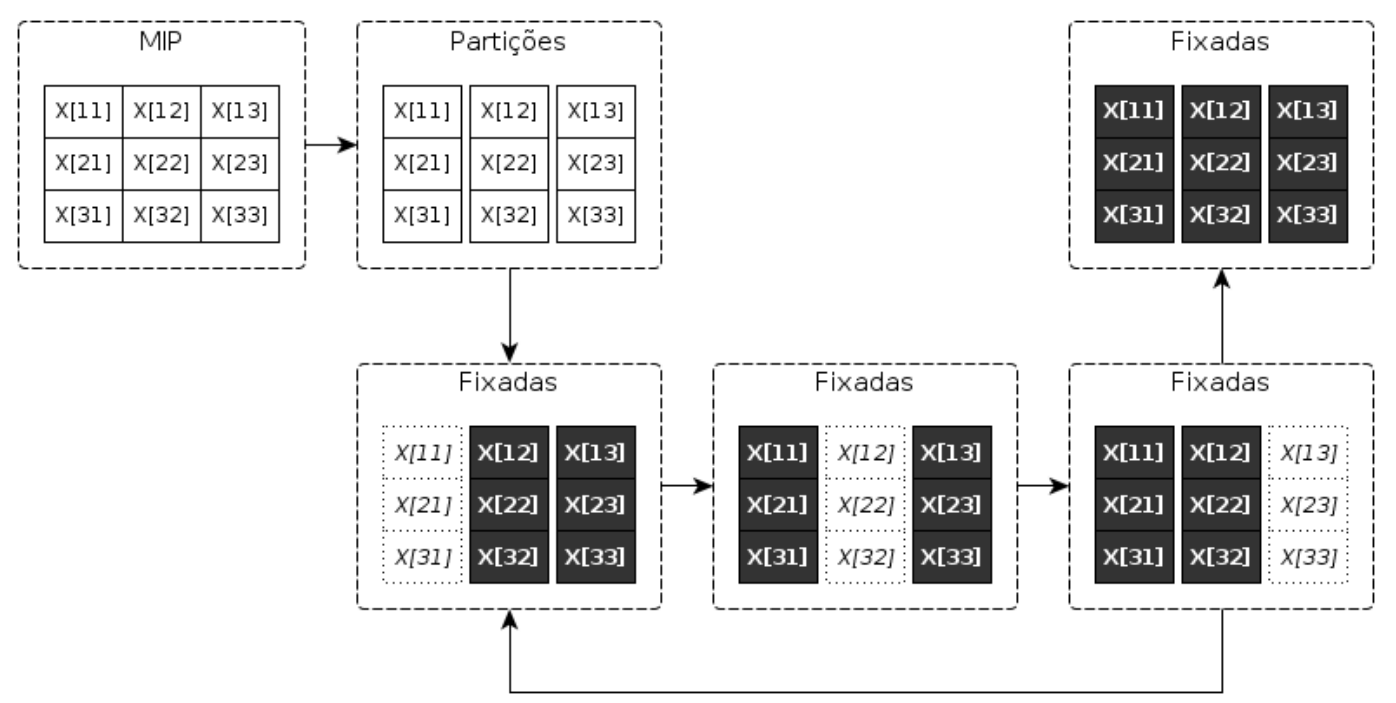

Figura 4.8: Representação genérica de uma heurística fix and optimize.

A cada iteração, o modelo inteiro misto é reduzido, fixando as variáveis de todas as partições com os valores inteiros da solução incumbente, variáveis destacadas em preto na Figura 4.8, exceto para as que compõem a partição a ser otimizada. Dessa forma, o processamento heurístico consiste em reotimizar todas as partições de variáveis, uma a uma.

Após a execução do último subconjunto de variáveis, espera-se que a solução incumbente seja melhor do que a inicial. Caso este objetivo seja atingido, a heurística pode ser aplicada recursivamente, enquanto for possível encontrar soluções factíveis melhores ou até algum critério 
de parada ser atingido.

Para esta heurística foram aplicadas apenas as decomposições de variáveis com relação aos períodos (FO-P) e aos itens (FO-I), conforme explicado na Seção 4.2, sem que fosse utilizada uma estratégia para selecionar as soluções mais promissoras. 


\section{CAPÍtulO 5}

\section{GERAÇÃO DAS INSTÂNCIAS}

\subsection{Introdução}

A indústria química é um setor no qual o sigilo sobre as fórmulas de seus processos produtivos deve ser intenso, pois processos mais eficientes garantem vantagens operacionais e econômicas em relação às empresas concorrentes. Por essa razão, os dados utilizados para gerar as instâncias de teste desta dissertação foram fornecidos pela empresa em questão, previamente modificados, por questão de confidencialidade.

O problema completo fornecido pela indústria é composto por 474 produtos, 134 matériasprimas, 98 tanques e 15 reatores, além das demandas, dos preços de compra das matérias-primas e de venda dos produtos, por um período de 12 meses, considerando duas plantas produtivas da empresa.

Durante o seu estudo, Alvares (2010) utilizou um subconjunto correspondente a menos de $10 \%$ dos dados efetivamente fornecidos, portanto, não houve uma análise criteriosa envolvendo o restante dos dados para averiguar se estes introduziriam alguma infactibilidade ao problema completo. Dessa forma, tornou-se necessário revisar todo conteúdo disponível, buscando possíveis inconsistências que poderiam inviabilizar os testes computacionais. 


\subsection{Tratamento Inicial dos Dados}

Inicialmente, decidiu-se reduzir o problema completo fornecido pela indústria, considerando apenas uma planta produtiva, com 281 produtos, 53 matérias-primas, 7 reatores, 56 tanques e 4 períodos.

Posteriormente, foi desenvolvido um procedimento computacional para analisar detalhadamente as informações relacionadas às matérias-primas, aos produtos e, principalmente, à estrutura das reações que originam os produtos. Com esta avaliação foram detectadas inconsistências relativas aos custos de matérias-primas, às demandas, à utilização de insumos nas reações e aos produtos obtidos. Como consequência dessas inconsistências, diversos produtos teriam que ser desconsiderados, dentre os quais estavam todos os produtos que constituíam o terceiro e o quarto nível da estrutura produtiva.

Por esse motivo, desenvolveu-se um novo procedimento para efetuar as correções necessárias nos dados inconsistentes. Primeiramente, os custos ausentes das matérias-primas e as demandas externas que não haviam sido informadas, foram gerados aleatoriamente ${ }^{1}$ dentro de um intervalo que compreendia a maior parte dos custos informados. Em seguida, tanto os insumos considerados em duplicidade como os que apresentavam utilização nula foram removidos das reações.

Após esta etapa, todas as reações foram reavaliadas para certificar-se que a somatória das quantidades dos insumos utilizados fosse superior à dos produtos fabricados, assegurando que a Lei de Lavoisier ${ }^{2}$ não fosse violada. Quando alguma violação era observada, a quantidade dos insumos utilizadas na reação era multiplicada por um fator corretor, a fim de que a somatória dos insumos correspondesse à $105 \%$ do volume final produzido.

\subsection{Geração dos Dados}

Após o tratamento inicial dos dados fornecidos pela indústria, o problema resultante passou a considerar corretamente os 281 produtos. Portanto, como este problema apresentava estrutura de produtos com quatro níveis, ele foi utilizado como base para a geração de classes com estrutura de três, dois e um nível. O procedimento adotado nessa operação consistia em remover todos os produtos pertencentes ao maior nível de uma classe para originar a classe de nível imediatamente inferior.

\footnotetext{
${ }^{1}$ Apesar da denominação utilizada, deve ficar claro que toda menção à aleatoriedade na verdade utiliza sequências computacionais pseudo-aleatórias.

${ }^{2} \mathrm{Na}$ natureza, nada se cria, nada se perde, tudo se transforma.
} 
Porém, como existiam produtos que apresentavam apenas demanda interna, quando o nível mais alto era removido, a demanda de alguns produtos intermediários tornava-se nula. Deste modo, esses produtos também foram desconsiderados para a composição das novas classes. Esta situação é ilustrada pela Figura 5.1, na qual apenas os produtos P8, P9 e P10 possuem demanda externa. Portanto, quando P10 é removido para a geração da classe com estrutura de três níveis, os produtos P7 e P4 são desconsiderados nessa nova classe.

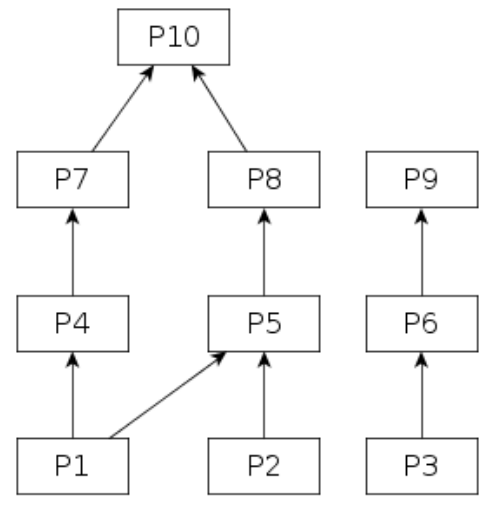

(a)

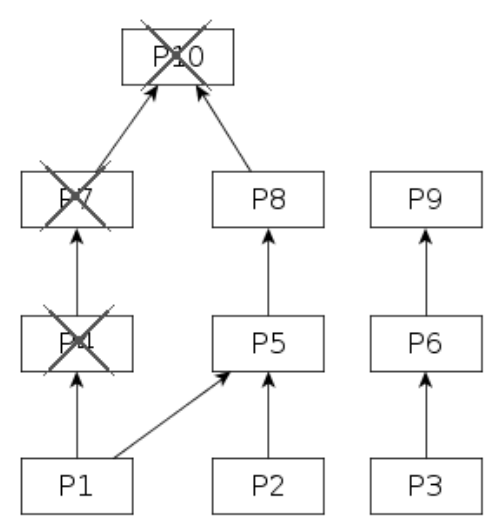

(b)

Figura 5.1: Remoção de produto intermediário com demanda nula. Estrutura de quatro níveis (a), estrutura de três níveis (b).

\section{Determinação das Capacidades Produtivas}

Após a definição das quatro classes, foi necessário ajustar as capacidades produtivas dos seus reatores de forma independente, visto que as informações relativas às demandas correspondiam às duas plantas. Portanto, as classes com estrutura de produtos de três e quatro níveis apresentam superutilização dos reatores, enquanto as outras duas os subutilizavam.

$$
D_{i, t}=d_{i, t}+\sum_{j \in \Phi(i)} \sum_{p=1}^{P_{j}} \frac{D_{j, t}}{P_{j}} * \frac{r_{i, j, p}}{f_{i, p}}, \quad \forall t, i \in\{S(n) \mid n \in\{N, \ldots, 2,1\}\}
$$

Para o procedimento de ajuste das capacidades, primeiramente foi determinada a demanda total, de acordo com a equação (5.1), na qual $D_{i t}$ e $d_{i t}$ representam a demanda total e a demanda externa do produto $i$ no período $t$, respectivamente. O subconjunto $\Phi(i)$ corresponde aos produtos do nível imediatamente superior a $i$, obviamente este subconjunto é vazio para os produtos pertencentes ao nível mais alto, $P_{j}$ constitui o número de processos apresentados pelo produto $j, r_{i, j, p}$ denota o consumo do produto intermediário $i$ para a produção do produto $j$ através do processo $p$ e $f_{i, p}$ representa a quantidade produzida do produto $i$ pelo processo $p$.

Esta equação pode ser compreendida visualmente pela Figura 5.2, na qual a demanda do 


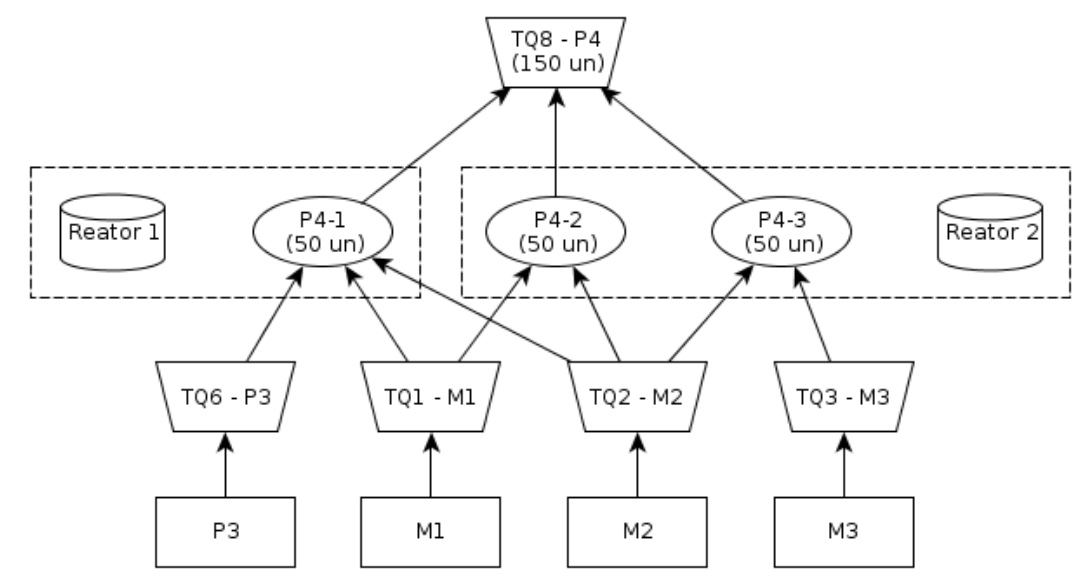

Figura 5.2: Divisão da demanda entre processos para determinação da demanda total.

nível superior é considerada para determinar a demanda interna do nível inferior. Neste caso observa-se que o produto $\mathrm{P} 4$ pode ser obtido por 3 reações, dentre as quais sua demanda é particionada igualmente, portanto, assume-se que o consumo de P3 para produção de P4 é a quantidade necessária para que sejam produzidas 50 unidades deste produto. Sendo assim, a demanda total para P3 é dada pela sua demanda externa somada a esta demanda interna.

$$
C A P_{k, t}=\sum_{i} \sum_{p=1}^{P_{i}} \frac{D_{i, t}}{P_{i}} * \frac{b_{i, k, p}}{f_{i, p}}, \quad \forall r, t
$$

Após delimitar a demanda total, a capacidade produtiva dos reatores foi determinada como na equação (5.2), em que $C A P_{k, t}$ representa a capacidade do reator $r$ no período $t, D_{i, t}$ corresponde à demanda total do produto $i$ no período $t, P_{i}$ constitui o número de processos apresentados pelo produto $i, b_{i, k, p}$ denota o tempo consumido no reator $r$ para a produção do produto $i$ através do processo $p$ e $f_{i, p}$ representa a quantidade produzida do produto $i$ pelo processo $p$.

A equação (5.2) pode ser ilustrada pela Figura 5.3, na qual P3 possui três processos, sendo um no reator 1 e dois no reator 2. Com uma demanda total de 360 unidades, cada processo ficou encarregado de produzir 120 unidades. Como a produtividade de P3-1 é de 5 unidades por minuto, este processo contribui com 24 minutos para a nova capacidade de R1, enquanto P3-2 e P3-3 contribuem com 20 e 15 minutos, respectivamente, para a nova capacidade de R2.

Este procedimento foi replicado a todos os produtos, mas sem garantias de que uma solução factível possa ser obtida com a resolução deste problema inteiro misto, pois a necessidade de se produzir bateladas inteiras faz com que a utilização dos reatores seja sempre maior ou igual aos valores determinados pela equação (5.2). Para contornar essa situação, foi analisada a estrutura do problema, apresentada na Seção 5.4, e concluiu-se que seria necessário acrescentar uma 


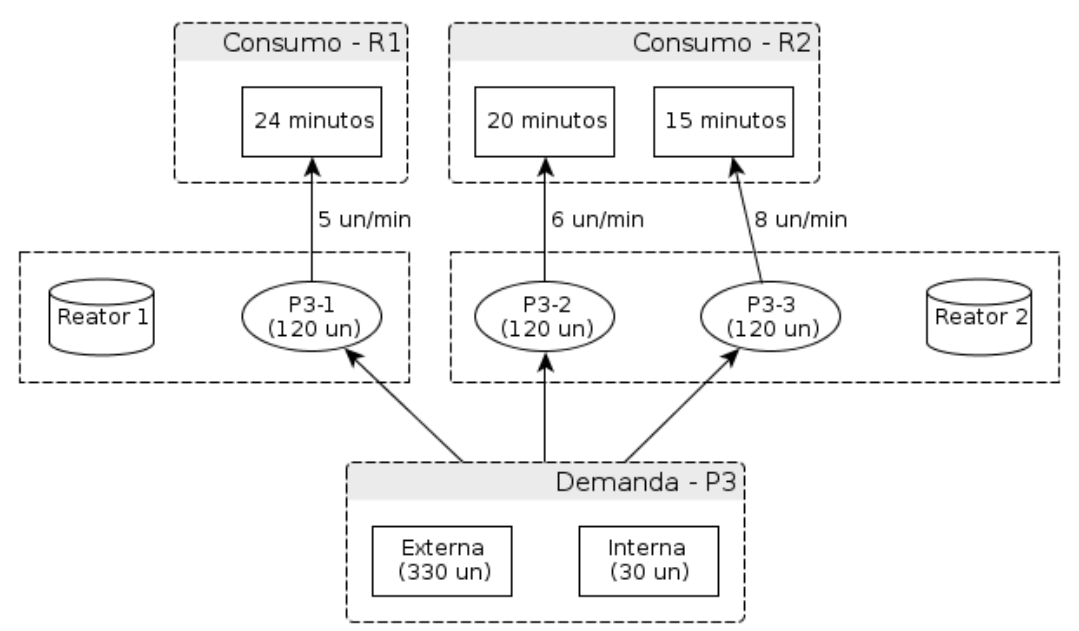

Figura 5.3: Contribuição de cada reação para determinação da capacidade dos reatores.

folga aos valores obtidos por esse procedimento, sendo assim, foram considerados $125 \%$ da capacidade obtida para o reator $6,120 \%$ para o reator 3 e $110 \%$ para os demais reatores.

\section{Determinação dos Tanques de Armazenamento}

Com as capacidades dos reatores adequadas às classes, o foco passou a ser os tanques de armazenamento, já que essas informações estavam incompletas quando foram fornecidas pela empresa. Eliminando algumas inconsistências observadas nas planilhas de dados, observou-se que menos de $30 \%$ dos produtos haviam sido relacionados, dos quais, aproximadamente $70 \%$ compartilhavam tanques com outro produto. Visando resolver este problema, cada uma das quatro classes originaram três subclasses: a primeira com compartilhamento mínimo dos tanques, ou seja, cada tanque era destinado a um único produto, a segunda com compartilhamento médio e a terceira com compartilhamento máximo, as quais apresentavam cerca de $50 \%$ e $100 \%$ dos tanques compartilhados por algum produto, respectivamente.

Para elaborar a subclasse com compartilhamento mínimo, foi necessário criar tanques adicionais, pois inicialmente haviam apenas 54 tanques de armazenamento. Nesse processo foram determinadas as capacidades dos novos tanques aleatoriamente, variando na faixa de capacidade observada nos dados fornecidos pela indústria.

Após todos os produtos estarem relacionados a pelo menos um tanque de armazenamento (originalmente alguns produtos utilizavam dois tanques), a primeira subclasse foi obtida ao transformar todos os tanques em cativos. Para isso, quando um tanque era compartilhado entre dois produtos, criou-se um novo tanque, com capacidade idêntica à do original, e cada um dos produtos passou a utilizar um desses tanques. 
A partir da configuração anterior, a segunda subclasse foi definida após aproximadamente metade dos produtos serem selecionados aleatoriamente, dois a dois, e passarem a compartilhar somente um dos tanques aos quais eram designados, com a escolha sendo realizada através de sorteio, enquanto o outro tanque foi desconsiderado dos dados, por não estar relacionado a nenhum produto. Finalmente, este procedimento foi aplicado novamente para originar a terceira subclasse, a qual apresenta o compartilhamento máximo dos tanques entre os produtos.

\section{Perturbação nos Parâmetros}

Toda a estrutura produtiva e de armazenamento já estava definida, mas ainda faltava reproduzir variações inerentes ao mercado. Para isso, foram geradas 5 instâncias para cada uma das subclasses obtidas anteriormente, de forma que o custo das matérias-primas e as demandas sofressem uma variação aleatória de $\pm 10 \%$. Por último, o preço de venda dos produtos foi determinado aleatoriamente entre uma faixa de 200 a $450 \%$ da somatória dos custos de seus itens componentes.

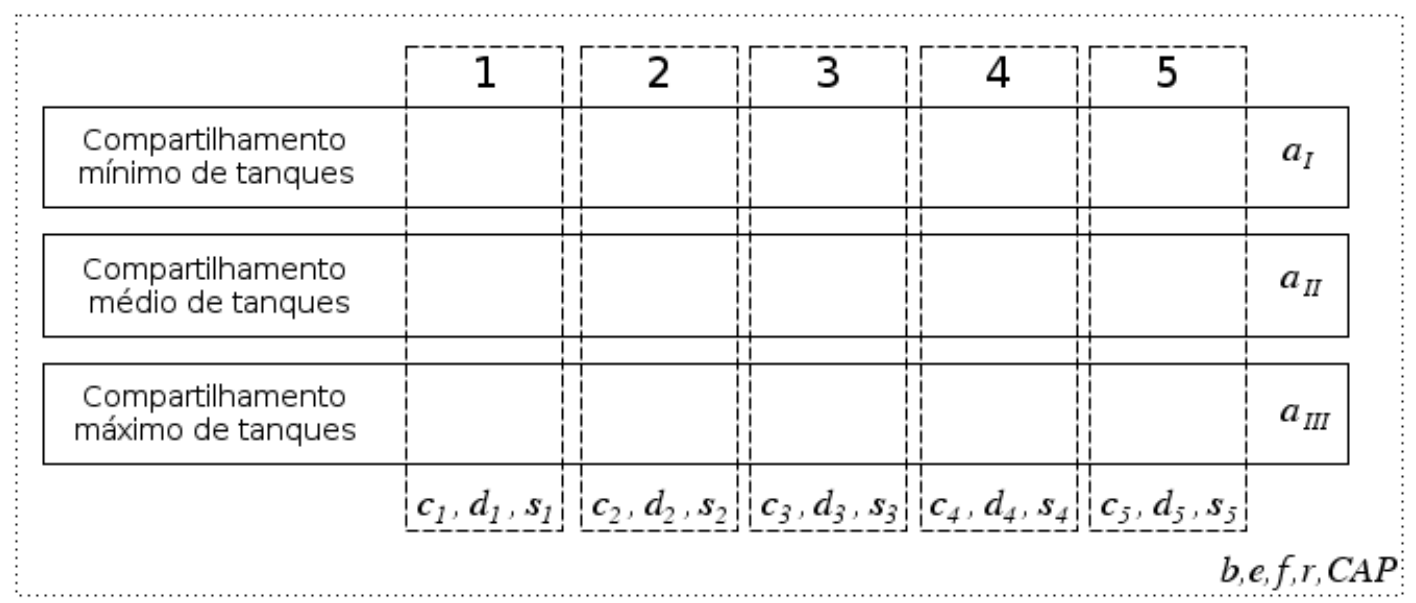

Figura 5.4: Contribuição de cada reação para determinação da capacidade dos reatores.

A relação dos parâmetros entre as classes, subclasses e instâncias está resumida na Figura 5.4. Os produtos comuns às quatro classes apresentam os mesmos parâmetros $b, e, f$, $r$ e $C A P$, os quais correspondem ao tempo de processamento dos produtos, à quantidade de matéria-prima consumida nas reações, à quantidade produzida dos produtos, por batelada, à quantidade utilizada de um produto intermediário na reações e ao tempo total dos reatores por período, respectivamente, ou seja, todos os fatores que definem as reações de um produto são iguais para todas as instâncias geradas que o contém.

Com relação à capacidade de armazenamento dos tanques, representado pelo parâmetro $a$, os dados são compartilhados apenas entre as instâncias de 1 a 5 de cada uma das subclasses, pois 
a configuração de compartilhamento é distinta entre subclasses de uma mesma classe e entre subclasses de classes distintas, ou seja, os parâmetros de armazenamento são os mesmos para as 5 instâncias da classe com estrutura de produto de quatro níveis e com compartilhamento máximo de tanques, mas diferem de todas as outras 55 instâncias do conjunto de testes.

Já os parâmetros $c, d$ e $s$, que correspondem ao custo das matérias-primas, à demanda e ao preço de venda dos produtos, respectivamente, são comuns aos subconjuntos das instâncias de cada classe, ou seja, as 3 instâncias correspondentes à coluna de código 1, de cada percentual de compartilhamento, apresentam esses parâmetros idênticos, porém, diferem-se das outras 57 instâncias do conjunto de testes.

\subsection{Estruturas do Problema}

O processo de geração de dados originou 60 instâncias que podem ser agrupadas em 4 classes, de acordo com o nível dos produtos, que por sua vez podem ser agrupadas em 12 subclasses, de acordo com o percentual de tanques multipropósitos, como mostra a Tabela 5.1.

Tabela 5.1: Estrutura dos Dados do Problema

\begin{tabular}{cccccc}
\hline Subclasse & Produtos & Níveis & Períodos & Máquinas & Tanques Multipropósito \\
\hline 1.1 & 46 & 1 & 4 & 5 & 0 \\
1.2 & 46 & 1 & 4 & 5 & 11 \\
1.3 & 46 & 1 & 4 & 5 & 23 \\
\hline 2.1 & 228 & 2 & 4 & 7 & 0 \\
2.2 & 228 & 2 & 4 & 7 & 57 \\
2.3 & 228 & 2 & 4 & 7 & 114 \\
\hline 3.1 & 278 & 3 & 4 & 7 & 0 \\
3.2 & 278 & 3 & 4 & 7 & 69 \\
3.3 & 278 & 3 & 4 & 7 & 138 \\
\hline 4.1 & 281 & 4 & 4 & 7 & 0 \\
4.2 & 281 & 4 & 4 & 7 & 70 \\
4.3 & 281 & 4 & 4 & 7 & 140 \\
\hline
\end{tabular}

Como a classe de quarto nível engloba todos os produtos das demais classes, esta foi adotada como base para ilustrar as estruturas de produtos e de reatores. A representação gráfica dessas estruturas pode ser considerada um grafo direcionado ${ }^{3}$, no qual o produto da origem do arco é utilizado na produção do que se encontra no destino do arco.

A Figura 5.5 representa a estrutura de produtos da planta considerada neste trabalho, com seus 281 itens e quatro níveis. Cada retângulo delimita um dos níveis da classe em questão, ou

\footnotetext{
${ }^{3}$ Um grafo direcionado ou orientado é definido como um par $(V, A)$, no qual $V$ é um conjunto de vértices e $A$ é um conjunto ordenado de pares de elementos distintos de $V$ que representam as ligações entre os vértices http://www2.icmc.sc.usp.br/manuals/sce183/gfint.html
} 


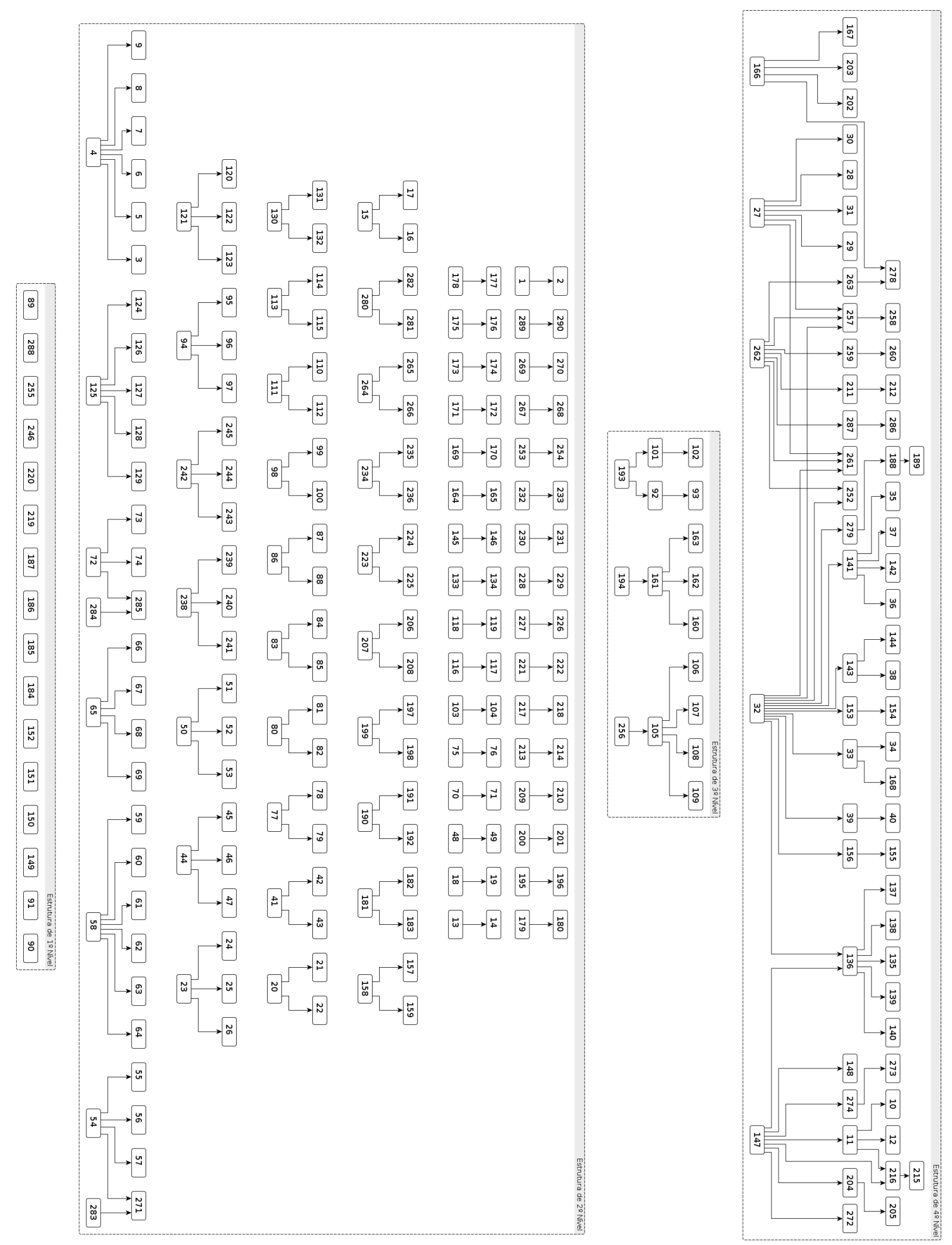

Figura 5.5: Estrutura de produto completa da unidade produtiva em estudo. 
seja, o primeiro apresenta os dois produtos pertencentes ao quarto nível, P189 e P215, e toda a interdependência dos demais produtos, formando uma estrutura coesa. Considerando a Teoria de Grafos esta estrutura seria um grafo direcionado conexo ${ }^{4}$.

O segundo retângulo apresenta os produtos pertencentes à estrutura de terceiro nível que não estão relacionados com a estrutura de quarto nível, portanto, somente 9 produtos deste nível foram exibidos neste caso. Ao contrário da estrutura anterior, nem todos os seus produtos estão relacionados entre si. Portanto, segundo a Teoria dos Grafos este nível seria um grafo desconexo com três componentes conexas. De forma semelhante, a Figura 5.5 representada ainda as estruturas de segundo e primeiro nível.

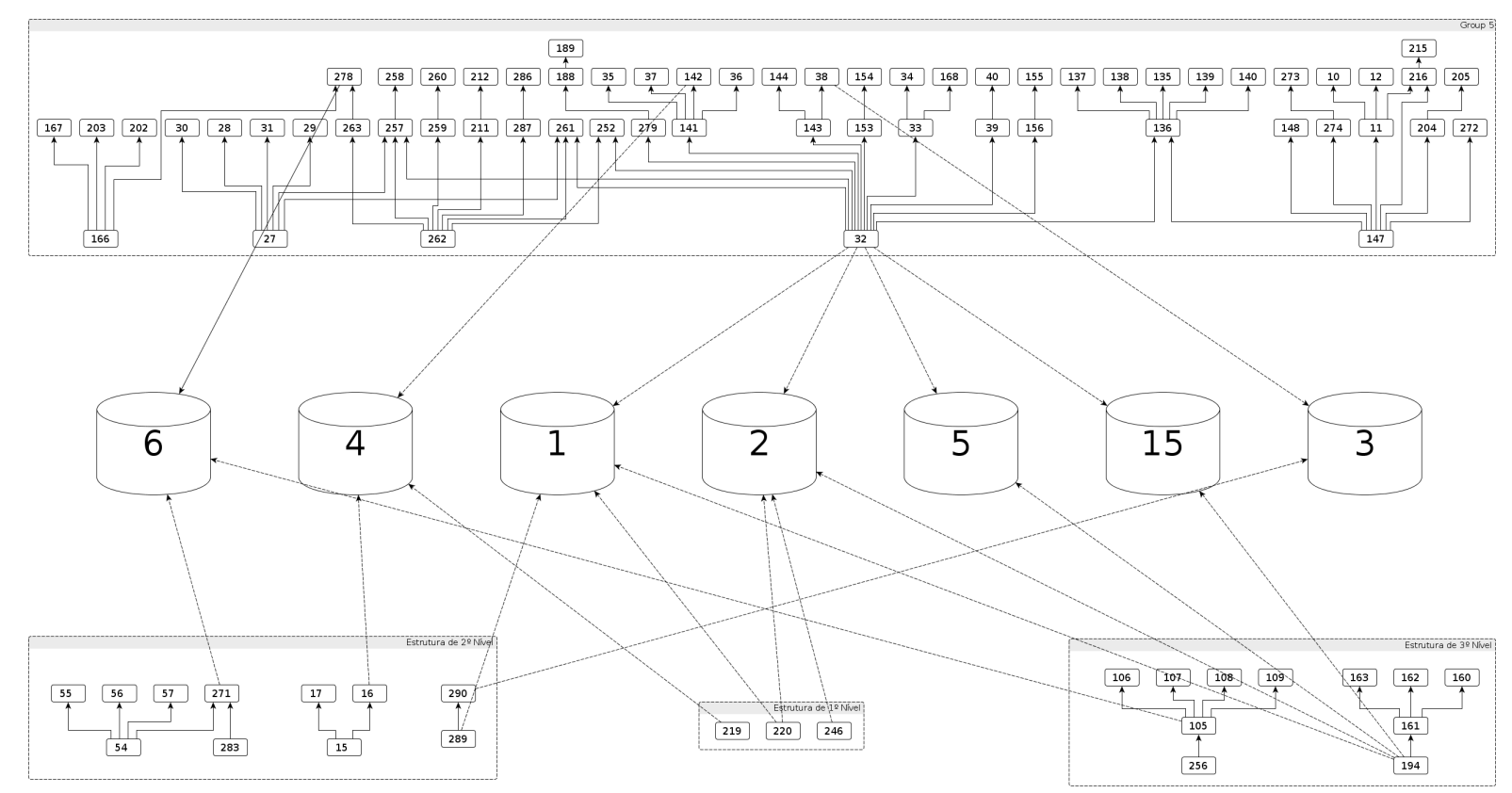

Figura 5.6: Compartilhamento dos reatores entre as estruturas de produtos.

A visualização das estruturas de produto exibidas na Figura 5.5 pode proporcionar a falsa impressão de que este problema permite a decomposição em subproblemas independentes, cujas soluções ótimas seriam agrupadas para comporem a solução ótima do problema original. Porém, como ilustrado na Figura 5.6, estruturas distintas utilizam os mesmos reatores em seus processos, originando concorrência por esses equipamentos, tornando necessário considerar restrições que relacionem os produtos e, consequentemente, as estruturas.

Analisando mais detalhadamente as relações entre produtos e reatores, surge uma nova estrutura, representada pela Figura 5.7, na qual os produtos estão diretamente ligados aos reatores em que seus processos ocorrem. Logo, é possível observar que os reatores 3, 4 e 6 são utilizados

\footnotetext{
${ }^{4} \mathrm{Um}$ grafo direcionado é conexo caso exista uma sequência de vértices que interligue quaisquer pares de vértices $i$ e $j$, para $i \neq j$, do gráfico considerado, sem considerar a direção da sequência de vértices (GONDRAN; MINOUX, 2008).
} 
com exclusividade pelos seus produtos, os reatores 1 e 2 possuem alguns produtos exclusivos e outros compartilhados com mais reatores, enquanto os reatores 5 e 15 compartilham todos os itens que produzem.

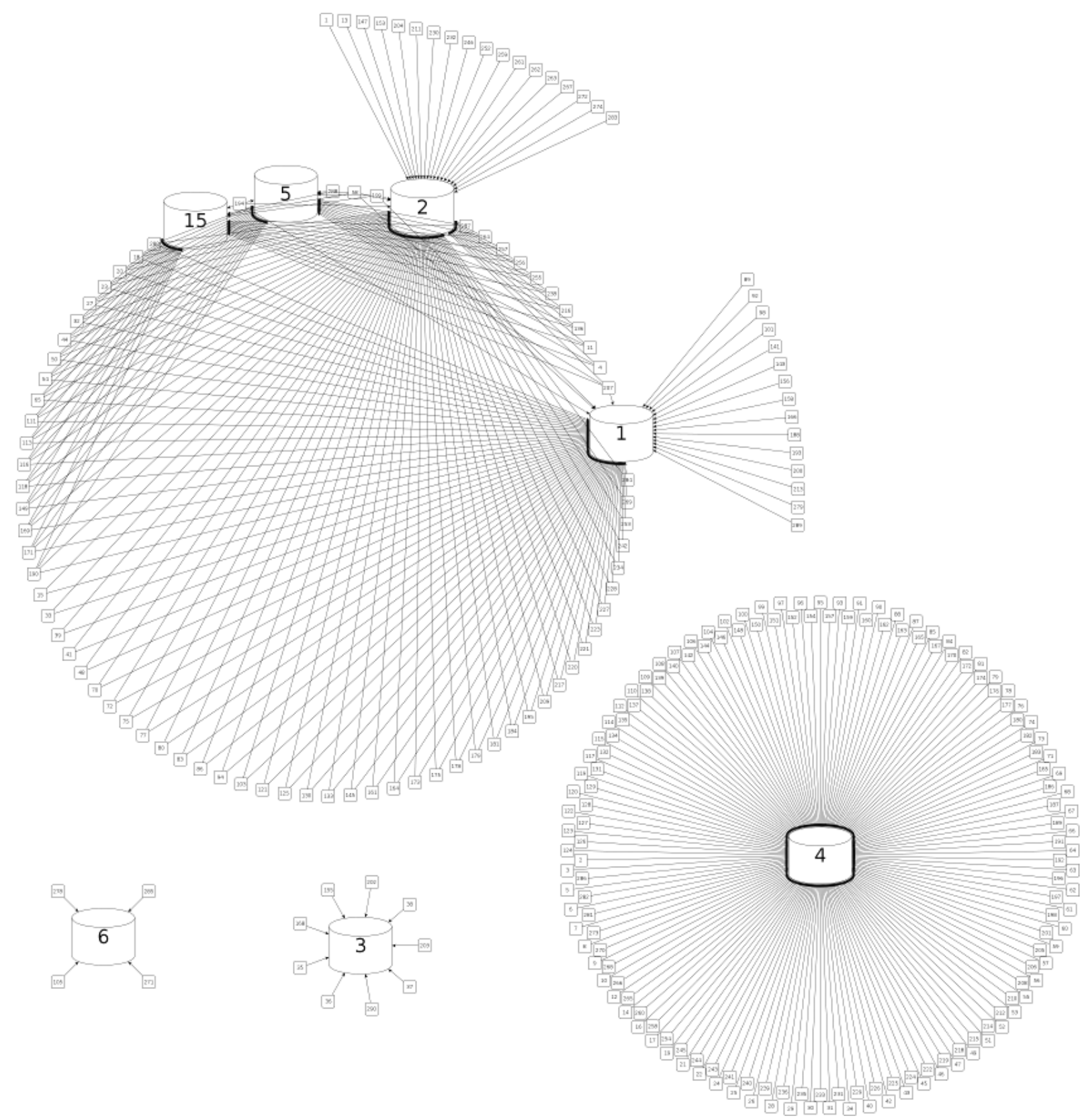

Figura 5.7: Estrutura de relacionamento para a utilização dos reatores no processo produtivo.

Com isso, seria plausível supor que o fluxo produtivo poderia ser particionado em 4 conjuntos, cujas soluções seriam obtidas distintamente e, em seguida, utilizada para compor a solução do problema inicial. Porém, devido às características do problema, tanques de armazenamento são compartilhados entre produtos que encontram-se em diferentes partições de reatores, o que também torna necessário a consideração de restrições que relacionam os produtos e, consequentemente, inviabiliza esta nova abordagem. 


\section{CAPÍtULO 6}

\section{TESTES COMPUTACIONAIS}

As heurísticas propostas foram implementadas utilizando a linguagem $\mathrm{C}++$ e compiladas com o g++ versão 4.6.2, em um microcomputador com processador Intel ${ }^{\circledR}$ Xeon ${ }^{\circledR}$ X5560, de frequência 2,8 GHz e $8 \mathrm{MB}$ de memória cache, com memória principal de 7,8 GB e sistema operacional openSUSE 12.1, baseado no Linux.

Os experimentos computacionais deste trabalho foram divididos em duas etapas. Na primeira foram realizados testes com heurísticas construtivas para as instâncias que apresentavam estrutura de produtos com até quatro níveis, para as quais foram investigados parâmetros como política de divisão de tempo entre as iterações, tempo total de processamento, tamanho do pool de soluções e os custos de preparação de máquina.

$\mathrm{Na}$ segunda etapa, foram realizados testes com as heurísticas construtivas e as de melhoria para as mesmas instâncias da primeira etapa, considerando os parâmetros definidos. Posteriormente, foram realizados testes com novas instâncias, que apresentavam características mais próximas às encontradas no problema real enfrentado pela empresa. Para esse último conjunto de instâncias, em que o tempo de processamento foi limitado a uma hora, foram analisados o modelo proposto na Seção 3.3, os custos de preparação de máquina e o compartilhamento de tanques apenas entre os produtos intermediários, visto que os produtos finais podem ser embalados e enviados ao depósito a partir do momento que seu processo produtivo é finalizado.

Para os experimentos computacionais, foi utilizada a opção de pré-processamento (presolve), disponibilizada pelo próprio CPLEX 12.4, na qual uma série de procedimentos busca reduzir o modelo inteiro misto original em um modelo equivalente mais simples. O método de busca foi 
definido como sendo o branch-and-cut tradicional ${ }^{1}$, para garantir igualdade de processamento entre as heurísticas, uma vez que o acesso às soluções factíveis durante a execução do CPLEX é possível apenas através desse método. Também foi definido que não haveria utilização de processamento paralelo, ou seja, as execuções ficaram restritas à utilização de apenas um núcleo do processador.

\subsection{Critérios de Parada}

A determinação do momento exato em que o processamento deve ser encerrado é definida através de critérios de parada, os quais geralmente são constituídos por parâmetros como o número de iterações, a diferença percentual (GAP relativo) ou real (GAP absoluto) entre a solução incumbente e o limitante para a solução ótima, o tempo total de execução, entre outros.

\section{Número Máximo de Iterações}

As heurísticas propostas baseiam-se na resolução de diversos subproblemas inteiros mistos, derivados do problema original, que são resolvidos utilizando o CPLEX 12.4. Para cada um desses subproblemas, o software utilizado não apresenta parâmetros para limitar o número de iterações do seu processamento.

Com relação à geração dos subproblemas, a partir das heurísticas, o número de iterações do relax-and-fix é definido pelo número de partições, enquanto que a execução do fix-and-optimize foi limitado a 10 ciclos completos de iterações para todas as suas partições.

\section{Consumo de Memória Principal}

O CPLEX 12.4 considera $10^{75} \mathrm{MB}$ (megabytes) como o limite padrão para utilização de memória principal ${ }^{2}$. Porém, ao ser levado em consideração o tamanho da memória principal do computador utilizado para os testes e a quantidade requisitada para o funcionamento do sistema operacional, optou-se por redefinir este parâmetro para $7 \times 10^{3} \mathrm{MB}$.

\footnotetext{
${ }^{1}$ Detalhes podem ser encontrados em: http://pic.dhe.ibm.com/infocenter/cosinfoc/v12r4/topic/ ilog.odms.cplex.help/refcallablelibrary/html/concepts.html

${ }^{2}$ Lista de parâmetros do CPLEX 12.4 encontra-se disponível em: http: //pic. dhe.ibm.com/infocenter/ cosinfoc/v12r2/topic/ilog.odms.cplex.help/Content/Optimization/Documentation/CPLEX/ _pubskel/CPLEX934.html
} 


\section{GAP Relativo}

O software utilizado para os experimentos computacionais adota como padrão para o GAP relativo o valor de $0,01 \%$. Porém, ao analisar as instâncias das quatro classes de problemas geradas para esta dissertação, verificou-se que todas apresentavam soluções factíveis, com o valor da função objetivo variando no intervalo de $2 \times 10^{7}$ a $9 \times 10^{7}$. Sendo assim, este parâmetro foi definido como $10^{-5} \%$, para que o processamento fosse interrompido quando a solução factível divergisse do limitante inferior por menos de uma dezena de unidades.

\section{Tempo Total de execução}

O CPLEX 12.4 considera, por padrão, o tempo máximo para execução de $10^{75}$ segundos. Para tornar esse valor mais usual, foi definido 1 minuto para os experimentos iniciais, visto que este parâmetro seria recalculado em uma etapa de definição de parâmetros. Já para os experimentos finais, definiu-se uma hora como o tempo limite para a execução das instâncias mais parecidas com as encontradas na empresa.

\subsection{Testes Iniciais}

Após os critérios de parada terem sido definidos, iniciou-se a primeira etapa de testes, baseada nas classes de instâncias definidas na Seção 5.4, de acordo com a Tabela 5.1. Estes testes utilizaram o modelo principal, Subseção 3.3.1, e tinham como objetivo determinar a heurística construtiva mais promissora, visando utilizá-la em novos testes a fim de encontrar um conjunto de parâmetros de boa qualidade, os quais serão utilizados na etapa final de testes.

Durante os testes iniciais foram consideradas sete heurísticas construtivas: relax-and-fix forward (RF-FP), relax-and-fix backward (RF-BP), relax-and-fix por item (RF-I), relax-and-fix por nível (RF-L), LP-and-fix para valores inteiros (LP-I), LP-and-fix para valores inteiros não nulos (LP-NN) e $L P$-and-fix com arredondamento para valores inteiros não nulos (LP-RNN).

As médias dos GAPs relativos obtidos após as execuções encontram-se na Tabela 6.1, a qual agrupa as subclasses, com cinco instâncias cada, em três partes: a primeira com as instâncias em que os produtos apresentavam compartilhamento mínimo de tanques (1.1, 2.1, 3.1 e 4.1), a segunda com as de compartilhamento médio $(1.2,2.2,3.2$ e 4.2$)$ e a terceira com as que apresentam compartilhamento máximo $(1.3,2.3,3.3$ e 4.3$)$. 
O cálculo do GAP relativo foi efetuado seguindo a equação (6.1), para cada um dos testes realizados, e levou em consideração o melhor limitante inferior para o problema fornecido pelo CPLEX, após uma hora de execução.

$$
\text { GAP }=\frac{\text { Solução Factível }- \text { Limitante Inferior }}{\text { Limitante Inferior }}
$$

Tabela 6.1: GAPs relativos médios das heurísticas construtivas.

\begin{tabular}{|c|c|c|c|c|c|c|c|}
\hline Subclasse & RF-FP(\%) & RF-BP(\%) & RF-I(\%) & RF-L(\%) & LP-I(\%) & LP-NN(\%) & LP-RNN(\%) \\
\hline 1.1 & $0,37^{[5]}$ & $0,57^{[3]}$ & $\mathbf{0 , 1 9}{ }^{[4]}$ & $0,26^{[5]}$ & $1,47^{[3]}$ & $0,27^{[5]}$ & $0,29^{[5]}$ \\
\hline 2.1 & $\mathbf{0 , 7 2}[5]$ & $3,65[4]$ & - $[0]$ & $1,36^{[5]}$ & $-[0]$ & $1,14^{[5]}$ & $0,99[4]$ \\
\hline 3.1 & $\mathbf{0 , 8 1}[5]$ & $2,35^{[3]}$ & - $[0]$ & $0,95^{[5]}$ & - $[0]$ & $1,23^{[5]}$ & $1,54^{[2]}$ \\
\hline 4.1 & $\mathbf{1 , 0 9}[5]$ & $3,23^{[4]}$ & - $[0]$ & $1,20^{[5]}$ & $-[0]$ & $1,71^{[3]}$ & $1,79^{[4]}$ \\
\hline 1.2 & $0,57^{[5]}$ & $1,31^{[5]}$ & $3,19^{[4]}$ & $\mathbf{0 , 5 3}{ }^{[5]}$ & $5,32^{[3]}$ & $1,78^{[5]}$ & $1,80^{[5]}$ \\
\hline 2.2 & $\mathbf{1 , 9 0}[5]$ & $17,72^{[3]}$ & $-[0]$ & $6,68^{[4]}$ & - $[0]$ & $5,76^{[5]}$ & $6,33^{[4]}$ \\
\hline 3.2 & $2,47^{[5]}$ & $7,05^{[4]}$ & - $[0]$ & $4,71^{[5]}$ & - $[0]$ & $7,70^{[2]}$ & $7,39[1]$ \\
\hline 4.2 & $\mathbf{2 , 8 2}[5]$ & $9,15^{[1]}$ & - $[0]$ & $5,08^{[5]}$ & - $[0]$ & $14,84^{[1]}$ & $12,18^{[1]}$ \\
\hline 1.3 & $1,16^{[5]}$ & $2,23^{[5]}$ & $4,86^{[4]}$ & $1,09[5]$ & $11,60^{[3]}$ & $3,48^{[5]}$ & $3,63^{[5]}$ \\
\hline 2.3 & $\mathbf{3 , 6 4}[5]$ & $18,17^{[2]}$ & $-[0]$ & $67,64[1]$ & - $[0]$ & $11,24[3]$ & $10,61[3]$ \\
\hline 3.3 & $5,48[5]$ & $16,56^{[2]}$ & - $[0]$ & $9,91^{[5]}$ & - $[0]$ & $29,92^{[4]}$ & $31,43^{[2]}$ \\
\hline 4.3 & $\mathbf{5 , 2 3}[5]$ & $23,67[3]$ & - $[0]$ & $9,01^{[5]}$ & - $[0]$ & - $[0]$ & - $[0]$ \\
\hline
\end{tabular}

Pode-se observar que a maioria das heurísticas não foram capazes de encontrar uma solução factível para as cinco instâncias de cada subclasse. Os números em sobrescrito e entre colchetes representam a quantidade de instâncias resolvidas por cada heurística.

As heurísticas relax-and-fix por item (RF-I) e LP-and-fix para valores inteiros (LP-I) serão desconsideradas no decorrer desta dissertação devido ao baixo desempenho apresentado, não conseguindo resolver ao menos uma instância com estrutura multiestágio $(2.1,3.1,4.1,2.2$, $3.2,4.2,2.3,3.3,4.3)$, com o tempo limite de 1 minuto.

O problema encontrado na heurística RF-I deve-se exclusivamente à estrutura de produtos. Uma vez que não há ordem entre produtos finais e intermediários, a produção de alguns destes últimos é definida antes da produção dos que os utilizam. Sendo assim, ocorre escassez de itens intermediários no momento de definição da produção dos itens finais.

Já com relação à heurística LP-I, o problema ocorre devido ao excesso de variáveis nulas presentes na solução ótima do problema relaxado e que são fixadas para a resolução do problema inteiro misto (em média, mais de $90 \%$ das variáveis inteiras). Sendo assim, quando as variáveis são integralizadas, verifica-se a necessidade de produção adicional, através de novos processos, para atender a demanda plenamente, o que não é possível devido às fixações previamente realizadas. Este fato é agravado quando consideram-se as estruturas multiestágio, pelos mesmos motivos constatados na heurística anterior. 
A análise dos resultados apresentados na Tabela 6.1 deve ser realizada em duas fases. Primeiramente, observando apenas as instâncias com estrutura de produtos monoestágio $(1.1,1.2 \mathrm{e}$ 1.3), a heurística relax-and-fix por nível (RF-L) apresenta desempenho geral superior às demais, porém, não muito distante da heurística relax-and-fix forward (RF-FP).

Para as demais subclasses, as quais possuem estrutura multiestágio, a heurística relax-andfix forward (RF-FP) destacou-se consideravelmente. Portanto, como o problema enfrentado pela indústria química é composto por estruturas multiestágio, esta heurística foi selecionada para novos testes, com objetivo de definir parâmetros a serem utilizados nos testes finais.

\subsection{Definição de Parâmetros}

Baseando-se na heurística relax-and-fix forward (RF-FP), foram realizados testes para definir os seguintes parâmetros: tempo total de processamento empregado para cada teste, assim como a sua divisão entre as iterações, o tamanho do pool de soluções a ser considerado, para uma variação desta heurística, e a definição dos custos de preparação das máquinas.

As Subseções 6.3.1 e 6.3.2 empregaram o modelo principal, definido pelas equações (3.1) a (3.9), enquanto a Subseção 6.3.3 utilizou o modelo que apresentava custos de preparação de máquina, definido pelas equações (3.10) a (3.19).

\subsubsection{Tempo Utilizado nos Experimentos}

O tempo destinado à execução das heurísticas apresentam dois fatores fundamentais: o tempo total disponibilizado para a execução e a sua divisão entre as iterações da heurística.

\section{Política de Divisão de Tempo entre Iterações}

Para este parâmetro foram analisadas três políticas de divisão de tempo para a heurística relax-and-fix forward (RF-FP): uma decrescente, outra crescente e a última, igualitária.

A política decrescente inicia alocando metade do tempo de execução à primeira iteração, em seguida, destinando um quarto do valor inicial ao segundo período, e assim sucessivamente, sempre reduzindo pela metade o tempo da iteração anterior. Dessa forma, esta política é expressa por $\tau / 2^{t}$, no qual $\tau$ representa o tempo computacional limite para a execução e $t$ o período em questão.

Para que o tempo de processamento total fosse utilizado, destinou-se à última iteração um 
tempo idêntico ao da penúltima, ou seja,

$$
\sum_{t=1}^{T-1} \tau / 2^{t}+\tau / 2^{T-1}=\tau
$$

com $T$ representando o número total de iterações.

A política crescente utiliza uma lógica contrária à decrescente, destinando menos tempo às iterações iniciais e dobrando este valor a cada iteração, fazendo com que a última dure $\tau / 2$ segundos. Já a política de divisão igualitária assume que todas as iterações executarão pelo mesmo tempo, ou seja, $\tau / T$.

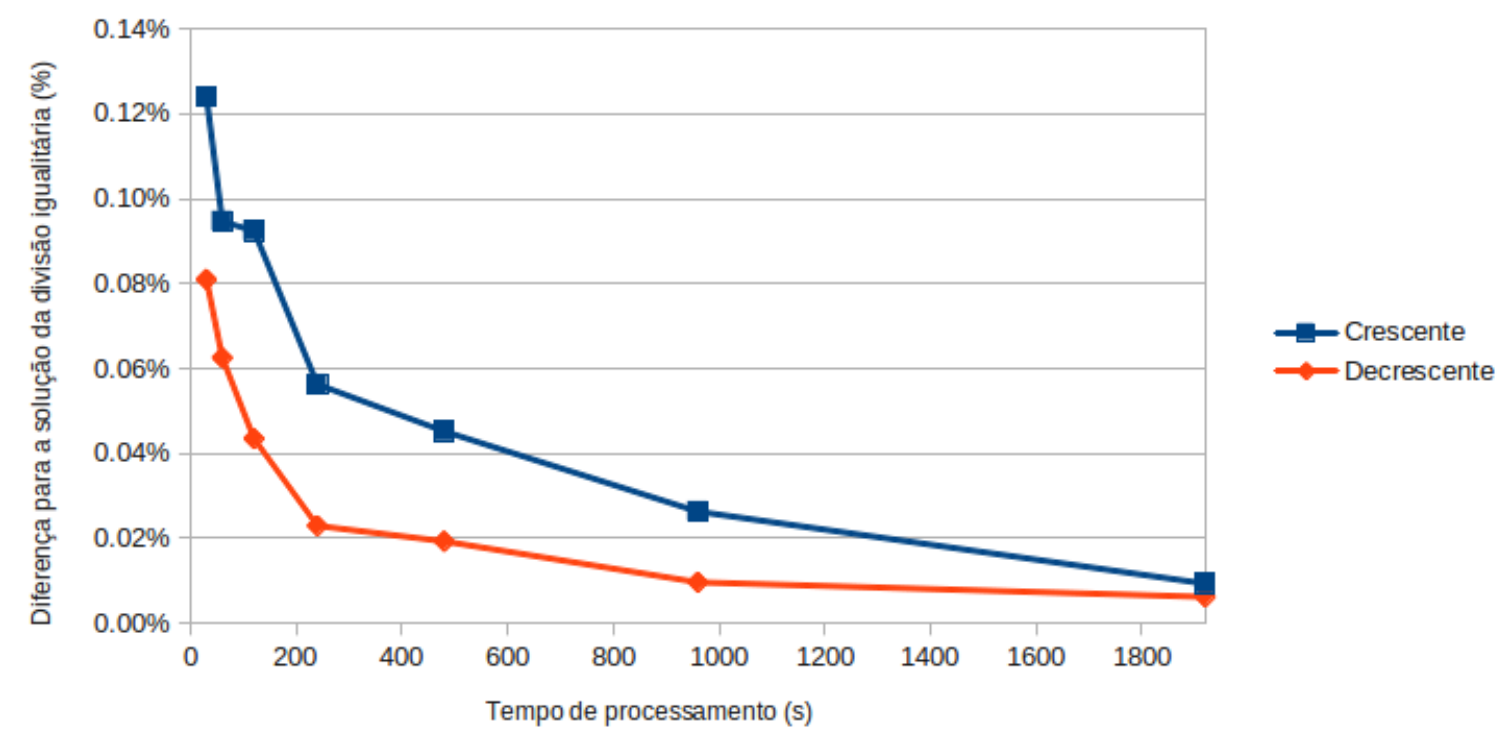

Figura 6.1: Diferença média das soluções para a política de divisão igualitária de tempo entre as iterações.

As Tabelas 6.2, 6.3 e 6.4 exibem a média dos GAPs relativos para as três políticas consideradas. Nota-se que, em média, a divisão igualitária de tempo obteve as soluções com os menores GAPs. A Figura 6.1 ilustra esse fato através da diferença média dos GAPs de todas as instâncias da divisão igualitária de tempo para as demais políticas.

Apesar da tendência de queda entre a diferença dos GAPs das políticas, optou-se por selecionar a divisão igualitária para os testes posteriores, motivado pela simplicidade desta estratégia e pela sua superioridade, mesmo que pequena, perante as demais políticas empregadas nos testes. Porém, caso o tempo total de execução fosse muito superior à faixa avaliada, novos experimentos seriam necessários para determinar a política ideal para a nova situação. 
Tabela 6.2: Média dos GAPs relativos com divisão crescente do tempo entre as iterações

\begin{tabular}{|c|c|c|c|c|c|c|c|}
\hline \multirow{2}{*}{ Subclasse } & \multicolumn{7}{|c|}{ Tempo Total de Processamento } \\
\hline & 30s & $60 \mathrm{~s}$ & $120 \mathrm{~s}$ & $240 \mathrm{~s}$ & $480 \mathrm{~s}$ & $960 \mathrm{~s}$ & $1920 \mathrm{~s}$ \\
\hline 1.1 & $0,38 \%{ }^{[5]}$ & $0,38 \%[5]$ & $0,38 \%[5]$ & $0,37 \%{ }^{[5]}$ & $0,37 \%[5]$ & $0,37 \%{ }^{[5]}$ & $0,37 \%[5]$ \\
\hline 2.1 & $3 \%[5]$ & $0,73 \%[5]$ & $0,72 \%[5]$ & $0,72 \%[5]$ & $0,72 \%[5]$ & $0,71 \%[5]$ & $0,72 \%[5]$ \\
\hline 3.1 & $31 \%[5]$ & $0,82 \%[5]$ & $0,82 \%[5]$ & $0,80 \%[5]$ & $0,80 \%[5]$ & $0,80 \%[5]$ & $0,81 \%[5]$ \\
\hline 4.1 & $11 \%[5]$ & $1,09 \%[5]$ & $1,09 \%[5]$ & $1,09 \%[5]$ & $1,08 \%[5]$ & $1,07 \%[5]$ & $1,07 \%[5]$ \\
\hline 1.2 & $8 \%[5]$ & $0,58 \%[5]$ & $0,59 \%[5]$ & $0,59 \%[5]$ & $0,59 \%[5]$ & $0,58 \%[5]$ & $0,58 \%[5]$ \\
\hline 2. & $\%[5]$ & $1,97 \%[5]$ & $1,89 \%[5]$ & $1,83 \%[5]$ & $1,83 \%[5]$ & $1,82 \%[5]$ & $1,81 \%[5]$ \\
\hline 3.2 & $7 \%[5]$ & $2,70 \%[5]$ & $2,50 \%[5]$ & $2,39 \%[5]$ & $2,38 \%[5]$ & $2,34 \%[5]$ & $2,33 \%[5]$ \\
\hline & $1 \%[5]$ & $2,95 \%[5]$ & $2,79 \%[5]$ & $2,73 \%[5]$ & $2,66 \%[5]$ & $2,62 \%[5]$ & $2,61 \%[5]$ \\
\hline 1.3 & $3 \%[5]$ & $1,12 \%[5]$ & $1,10 \%[5]$ & $1,18 \%[5]$ & $1,18 \%[5]$ & $1,16 \%{ }^{[5]}$ & $1,15 \%[5]$ \\
\hline 2.3 & $15 \%[5]$ & $3,74 \%[5]$ & $3,65 \%[5]$ & $3,33 \%[5]$ & $3,26 \%[5]$ & $3,15 \%[5]$ & $3,08 \%[5]$ \\
\hline & $2 \%$ & $5,61 \%[5]$ & $5,27 \%[5]$ & $4,98 \%[5]$ & $4,68 \%[5]$ & $4,61 \%[5]$ & $4,49 \%[4]$ \\
\hline 4.3 & $6,18 \% \%^{[5]}$ & $5,33 \%[5]$ & $5,08 \%{ }^{[5]}$ & $4,85 \%[5]$ & $4,64 \%[5]$ & $4,55 \%[5]$ & $4,45 \%[5]$ \\
\hline
\end{tabular}

Tabela 6.3: Média dos GAPs relativos com divisão decrescente do tempo entre as iterações

\begin{tabular}{|c|c|c|c|c|c|c|c|}
\hline \multirow{2}{*}{ Subclasse } & \multicolumn{7}{|c|}{ Tempo Total de Processamento } \\
\hline & 30s & 60s & $120 \mathrm{~s}$ & 240s & $480 \mathrm{~s}$ & $960 s$ & $1920 \mathrm{~s}$ \\
\hline 1.1 & $0,38 \%$ & $0,38 \%$ & $0,37 \%$ & $0,37 \%[5]$ & $0,37 \%[5]$ & $0,37 \%$ & $0,37 \%[5]$ \\
\hline 2.1 & $0,76 \%[5]$ & $0,73 \%[5]$ & $0,73 \%[5]$ & $0,72 \%[5]$ & $0,71 \%[5]$ & $0,72 \%[5]$ & $0,72 \%$ \\
\hline 3.1 & $0,87 \%$ & $0,84 \%$ & $0,82 \%$ & $0,82 \%[5]$ & $0,80 \%[5]$ & $0,81 \%$ & $0,81 \%$ \\
\hline 4.1 & $1,11 \%{ }^{[5]}$ & $1,10 \%{ }^{[5]}$ & $1,09 \%[5]$ & $1,08 \%[5]$ & $1,09 \%[5]$ & $1,08 \%$ & $1,08 \%[5]$ \\
\hline 1.2 & $0,58 \%[5]$ & $0,57 \%[5]$ & $0,58 \%[5]$ & $0,58 \%{ }^{[5]}$ & $0,58 \%[5]$ & $0,58 \%[5]$ & $0,58 \%[5]$ \\
\hline 2.2 & $2,08 \%[5]$ & $1,93 \%[5]$ & $1,91 \%$ & $1,86 \%[5]$ & $1,81 \%$ & $1,80 \%$ & $1,80 \%[5]$ \\
\hline 3.2 & $2,79 \%$ & $2,67 \%[5]$ & $2,49 \%$ & $2,39 \%[5]$ & $2,34 \%[5]$ & $2,35 \%[5]$ & $2,32 \%[5]$ \\
\hline 4.2 & $3,14 \%[5]$ & $2,87 \%[5]$ & $2,74 \%[5]$ & $2,69 \%$ & $2,61 \%{ }^{[5]}$ & $2,63 \%[5]$ & $2,61 \%[5]$ \\
\hline 1.3 & $1,16 \%$ & $1,19 \%$ & $1,18 \%$ & $1,15 \%[5]$ & $1,16 \%[5]$ & $1,16 \%$ & $1,16 \%[5]$ \\
\hline 2.3 & $4,06 \%$ & $3,63 \%[5]$ & $3,37 \%$ & $3,24 \%[5]$ & $3,13 \%[5]$ & $3,11 \%$ & $3,07 \%$ \\
\hline 3.3 & $6,17 \%$ & $5,30 \%$ & $5,05 \%$ & $4,83 \%[5]$ & $4,69 \%[5]$ & $4,53 \%[5]$ & $4,49 \%[5]$ \\
\hline 4.3 & $5,71 \%$ & $5,41 \%{ }^{[5]}$ & $4,97 \%$ & $4,74 \%{ }^{[5]}$ & $4,59 \%[5]$ & $4,46 \%$ & $4,42 \%[5]$ \\
\hline
\end{tabular}

Tabela 6.4: Média dos GAPs relativos com divisão igualitária do tempo entre as iterações

\begin{tabular}{|c|c|c|c|c|c|c|c|}
\hline \multirow{2}{*}{ Subclasse } & \multicolumn{7}{|c|}{ Tempo Total de Processamento } \\
\hline & 30s & 60s & $120 \mathrm{~s}$ & $240 \mathrm{~s}$ & $480 \mathrm{~s}$ & $960 \mathrm{~s}$ & $1920 \mathrm{~s}$ \\
\hline 1.1 & $0,38 \%[5]$ & $0,37 \%[5]$ & $0,37 \%[5]$ & $0,37 \%[5]$ & $0,37 \%[5]$ & $0,37 \%[5]$ & $0,37 \%[5]$ \\
\hline 2.1 & $0,73 \%[5]$ & $0,72 \%[5]$ & $0,71 \%[5]$ & $0,72 \%[5]$ & $0,72 \%[5]$ & $0,71 \%[5]$ & $0,72 \%[5]$ \\
\hline 3.1 & $0,83 \%$ & $0,81 \%[5]$ & $0,81 \%[5]$ & $0,81 \%[5]$ & $0,81 \%[5]$ & $0,81 \%[5]$ & $0,81 \%[5]$ \\
\hline 4.1 & $1,10 \%$ & $1,09 \%[5]$ & $1,08 \%[5]$ & $1,08 \%[5]$ & $1,08 \%[5]$ & $1,08 \%[5]$ & $1,08 \%[5]$ \\
\hline 1.2 & $0,60 \%$ & $0,59 \%$ & $0,59 \%$ & $0,58 \%$ & $0,58 \%{ }^{[5]}$ & $0,58 \%[5]$ & $0,58 \%[5]$ \\
\hline 2.2 & $1,99 \%$ & $1,88 \%[5]$ & $1,86 \%[5]$ & $1,82 \%[5]$ & $1,82 \%[5]$ & $1,79 \%[5]$ & $1,79 \%[5]$ \\
\hline 3.2 & $2,68 \%[5]$ & $2,53 \%[5]$ & $2,41 \%[5]$ & $2,35 \%[5]$ & $2,36 \%[5]$ & $2,31 \%$ & $2,30 \%[5]$ \\
\hline 4.2 & $2,96 \%[5]$ & $2,76 \%[5]$ & $2,72 \%[5]$ & $2,64 \%[5]$ & $2,62 \%[5]$ & $2,61 \%[5]$ & $2,61 \%[5]$ \\
\hline 1.3 & $1,17 \%$ & $1,19 \%{ }^{[5]}$ & $1,17 \%$ & $1,16 \%{ }^{[5]}$ & $1,15 \%{ }^{[5]}$ & $1,18 \%{ }^{[5]}$ & $1,16 \%$ \\
\hline 2.3 & $3,86 \%[5]$ & $3,57 \%$ & $3,29 \%[5]$ & $3,23 \%$ & $3,09 \%[5]$ & $3,10 \%$ & $3,06 \%[5]$ \\
\hline 3.3 & $5,86 \%[5]$ & $5,26 \%[5]$ & $4,93 \%[5]$ & $4,71 \%[5]$ & $4,52 \%[5]$ & $4,47 \%[5]$ & $4,46 \%[5]$ \\
\hline 4.3 & $5,67 \%$ & $5,10 \%$ & $4,84 \%[5]$ & $4,73 \%[5]$ & $4,54 \%[5]$ & $4,46 \%[5]$ & $4,40 \%$ \\
\hline
\end{tabular}




\section{Tempo Total de Execução}

O tempo total de processamento foi determinado através de análises das variações dos GAPs entre execuções com tempos de processamento distintos, as quais foram calculadas de acordo com a equação (6.2). Esta equação considera apenas as execuções com tempos de processamento adjacentes, ou seja, foram calculadas as variações dos GAPs entre execuções de 60 e 30 segundos, 120 e 60 segundos, e dessa forma até 1920 e 960 segundos.

$$
\text { Variação }(\%)=\frac{\operatorname{Solução}(2 * t)-\operatorname{Solução}(t)}{\operatorname{Solução}(t)}
$$

Os resultados dessa análise encontram-se na Tabela 6.5, segundo a qual nota-se que as instâncias com compartilhamento máximo de tanques (1.3, 2.3, 3.3 e 4.3) apresentam uma suavização no percentual de redução dos GAPs a partir da quinta coluna (960-480s), mantendose inferior a $0,10 \%$, apesar do tempo de processamento ser dobrado a cada execução.

Tabela 6.5: Média dos GAPs relativos com divisão igualitária do tempo entre as iterações

\begin{tabular}{|c|c|c|c|c|c|c|}
\hline \multirow{2}{*}{ Subclasse } & \multicolumn{6}{|c|}{ Diferença entre GAP das soluções } \\
\hline & 60-30s & 120-60s & $240-120 s$ & 480-240s & $960-480 s$ & 1920-960s \\
\hline 1.1 & $-0,01 \%[5]$ & $0,00 \%[5]$ & $0,00 \%[5]$ & $0,00 \%$ & $0,00 \%[5]$ & $0,00 \%$ \\
\hline 2.1 & $-0,01 \%[5]$ & $-0,01 \%[5]$ & $0,00 \%[5]$ & $0,01 \%[5]$ & $-0,01 \%[5]$ & $0,00 \%[5]$ \\
\hline 3.1 & $-0,02 \%[5]$ & $-0,01 \%[5]$ & $0,00 \%[5]$ & $0,00 \%$ & $0,00 \%$ & $0,00 \%$ \\
\hline 4.1 & $-0,01 \%[5]$ & $-0,01 \%[5]$ & $0,00 \%[5]$ & $0,00 \%[5]$ & $0,00 \%[5]$ & $0,00 \%[5]$ \\
\hline 1.2 & $-0,01 \%[5]$ & $0,00 \%[5]$ & $-0,01 \%[5]$ & $0,00 \%[5]$ & $0,00 \%[5]$ & $0,00 \%[5]$ \\
\hline 2.2 & $-0,11 \%[5]$ & $-0,02 \%[5]$ & $-0,04 \%[5]$ & $0,00 \%$ & $-0,03 \%[5]$ & $0,00 \%$ \\
\hline 3.2 & $-0,16 \%[5]$ & $-0,12 \%[5]$ & $-0,06 \%[5]$ & $0,01 \%[5]$ & $-0,05 \%[5]$ & $0,00 \%$ \\
\hline 4.2 & $-0,19 \%$ & $-0,04 \%$ & $-0,08 \%[5]$ & $-0,02 \%$ & $-0,01 \%[5]$ & $0,00 \%$ \\
\hline 1.3 & $0,02 \%$ & $-0,02 \%[5]$ & $-0,01 \%[5]$ & $-0,01 \%[5]$ & $0,03 \%$ & $-0,02 \%[5]$ \\
\hline 2.3 & $-0,29 \%[5]$ & $-0,28 \%[5]$ & $-0,06 \%[5]$ & $-0,14 \%$ & $0,01 \%$ & $-0,04 \%[5]$ \\
\hline 3.3 & $-0,60 \%[5]$ & $-0,33 \%[5]$ & $-0,22 \%[5]$ & $-0,19 \%[5]$ & $-0,04 \%[5]$ & $-0,02 \%[5]$ \\
\hline 4.3 & $-0,57 \%[5]$ & $-0,26 \%[5]$ & $-0,11 \%[5]$ & $-0,18 \%$ & $-0,08 \%[5]$ & $-0,06 \%$ \\
\hline
\end{tabular}

Ao analisar às instâncias com percentual médio (1.2, 2.2, 3.2 e 4.2), a partir da segunda coluna (120-60s) constata-se uma pequena redução das variações, também inferior a 0,10\%, a qual é realçada após a quarta coluna (480-240s), e que pode ser visualizado através da Figura 6.2. Já para o compartilhamento mínimo (1.1, 2.1, 3.1 e 4.1), a partir da terceira coluna (240-120s) não observa-se mais redução nos valores das soluções.

Apesar de em ambos os casos ainda ser possível encontrar reduções nas médias dos GAPs, para as colunas citadas, este percentual pode ser considerado muito baixo quando comparado ao tempo adicional necessário. Por exemplo, ao considerar as subclasses que mais se aproximam 
do problema real (1.2, 2.2, 3.2 e 4.2), a maior redução de GAP médio entre execuções com 240 e 1920 segundos é verificada em 3.2, correspondendo a uma variação de apenas 0,04\%. Dessa forma, adotou-se 300 segundos como o tempo padrão para o limite de processamento desse conjunto de instâncias.

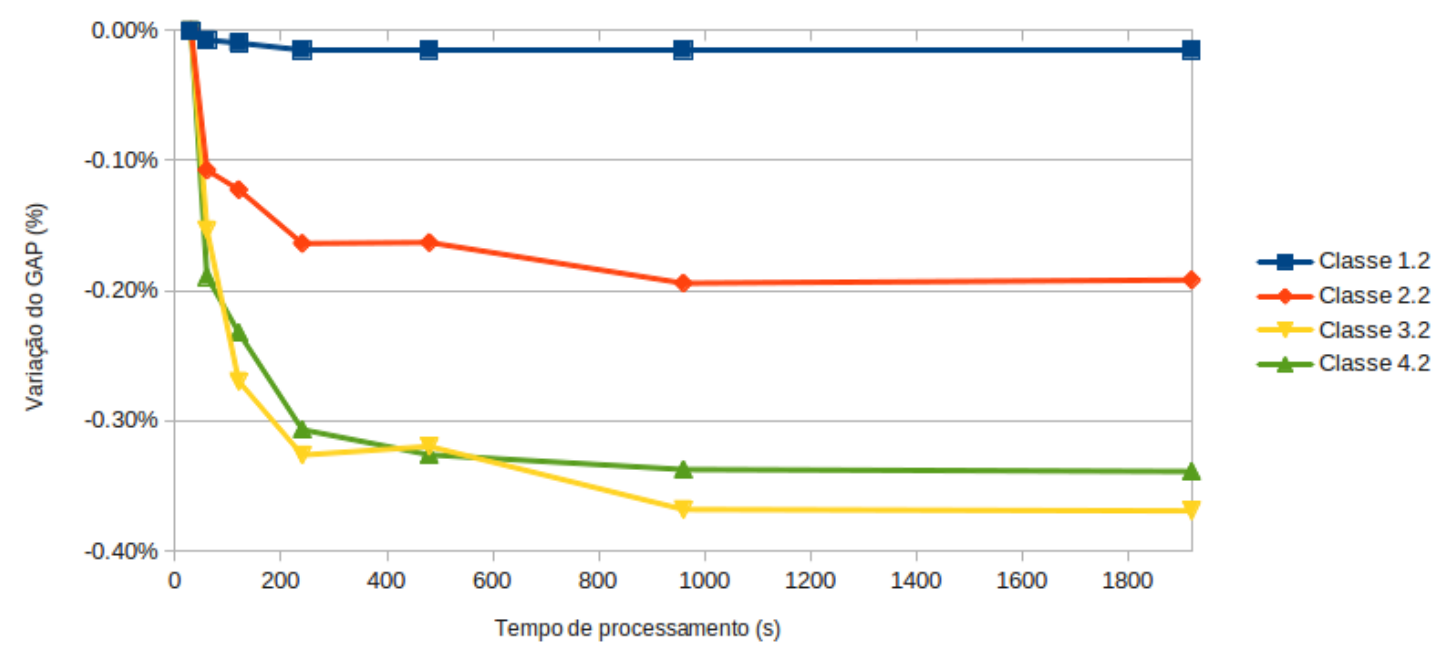

Figura 6.2: Variação das soluções para o compartilhamento médio de tanques utilizando a divisão de tempo igualitária do tempo de execução.

\subsubsection{Tamanho do Pool de Soluções}

Para entender a influência do tamanho do pool de soluções na heurística relax-and-fix, é importante observar a evolução das soluções através da variação do tempo total de execução. Para isso, foram considerados testes em que o número total de soluções armazenadas variava de duas até trinta e duas, com tempo de execução entre 30 e 1920 segundos.

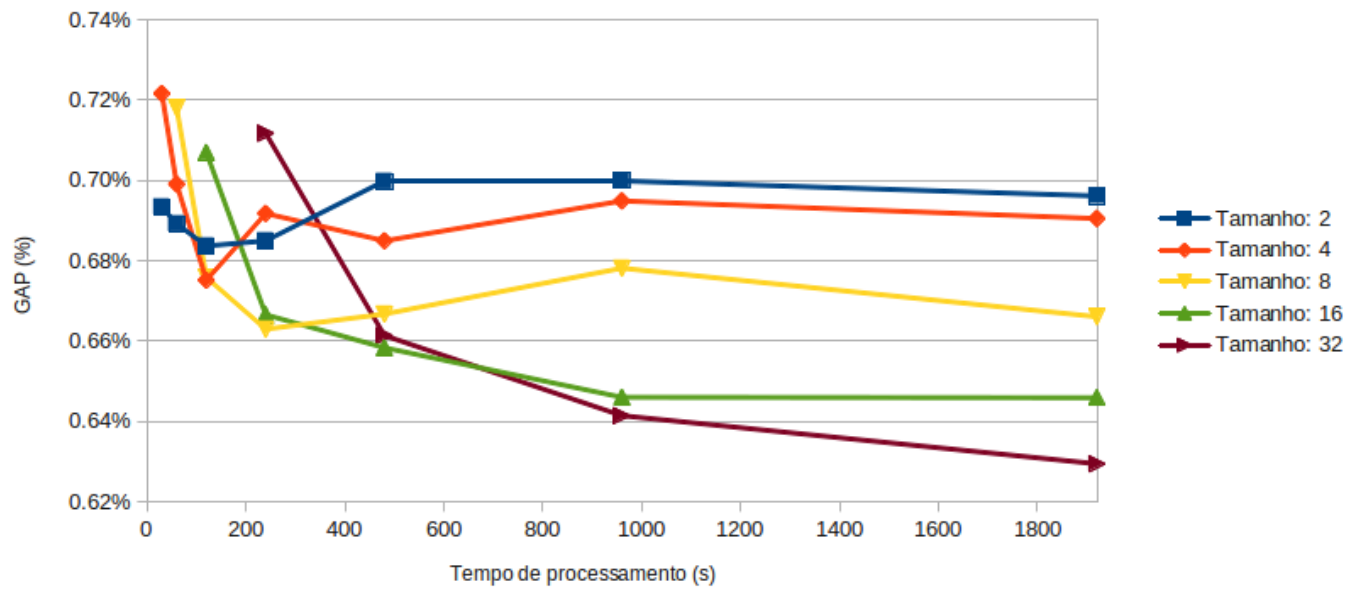

Figura 6.3: Redução do GAP médio para instâncias monoestágio com a variação do tamanho do pool de soluções. 
Analisando a qualidade das soluções para as instâncias monoestágio (1.1, 1.2 e 1.3), é possível representar a média de seus GAPs através da Figura 6.3, na qual nota-se que durante os experimentos alguns tamanhos específicos de pool não utilizaram todo o intervalo de tempos de execução, por exemplo, no caso do pool de tamanho 8, em que os testes iniciaram a partir de 60 segundos. Este fato deve-se por característica do software utilizado nos experimentos, cujo valor mínimo para o tempo de execução é um segundo. Portanto, a conjunção do número de partições do problema e de soluções armazenadas no pool foi fundamental para determinar qual o tempo mínimo de execução que as variações desta heurística poderiam utilizar.

Apesar de não ser possível utilizar completamente o intervalo de tempo nos testes, a Figura 6.3 evidencia que a partir de 960 segundos, a heurística relax-and-fix utilizando os maiores pools de solução foram capazes de encontrar as melhores soluções, mostrando que esta abordagem pode ser mais eficiente do que o relax-and-fix tradicional.

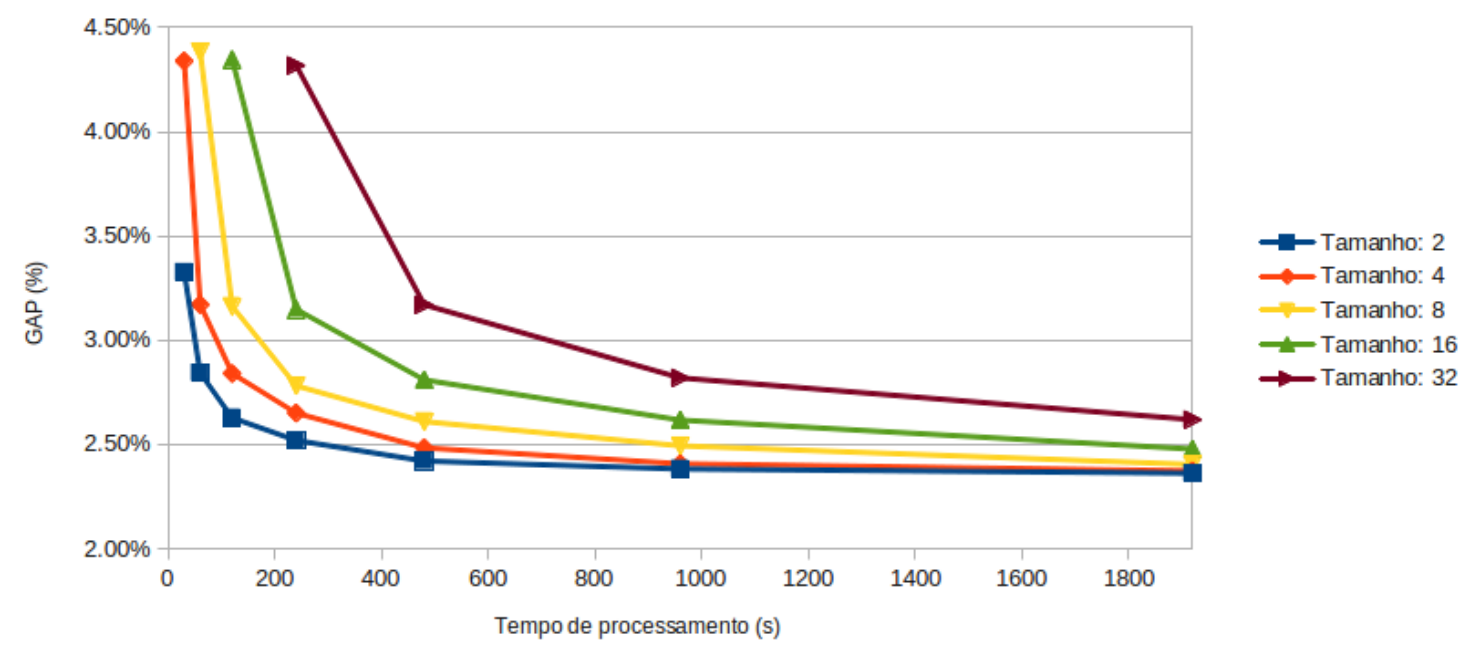

Figura 6.4: Redução do GAP médio para instâncias multiestágio com a variação do tamanho do pool de soluções.

Ao serem analisadas as soluções das instâncias multiestágio (2.1, 2.2, 2.3, 3.1, 3.2, 3.3, 4.1, 4.2 e 4.3), cujos GAPs médios são representadas pela Figura 6.4, observa-se um padrão bem definido, ao contrário do anterior, porém, como a resolução destas instâncias são mais complexas, o intervalo de tempo definido para os testes não foi suficiente para exibir os ganhos proporcionados pelo aumento do pool de soluções. Dessa forma, adotou-se para os testes finais um pool com tamanho dois.

Apesar do valor adotado para este parâmetro no decorrer dos experimentos, ao ser realizada uma investigação mais detalhada nas soluções das instâncias multiestágio, considerando-se apenas as subclasses em que não há compartilhamento de tanques (2.1, 3.1 e 4.1), nota-se que com 1920 segundos de execução, a solução obtida através do pool de tamanho dois apresenta quali- 


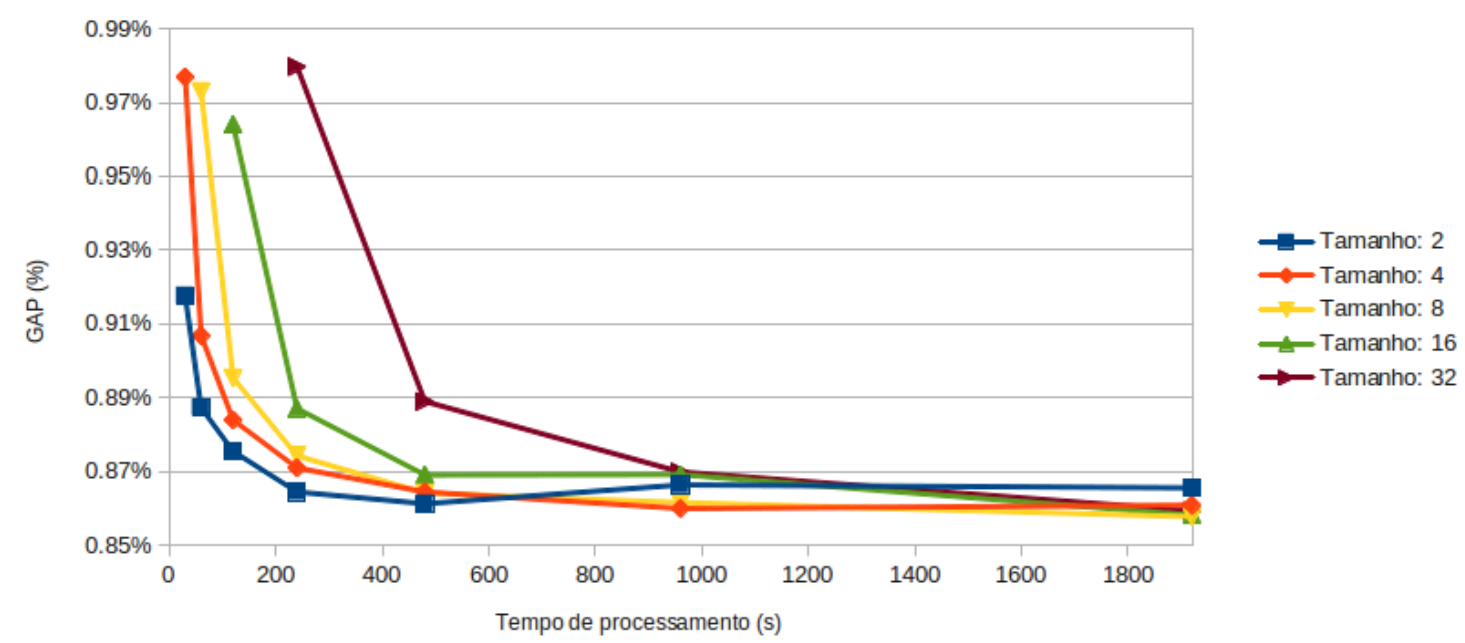

Figura 6.5: Redução do GAP médio para instâncias multiestágio, com compartilhamento mínimo de tanques, pela variação do tamanho do pool de soluções.

dade inferior às demais, como ilustrado pela Figura 6.5. Este fato indica a possibilidade de um comportamento semelhante ao das instâncias monoestágio, desde que o tempo limite de execução seja maior ou o número de produtos considerados seja reduzido, o que está fora do escopo deste trabalho.

\subsubsection{Custo de Preparação de Máquinas}

Para esta etapa foram consideradas as equações (3.10) a (3.19), para as quais diversos parâmetros $\lambda_{i, p, t}$ foram testados, os quais podem ser divididos em duas classes, uma baseada em percentuais do preço de venda dos produtos e outra baseada em valores constantes. Foram selecionados três parâmetros de cada classe, os quais são exibidos na Tabela 6.6, que representa as reduções médias do número de setup obtidas nos experimentos, com relação à função objetivo original, para cada uma das subclasses.

Porém, como consequência dessa redução, é necessário avaliar o aumento do valor das novas soluções em relação às soluções obtidas pelo modelo original, cujos percentuais são exibidos entre colchetes e em sobrescrito. Após a análise de ambos os percentuais para todas as variações, optou-se por adotar o próprio valor dos produtos como penalização para os setups, ou seja, sempre que um novo processo for iniciado, computa-se um custo igual ao preço de venda de uma tonelada deste produto. 
Tabela 6.6: Redução média do número de preparação de máquinas, utilizando a heurística relaxand-fix.

\begin{tabular}{cccccccc}
\hline \multirow{2}{*}{ Subclasse } & \multicolumn{4}{c}{ Percentual } & \multicolumn{3}{c}{ Valor Absoluto } \\
\cline { 2 - 6 } & $\mathbf{2 5 \%}$ & $\mathbf{1 0 0 \%}$ & $\mathbf{4 0 0 \%}$ & $\mathbf{2 5 6}$ & $\mathbf{4 0 9 6}$ & $\mathbf{6 5 5 3 6}$ \\
\hline 1.1 & $13,68 \%[0,07]$ & $22,54 \%[0,28]$ & $26,35 \%[0,59]$ & $4,38 \%[0,03]$ & $22,13 \%[0,25]$ & $27,10 \%[0,76]$ \\
2.1 & $6,22 \%[0,04]$ & $10,49 \%[0,25]$ & $11,94 \%[0,50]$ & $2,05 \%[0,01]$ & $9,70 \%[0,14]$ & $12,19 \%[0,57]$ \\
3.1 & $5,98 \%[0,06]$ & $9,13 \%[0,26]$ & $10,71 \%[0,46]$ & $1,87 \%[0,01]$ & $8,04 \%[0,13]$ & $10,87 \%[0,51]$ \\
4.1 & $5,74 \%[0,08]$ & $9,23 \%[0,26]$ & $10,67 \%[0,50]$ & $1,64 \%[0,01]$ & $8,18 \%[0,15]$ & $10,87 \%[0,54]$ \\
\hline 1.2 & $11,89 \%[0,02]$ & $21,80 \%[0,27]$ & $27,41 \%[0,81]$ & $4,87 \%[0,02]$ & $21,41 \%[0,27]$ & $28,77 \%[1,14]$ \\
2.2 & $5,22 \%[0,08]$ & $10,01 \%[0,30]$ & $12,97 \%[0,76]$ & $1,84 \%[0,04]$ & $8,89 \%[0,15]$ & $13,50 \%[0,92]$ \\
3.2 & $5,18 \%[0,13]$ & $8,74 \%[0,38]$ & $11,65 \%[0,68]$ & $2,35 \%[0,13]$ & $8,10 \%[0,23]$ & $12,35 \%[0,82]$ \\
4.2 & $5,25 \%[0,09]$ & $8,82 \%[0,31]$ & $11,36 \%[0,68]$ & $2,19 \%[0,06]$ & $7,91 \%[0,19]$ & $12,04 \%[0,87]$ \\
\hline 1.3 & $9,32 \%[0,06]$ & $19,34 \%[0,28]$ & $27,08 \%[1,09]$ & $3,94 \%[0,03]$ & $18,07 \%[0,29]$ & $29,61 \%[1,62]$ \\
2.3 & $5,35 \%[0,18]$ & $8,92 \%[0,36]$ & $13,59 \%[0,97]$ & $2,48 \%[0,17]$ & $7,47 \%[0,24]$ & $14,72 \%[1,30]$ \\
3.3 & $4,92 \%[0,20]$ & $7,70 \%[0,40]$ & $12,06 \%[0,80]$ & $3,23 \%[0,36]$ & $7,01 \%[0,25]$ & $13,52 \%[1,26]$ \\
4.3 & $3,88 \%[0,34]$ & $7,43 \%[0,42]$ & $11,55 \%[0,98]$ & $1,84 \%[0,23]$ & $6,17 \%[0,32]$ & $12,91 \%[1,36]$ \\
\hline
\end{tabular}

\subsection{Testes Finais}

Na etapa final de testes, os parâmetros determinados nas seções anteriores, resumidos na Tabela 6.7 foram aplicados às heurísticas para a avaliação final. Em um primeiro momento, Subseção 6.4.1, foi utilizado o tempo limite de cinco minutos para os testes, a fim de medir o desempenho de todas as heurísticas para as quatro classes de instâncias.

Tabela 6.7: Resumo dos parâmetros determinados na Seção 6.3.

\begin{tabular}{ll}
\hline Parâmetro & Valor Adotado \\
\hline Divisão de tempo & Igualitária \\
Tempo de execução & 5 e 60 minutos \\
Tamanho do pool & 2 soluções \\
Custo de preparação & Preço de venda \\
\hline
\end{tabular}

Para as Subseções 6.4.2, 6.4.3 e 6.4.4, as avaliações passaram a considerar apenas as instâncias que mais se aproximavam da realidade da empresa, subclasse 4.2, com um novo tempo limite de uma hora, para o qual foram investigados o modelo apresentado na Seção 3.3, o problema considerando apenas o armazenamento de produtos intermediários e o problema considerando custos de preparação de máquina.

\subsubsection{Desempenho das Heurísticas Propostas}

Para esta fase de testes foram avaliadas as heurísticas propostas, com exceção da relaxand-fix por itens (RF-I) e LP-and-fix para valores inteiros (LP-I), que nos testes iniciais não 
encontraram soluções factíveis para nenhuma instância multiestágio. Os parâmetros utilizados são apresentados na Tabela 6.7 e os modelos inteiros mistos foram resolvidos utilizando o software CPLEX 12.4.

A Tabela 6.8 apresenta a média dos GAPs relativos do modelo inteiro misto (MIP) e das heurísticas relax-and-fix forward (RF-FP), relax-and-fix forward com pool de soluções (RFFPSP), relax-and-fix backward (RF-BP), relax-and-fix por nível (RF-L), LP-and-fix para valores inteiros não nulos (LP-NN) e LP-and-fix para valores próximos aos inteiros não nulos (LPRNN).

Tabela 6.8: Variação do GAP médio para as heurísticas construtivas.

\begin{tabular}{c|c|cccc|cc}
\hline Subclasse & MIP(\%) & RF-FP(\%) & RF-FPSP(\%) & RF-BP(\%) & RF-L(\%) & LP-NN(\%) & LP-RNN(\%) \\
\hline 1.1 & $0,23^{[5]}$ & $0,37^{[5]}$ & $0,37^{[5]}$ & $0,57^{[3]}$ & $0,23^{[5]}$ & $\mathbf{0 , 2 1}[5]$ & $0,23^{[5]}$ \\
2.1 & $0,80^{[5]}$ & $\mathbf{0 , 7 1}[5]$ & $\left.\mathbf{0 , 7 1}\right|^{[5]}$ & $3,55^{[4]}$ & $0,88^{[5]}$ & $0,79^{[5]}$ & $0,75^{[4]}$ \\
3.1 & $0,86^{[5]}$ & $0,81^{[5]}$ & $0,80^{[5]}$ & $2,06^{[4]}$ & $\mathbf{0 , 7 8} \mathbf{8}^{[5]}$ & $0,89^{[5]}$ & $0,92^{[2]}$ \\
4.1 & $1,25^{[4]}$ & $1,08^{[5]}$ & $1,09^{[5]}$ & $3,09^{[4]}$ & $\mathbf{1 , 0 7}^{[5]}$ & $1,21^{[4]}$ & $1,28^{[4]}$ \\
\hline 1.2 & $\mathbf{0 , 4 1}{ }^{[5]}$ & $0,58^{[5]}$ & $0,58^{[5]}$ & $1,31^{[5]}$ & $0,42^{[5]}$ & $1,72^{[5]}$ & $1,77^{[5]}$ \\
2.2 & $2,46^{[5]}$ & $\mathbf{1 , 8 3}^{[5]}$ & $\mathbf{1 , 8 3}^{[5]}$ & $18,93^{[3]}$ & $3,90^{[5]}$ & $5,07^{[5]}$ & $4,85^{[4]}$ \\
3.2 & $4,01^{[3]}$ & $\mathbf{2 , 3 5}[5]$ & $2,41^{[5]}$ & $5,60^{[3]}$ & $3,81^{[5]}$ & $6,38^{[3]}$ & $6,88^{[1]}$ \\
4.2 & $3,40^{[1]}$ & $\mathbf{2 , 6 1}[5]$ & $2,68^{[5]}$ & $8,13^{[3]}$ & $4,87^{[5]}$ & $12,46^{[2]}$ & $11,59^{[1]}$ \\
\hline 1.3 & $\mathbf{0 , 8 0}{ }^{[5]}$ & $1,15^{[5]}$ & $1,15^{[5]}$ & $2,22^{[5]}$ & $0,84^{[5]}$ & $3,46^{[5]}$ & $3,60^{[5]}$ \\
2.3 & $5,09^{[1]}$ & $\mathbf{3 , 1 2}[5]$ & $3,24^{[5]}$ & $19,82^{[2]}$ & $6,07^{[1]}$ & $9,44^{[3]}$ & $10,07^{[3]}$ \\
3.3 & $-{ }^{[0]}$ & $\mathbf{4 , 6 3}[5]$ & $4,91^{[5]}$ & $15,68^{[2]}$ & $7,96^{[5]}$ & $29,09[5]$ & $29,64^{[2]}$ \\
4.3 & $-{ }^{[0]}$ & $\mathbf{4 , 6 0}[5]$ & $4,68^{[5]}$ & $25,77^{[2]}$ & $8,31^{[5]}$ & $28,92^{[3]}$ & $28,15^{[3]}$
\end{tabular}

Analisando esses dados, nota-se que o desempenho médio das heurísticas LP-and-fix (LPNN e LP-RNN) e da heurística relax-and-fix backward (RF-BP) não foram satisfatórios, visto que elas não foram capazes de encontrar a solução para diversas instâncias e quando o fizeram, para as que apresentavam compartilhamento de tanques, suas soluções não tiveram qualidade tão boa quanto as demais.

As heurísticas $L P$-and-fix foram utilizadas neste estudo como um procedimento para fixar variáveis e, consequentemente, reduzir o esforço computacional para encontrar soluções factíveis. A LP-and-fix para valores inteiros não nulos (LP-NN) fixou a maior parte das variáveis binárias do modelo, portanto, após o procedimento de presolve do CPLEX, obteve-se uma redução média de 99,5\% de variáveis binárias, enquanto apenas 1,7\% para as variáveis inteiras.

Já a heurística $L P$-and-fix para valores próximos aos inteiros não nulos (LP-RNN), além de fixar os valores das variáveis binárias, também fixou algumas variáveis inteiras, mediante o arredondamento dos valores obtidos com a resolução do modelo relaxado, quando essas estavam próximas aos valores inteiros. Como esta heurística fixou mais variáveis do que a anterior, algumas por arredondamento, houve maior ocorrência de infactibilidade, sendo assim, foram resolvidos $65,0 \%$ dos testes enquanto a heurística anterior resolveu $83,3 \%$. 
A heurística relax-and-fix backward (RF-BP) não se mostrou muito eficiente por causa da ordem em que percorre os períodos, pois ao iniciar pelo último período, deslocando-se em direção ao primeiro, caso a solução incumbente de alguma iteração apresente períodos iniciais utilizando toda sua capacidade produtiva, é provável que ao final do processamento não seja obtido uma solução factível, pois a partir do momento que as variáveis forem integralizadas, é provável que ocorra superutilização das máquinas.

Tabela 6.9: Tempo de execução médio para as heurísticas construtivas.

\begin{tabular}{c|c|cccc|cc}
\hline Subclasse & MIP(s) & RF-FP(s) & RF-FPSP(s) & RF-BP(s) & RF-L(s) & LP-NN(s) & LP-RNN(s) \\
\hline 1.1 & 299,6 & 20,3 & 51,9 & 10,8 & 299,6 & 299,7 & 299,7 \\
2.1 & 301,8 & 287,3 & 249,7 & 283,8 & 281,1 & 302,7 & 243,1 \\
3.1 & 303,2 & 302,1 & 264,7 & 285,6 & 204,1 & 304,7 & 125,6 \\
4.1 & 302,9 & 301,0 & 259,1 & 286,0 & 214,0 & 304,5 & 239,7 \\
\hline 1.2 & 299,5 & 138,7 & 156,5 & 82,2 & 299,5 & 299,5 & 299,6 \\
2.2 & 301,4 & 305,7 & 261,9 & 279,5 & 301,3 & 302,0 & 241,9 \\
3.2 & 301,8 & 307,2 & 263,8 & 258,3 & 209,3 & 303,4 & 123,6 \\
4.2 & 301,4 & 307,4 & 263,9 & 273,4 & 228,3 & 302,9 & 242,9 \\
\hline 1.3 & 299,4 & 294,5 & 255,4 & 192,9 & 299,4 & 299,5 & 299,5 \\
2.3 & 300,3 & 305,3 & 261,1 & 252,1 & 300,9 & 301,6 & 240,7 \\
3.3 & 300,8 & 306,6 & 262,9 & 253,4 & 302,5 & 303,0 & 123,2 \\
4.3 & 301,1 & 306,5 & 262,6 & 245,6 & 227,8 & 302,5 & 242,9
\end{tabular}

Ao analisar os demais valores da Tabela 6.8, nota-se que o CPLEX provê as melhores soluções para problemas do tipo monoestágio (1.1, 1.2, 1.3), enquanto a heurística relax-andfix forward (RF-FP) apresenta o melhor desempenho para problemas do tipo multiestágio (2.1, 2.2, 2.3, 3.1, 3.2, 3.3, 4.1, 4.2 e 4.3), com valores bem próximos aos da heurística relax-and-fix forward com pool de soluções (RF-FPSP). Portanto, para os testes das próximas seções, que possuem tempo limite para execução de uma hora, a heurística RF-FP terá a oportunidade de ser melhor avaliada.

Por fim, avaliando a heurística relax-and-fix por nível (RF-L), observa-se um baixo percentual de resolução para instâncias da subclasse 2.3, na qual o compartilhamento de tanques é máximo, o que provavelmente deve-se à configuração dos tanques geradas inicialmente, visto que esta é a mesma para as 5 instâncias de cada subclasse, e as demais subclasses tiveram todas as instâncias resolvidas.

A Tabela 6.9 apresenta o tempo médio de processamento das instâncias, levando em consideração todas as execuções, até as que não encontraram nenhuma solução factível. Apesar de alguns registros apresentarem tempo maior do que o limite de execução, este fato ocorre pois os tempo exibidos correspondem não somente aos processamentos de otimização, mas sim ao tempo gasto desde a inicialização das variáveis até as suas impressões e liberação da memória. Com relação à heurística relax-and-fix forward com pool de soluções (RF-FPSP), não houve a 
utilização total do tempo disponível, para esses testes, o que pode ter prejudicado um pouco seu desempenho.

Tabela 6.10: Variação do GAP médio para as heurísticas de melhoria.

\begin{tabular}{|c|c|c|c|c|}
\hline Subclasse & $\operatorname{MIP}(\%)$ & RF-FP(\%) & FO-P(\%) & FO-I(\%) \\
\hline 1.1 & $0,23^{[5]}$ & $0,37^{[5]}$ & $0,30^{[5]}$ & $\mathbf{0 , 1 8}{ }^{[5]}$ \\
\hline 2.1 & $0,80^{[5]}$ & $0,71^{[5]}$ & $0,74^{[5]}$ & $\mathbf{0 , 6 0}[5]$ \\
\hline 3.1 & $0,86^{[5]}$ & $0,81^{[5]}$ & $0,82^{[5]}$ & $\mathbf{0 , 7 4}[5]$ \\
\hline 4.1 & $1,25^{[4]}$ & $1,08^{[5]}$ & $1,12^{[5]}$ & $\mathbf{1 , 0 4}[5]$ \\
\hline 1.2 & $0,41^{[5]}$ & $0,58^{[5]}$ & $0,52^{[5]}$ & $\mathbf{0 , 3 9}[5]$ \\
\hline 2.2 & $2,46^{[5]}$ & $1,83^{[5]}$ & $1,87^{[5]}$ & $\mathbf{1 , 8 2}[5]$ \\
\hline 3.2 & $4,01[3]$ & $\mathbf{2 , 3 5}[5]$ & $2,51^{[5]}$ & $2,63^{[5]}$ \\
\hline 4.2 & $3,40^{[2]}$ & $\mathbf{2 , 6 1}[5]$ & $2,73^{[5]}$ & $2,83^{[5]}$ \\
\hline 1.3 & $\mathbf{0 , 8 0}[5]$ & $1,15^{[5]}$ & $1,10^{[5]}$ & $0,89^{[5]}$ \\
\hline 2.3 & $5,09[1]$ & $\mathbf{3 , 1 2}[5]$ & $3,38^{[5]}$ & $3,62^{[5]}$ \\
\hline 3.3 & - $[0]$ & $\mathbf{4 , 6 3}[5]$ & $4,93^{[5]}$ & $5,48^{[5]}$ \\
\hline 4.3 & - $[0]$ & $\mathbf{4 , 6 0}[5]$ & $5,06^{[5]}$ & $5,07[5]$ \\
\hline
\end{tabular}

Além das heurísticas construtivas, também foram avaliadas as de melhoria, do tipo fix-andoptimize, cujos GAPs são exibidos na Tabela 6.10. Como essas heurísticas devem partir de uma solução inicial, foi concedido um percentual do tempo total de processamento para que a relax-and-fix forward encontrasse essas soluções, o qual foi definido após análises de algumas execuções.

No caso da heurística fix-and-optimize por período (FO-P) destinou-se 50\% da execução para obtenção de uma solução inicial, visto que nem todo o tempo de processamento era utilizado na etapa de melhoria. Já para a heurística fix-and-optimize por item (FO-I) destinou-se $10 \%$ da execução para a obtenção de uma solução inicial, pois para percorrer todas as partições era gasto mais tempo do que na heurística anterior.

Ao analisar os GAPs médios da Tabela 6.10, nota-se que as heurísticas fix-and-optimize por item (FO-I) e relax-and-fix forward (RF-FP) obtiveram as melhores soluções, a primeira para as instâncias mais simples (sem compartilhamento de tanques e com poucos níveis) e a segunda para instâncias mais complexas (com compartilhamento de tanque e com múltiplos níveis), conforme os valores destacados em negrito.

\subsubsection{Instâncias Similares ao Problema da Indústria}

A real necessidade da empresa em estudo foi definir um procedimento eficiente para o planejamento da produção a médio prazo, portanto, é viável permitir que os testes computacionais 
utilizem um tempo maior de processamento.

Sendo assim, a partir desta etapa o tempo máximo de processamento foi alterado para uma hora e foram geradas mais 5 instâncias para a subclasse que mais se aproximava da realidade da empresa (4.2), ou seja, foram consideradas 10 instâncias com 281 produtos, estrutura de produtos com 4 níveis e compartilhamento médio de tanques entre os produtos, com no máximo dois por tanque.

Considerando este novo parâmetro, o tempo destinado às heurísticas de melhoria precisou ser revisto, um percentual muito pequeno do tempo total estava sendo utilizado. Dessa forma, para a fix-and-optimize por período (FO-P) foi designado 70,0\% do tempo de processamento para a etapa de obtenção da solução inicial, enquanto para a fix-and-optimize por item (FO-I) foi designado $66,6 \%$ do tempo de para a obtenção da solução inicial.

Neste experimento foram consideradas apenas as heurísticas mais promissoras: relax-andfix forward (RF-FP), relax-and-fix com pool de soluções (RF-FPSP), fix-and-optimize por período (FO-P) e fix-and-optimize por item (FO-I), além do modelo completo (MIP).

Tabela 6.11: Resultados obtidos pelas heurísticas para instâncias similares ao problema real.

\begin{tabular}{c|ccccc}
\hline$\#$ & MIP(\%) & RF-FP(\%) & RF-FPSP(\%) & FO-P(\%) & FO-I(\%) \\
\hline 1 & 3,20 & 3,22 & 3,21 & 3,21 & $\mathbf{3 , 1 6}$ \\
2 & $\mathbf{2 , 2 1}$ & 2,44 & 2,39 & 2,33 & 2,30 \\
3 & - & 2,39 & 2,40 & $\mathbf{2 , 2 7}$ & 2,30 \\
4 & - & 2,44 & 2,44 & 2,37 & $\mathbf{2 , 2 8}$ \\
5 & - & 2,38 & 2,37 & 2,38 & $\mathbf{2 , 3 4}$ \\
6 & 2,48 & 2,35 & 2,36 & 2,32 & $\mathbf{2 , 2 3}$ \\
7 & 2,47 & 2,46 & 2,47 & 2,47 & $\mathbf{2 , 3 4}$ \\
8 & - & 2,35 & 2,32 & 2,32 & $\mathbf{2 , 2 4}$ \\
9 & - & 2,66 & 2,68 & 2,56 & $\mathbf{2 , 5 2}$ \\
10 & - & 2,78 & 2,76 & 2,67 & $\mathbf{2 , 6 4}$ \\
\hline GAP médio & 2,59 & 2,55 & 2,54 & 2,49 & $\mathbf{2 , 4 4}$ \\
Tempo médio (s) & 3592,8 & 3599,1 & 3148,3 & 3351,1 & 3472,9
\end{tabular}

A Tabela 6.11 exibe os GAPs obtidos para cada uma das instâncias e o tempo médio de execução das heurísticas, segundo os quais é possível concluir que todos os métodos obtiveram soluções relativamente próximas umas das outras. Pode-se dizer que as heurísticas construtivas (RF-FP e RF-FPSP) tiveram desempenho praticamente semelhante, enquanto a heurística FO-I apresentou um GAP médio $0,05 \%$ melhor do que a FO-P, utilizando aproximadamente 2 minutos a mais de processamento.

Ainda deve-se ressaltar o fato do CPLEX ter encontrado soluções com qualidade próximas às das heurísticas, ao considerar o modelo completo, apresentado uma diferença média de 
0,15\% em relação ao GAP da FO-I e 0,04\% ao da RF-FP, a melhor e a pior heurística, respectivamente. Entretanto, a resolução do MIP completo porporcionou a obtenção de soluções factíveis em apenas $40 \%$ dos casos de teste.

\subsubsection{Compartilhamento de Tanques Exclusivo a Produtos Intermediá- rios}

$\mathrm{Na}$ indústria química em questão, muitos produtos não apresentam demanda interna, os chamados produtos finais. Como não há necessidade de mantê-los no setor de produção, visto que não serão mais utilizados, é possível enviá-los ao setor de embalagem imediatamente após seus processos produtivos serem finalizados.

Considerando esta característica, os dados das 10 instâncias mais representativas (4.2) foram modificados e eliminaram a necessidade dos produtos finais competirem pelos tanques de armazenamento, reduzindo o número de produtos que utilizam esses equipamentos de 281 para 96 e, consequentemente, a complexidade do problema. Os resultados dos testes com esta característica encontram-se na Tabela 6.12.

Tabela 6.12: Resultados obtidos pelas heurísticas para instâncias com compartilhamento de tanques apenas pelos produtos intermediários.

\begin{tabular}{c|ccccc}
\hline & MIP(\%) & RF-FP(\%) & RF-FPSP(\%) & FO-P(\%) & FO-I(\%) \\
\hline GAP médio (\%) & $1,57^{10]}$ & $1,4^{[10]}$ & $1,45^{[10]}$ & $1,45^{[10]}$ & $\mathbf{1 , 3 8}^{[10]}$ \\
\hline Tempo médio (s) & 3591,9 & 3593,5 & 3145,4 & 3440,1 & 2621,8
\end{tabular}

As heurísticas consideradas foram capazes de encontrar soluções para todas as instâncias, dentro do tempo limite de processamento. Mas é possível notar que a aplicação da heurística relax-and-fix forward (RF-FP) seguida da fix-and-optimize por item (FO-I) forneceu as melhores soluções com um tempo de processamento inferior ao das demais heurísticas.

\subsubsection{Modelo Considerando Custos de Preparação de Máquina}

Um último conjunto de testes foi projetado para abordar outra característica importante, a preparação de máquinas. Como não foi fornecida nenhuma informação sobre quais valores são empregados na prática, o objetivo neste momento é apenas reduzir o número de setups, ao escolher processos distintos, tentando evitar o aumento do custo produtivo. Portanto, a penalização considerada para este caso, conforme determinado na Subseção 6.3.3, corresponde ao próprio valor de venda dos produtos. 
Tabela 6.13: Resultados obtidos pelas heurísticas considerando o custo de setup.

\begin{tabular}{c|ccccc}
\hline & MIP(\%) & RF-FP(\%) & RF-FPSP(\%) & FO-P(\%) & FO-I(\%) \\
\hline GAP (\%) & $-[0]$ & $2,84^{[10]}$ & $2,86^{[10]}$ & $\mathbf{2 , 7 4}[10]$ & $5,66^{[10]}$ \\
Variação do GAP (\%) & - & 0,29 & 0,31 & 0,24 & 3,14 \\
Redução de setups (\%) & - & 9,27 & 9,44 & 9,10 & 18,35 \\
Tempo de execução (s) & 3592,7 & 3595,3 & 3148,8 & 3315,3 & 3040,9
\end{tabular}

As instâncias utilizadas nessa etapa foram as mesmas consideradas na Subseção 6.4.2 e os resultados encontram-se na Tabela 6.13, segundo a qual constata-se que nenhuma instância foi resolvida pelo MIP após uma hora de processamento.

Os GAPs foram calculados com relação aos mesmos limitantes dos testes anteriores, uma vez que o objetivo é avaliar o aumento do custo produtivo em relação à redução do número de setups. Portanto, após a determinação da solução incumbente das instâncias, para cada um dos métodos, os custos de setup foram desconsiderados do valor das funções objetivos para facilitar a análise dos resultados.

As soluções obtidas pela heurística fix-and-optimize por item (FO-I) apresentaram um desempenho pior do que o das demais heurísticas. Este fato deve-se, curiosamente, ao bom desempenho desta heurística para resolver o problema considerando os custos de setup, quando o número de preparações necessárias em suas soluções foi muito menor do que para as outras heurísticas. Porém, ao desconsiderar a contribuição do custo de setup da função objetivo, a parcela restante, composta pelos custos de produção, estocagem e descarte, foi consideravelmente maior do que os das demais soluções.

Como o objetivo era reduzir o número de setups evitando o aumento do custo da função objetivo original, as demais heurísticas apresentaram resultados satisfatórios, reduzindo mais de $9,0 \%$ do número total de setups com um aumento em torno de $0,3 \%$ da função objetivo. Portanto, caso o tempo e/ou o custo de setup sejam considerados altos pela empresa, esta estratégia pode ser muito interessante para o seu planejamento da produção. 


\section{CAPÍtUlo 7}

\section{CONCLUSÕES E TRABALHOS FUTUROS}

Neste trabalho foi abordado um problema de dimensionamento de lotes inspirado em uma indústria química composto por múltiplos itens com estrutura multiestágio, com restrições de capacidade, múltiplas máquinas, múltiplos processos e compartilhamento de tanques entre produtos. O seu objetivo era encontrar um planejamento da produção que atendesse às demandas da indústria, buscando minimizar os custos produtivos para auxiliar na etapa de aquisição de matérias-primas, visto que diversos produtos apresentavam vários processos produtivos distintos, os quais utilizavam reagentes diferentes.

A base deste estudo teve como origem o trabalho de conclusão de curso de Alvares (2010), no qual foi proposto um modelo matemático, representando a etapa produtiva da indústria de forma simplificada, que visava maximizar o lucro da empresa ao tratar problemas reduzidos com estrutura de produtos de até dois níveis e 21 itens. Porém, quando foi considerado uma estrutura com três níveis e 22 produtos, o software de otimização CPLEX 12.2 não foi capaz de encontrar uma solução factível, a partir do modelo, após tempo limite de processamento de 2 horas.

Inicialmente foram utilizados os dados fornecidos pela indústria para a geração das instâncias, preservando apenas a estrutura dos processos produtivos, mas alterando as demais informações, como demanda e preço de venda dos produtos, custo das matérias-primas, capacidade dos tanques e reatores, entre outros. 
Em seguida foi proposto um modelo para minimizar os custos produtivos que também considerou a possibilidade de descarte de produtos, já que as demandas de cada instância não necessariamente eram múltiplas dos volumes das bateladas e, consequentemente, quando dois produtos que compartilhavam um tanque de armazenamento apresentavam estoque ao final do período, um deles deveria ser descartado para não tornar a instância infactível. Ainda foi considerada uma segunda função objetivo que considera o custo de preparação de máquinas, cujo objetivo secundário era minimizar o número total de processos utilizados, tornando a abordagem mais realista.

Para a resolução dos casos de teste, foram apresentadas três heurísticas construtivas do tipo LP-and-fix e quatro do tipo relax-and-fix. Neste último caso, utilizou-se uma variação para a mais promissora (RF-FP), sendo considerado um pool de soluções contendo as melhores soluções encontradas até o momento, visando aumentar o espaço de busca em relação à sua forma tradicional. Também foram apresentadas duas heurísticas de melhoria do tipo fix-andoptimize.

Considerando os experimentos com até 5 minutos de processamento, a heurística relax-andfix forward (RF-FP) mostrou-se a mais promissora das construtivas, sendo capaz de resolver todas as instâncias com estrutura de produtos multiestágio com GAP menor do que as demais. Com relação às heurísticas de melhoria, a fix-and-optimize com decomposição orientada a itens (FO-I) obteve desempenho médio superior à que considerava decomposição por período em 10 das 15 subclasses de instâncias e superior à RF-FP em 7 das 15 subclasses.

Já nos experimentos com até 1 hora de processamento, quando foram consideradas instâncias mais parecidas com o problema real enfrentado pela indústria, as quatro heurísticas testadas (RF-FP, RF-FPSP, FO-P e FO-I) obtiveram resultados muito próximos, com uma pequena superioridade para a fix-and-optimize com decomposição por itens (FO-I), apresentando um GAP médio $0.11 \%$ menor do que a relax-and-fix forward (RF-FP), a qual obteve os piores resultados médios.

Ainda considerando esse experimento, os GAPs médios obtidos pelo software CPLEX 12.4 ao resolver o modelo inteiro misto completo foram próximos aos obtidos pelas heurísticas, contudo, ele foi capaz de resolver apenas 4 das 10 instâncias de teste. Outra constatação relevante é o fato dos GAPs obtidos não terem apresentado uma variação muito grande em relação às execuções com 5 minutos, compreendendo o intervalo de $0.06 \%$ a $0.39 \%$, para as heurísticas relax-and-fix forward (RF-FP) e fix-and-optimize com decomposição por itens (FO-I), respectivamente.

Nos últimos dois experimentos, em que foi analisado o compartilhamento de tanques ex- 
clusivos para os produtos intermediários e o custo de preparação de máquina, a heurística fixand-optimize com decomposição por itens (FO-I) obteve as melhores soluções. Entretanto, para o problema com custo de preparação de máquina, esta superioridade não resultou em soluções mais eficientes, visto que a solução obtida com essa função objetivo foi utilizada para determinar o custo do planejamento considerando a função objetivo original. Dessa forma, apesar de reduzir o dobro de setups ao ser comparado com as demais, o custo do planejamento sofreu um acréscimo dez vezes maior do que o observado nas outras três heurísticas.

Como pesquisas futuras pode-se abordar o desenvolvimento de heurísticas para auxiliar a seleção dos processos produtivos mais promissores, permitir atraso na entrega dos produtos, estudar a estrutura de múltiplas plantas, com as características de transferência de produtos e matérias-primas, ou ainda incluir tempo de preparação de máquinas. Por outro lado, também poderia ser reduzido o número de produtos das instâncias, mudando o enfoque para um estudo mais teórico, criando dificuldades adicionais como, por exemplo, escassez de recursos em determinados períodos e estruturas multiestágio com mais níveis, favorecendo um estudo mais detalhado das heurísticas, principalmente com relação à utilização do pool de soluções, que pode levar a bons resultados. 


\section{REFERÊNCIAS BIBLIOGRÁFICAS}

AKARTUNALI, K.; MILLER, A. J. A heuristic approach for big bucket multi-level production planning problems. European Journal of Operational Research, v. 193, n. 2, p. 396 - 411, 2009.

ALVARES, S. T. Um problema de planejamento da produção em uma indústria química: Proposta de um modelo matemático. Trabalho de Conclusão de Curso, ICMC/USP, 2010.

ARAUJO, S. A. d.; ARENALES, M. N. Problema de dimensionamento de lotes monoestágio com restrição de capacidade: modelagem, método de resolução e resultados computacionais. Pesquisa Operacional, scielo, v. 20, n. 2, p. 287 - 306, 122000.

ARAUJO, S. A. de; ARENALES, M. N.; CLARK, A. R. Lot sizing and furnace scheduling in small foundries. Computers \& Operations Research, v. 35, n. 3, p. 916 - 932, 2008.

ARMENTANO, V. A.; FRANÇA, P. M.; TOLEDO, F. M. de. A network flow model for the capacitated lot-sizing problem. Omega, v. 27, n. 2, p. 275 - 284, 1999.

BALAS, E. Intersection cuts-a new type of cutting planes for integer programming. Operations Research, v. 19, n. 1, p. 19-39, 1971.

BARNHART, C.; JOHNSON, E. L.; NEMHAUSER, G. L.; SAVELSBERGH, M. W. P.; VANCE, P. H. Branch-and-price: Column generation for solving huge integer programs. Operations Research, v. 46, n. 3, p. 316-329, 1998.

BAUMANN, P.; TRAUTMANN, N. A continuous-time MILP model for short-term scheduling of make-and-pack production processes. International Journal of Production Research, v. 51, n. 6, p. 1707-1727, 2013.

BELVAUX, G.; WOLSEY, L. A. bc - prod: A specialized branch-and-cut system for lot-sizing problems. Management Science, v. 46, n. 5, p. 724-738, 2000.

BERRETTA, R.; RODRIGUES, L. F. A memetic algorithm for a multistage capacitated lotsizing problem. International Journal of Production Economics, v. 87, n. 1, p. 67 - 81, 2004. 
BILLINGTON, P. J.; MCCLAIN, J. O.; THOMAS, L. J. Mathematical programming approaches to capacity-constrained MRP systems: Review, formulation and problem reduction. $M a$ nagement Science, v. 29, n. 10, p. 1126-1141, 1983.

BILLINGTON, P. J.; MCCLAIN, J. O.; THOMAS, L. J. Heuristics for multilevel lot-sizing with a bottleneck. Management Science, v. 32, n. 8, p. 989-1006, 1986.

BLACKBURN, J. D.; MILLEN, R. A. Simultaneous lot-sizing and capacity planning in multistage assembly processes. European Journal of Operational Research, v. 16, n. 1, p. 84 - 93, 1984.

BURKARD, R. E.; KOCHER, M.; RUDOLF, R. Rounding strategies for mixed integer programs arising from chemical production planning. Citeseer, 1997.

CARRENO, J. J. Economic lot scheduling for multiple products on parallel identical processors. Management Science, v. 36, n. 3, p. 348-358, 1990.

CATTRYSSE, D.; MAES, J.; WASSENHOVE, L. N. V. Set partitioning and column generation heuristics for capacitated dynamic lotsizing. European Journal of Operational Research, v. 46, n. 1, p. $38-47,1990$.

CHOPRA, S.; MEINDL, P. Gerenciamento da cadeia de suprimentos: estratégia, planejamento e operação. [S.1.]: Pearson Education do Brasil, 2008.

CLARK, A. R.; ARMENTANO, V. A. The application of valid inequalities to the multi-stage lot-sizing problem. Computers \& Operations Research, v. 22, n. 7, p. 669 - 680, 1995.

DENIZEL, M.; SÜRAL, H. On alternative mixed integer programming formulations and LPbased heuristics for lot-sizing with setup times. Journal of the Operational Research Society, v. 57, n. 4, p. 389-399, 2006.

DIABY, M. Multi-item scheduling by Lagrangean relaxation: Capacitated lot-sizing. Tese (Doutorado) - State University of New York at Buffalo, Buffalo, NY, 1987. apud (DIABY et al., 1992).

DIABY, M.; BAHL, H.; KARWAN, M.; ZIONTS, S. Capacitated lot-sizing and scheduling by lagrangean relaxation. European Journal of Operational Research, v. 59, n. 3, p. 444 - 458, 1992.

DIXON, P. S.; SILVER, E. A. A heuristic solution procedure for the multi-item, single-level, limited capacity, lot-sizing problem. Journal of Operations Management, v. 2, n. 1, p. 23 - 39, 1981.

DREXL, A.; KIMMS, A. Lot sizing and scheduling - survey and extensions. European Journal of Operational Research, v. 99, n. 2, p. 221 - 235, 1997.

ELMAGHRABY, S. E. The economic lot scheduling problem (ELSP): Review and extensions. Management Science, v. 24, n. 6, p. 587-598, 1978.

FEDERGRUEN, A.; MEISSNER, J.; TZUR, M. Progressive interval heuristics for multi-item capacitated lot-sizing problems. Operations Research, v. 55, n. 3, p. 490-502, 2007. 
FERREIRA, D.; MORABITO, R.; RANGEL, S. Relax and fix heuristics to solve one-stage one-machine lot-scheduling models for small-scale soft drink plants. Computers \& Operations Research, v. 37, n. 4, p. $684-691,2010$.

FLEISCHMANN, B.; MEYR, H. The general lotsizing and scheduling problem. OperationsResearch-Spektrum, v. 19, n. 1, p. 11-21, 1997.

FLORIAN, M.; LENSTRA, J. K.; KAN, A. H. G. R. Deterministic production planning: Algorithms and complexity. Management Science, v. 26, n. 7, p. 669-679, 1980.

FRANÇA, P. M.; ARMENTANO, V. A.; BERRETTA, R. E.; CLARK, A. R. A heuristic method for lot-sizing in multi-stage systems. Computers \& Operations Research, v. 24, n. 9, p. 861 874, 1997.

FÜNDELING, C.-U.; TRAUTMANN, N. Scheduling of make and pack plants: a case study. In: MARQUARDT, W.; PANTELIDES, C. (Ed.). 16th European Symposium on Computer Aided Process Engineering and 9th International Symposium on Process Systems Engineering. [S.1.]: Elsevier, 2006. v. 21, p. 1551 - 1556.

GALEMBECK, F.; SANTOS, A. C. M. d.; SCHUMACHER, H. C.; RIPPEL, M. M.; ROSSETO, R. Indústria química: evolução recente, problemas e oportunidades. Química Nova, v. 30, n. 6, p. 1413 - 1419, 122007.

GEOFFRION, A. Lagrangean relaxation for integer programming. In: BALINSKI, M. (Ed.). Approaches to Integer Programming. [S.1.]: Springer Berlin Heidelberg, 1974, (Mathematical Programming Studies, v. 2). p. 82-114.

GONDRAN, M.; MINOUX, M. Graphs and algorithms. [S.1.]: Johy Wiley \& Sons, New York, 2008.

GRUNOW, M.; GÜNTHER, H.-O.; LEHMANN, M. Campaign planning for multi-stage batch processes in the chemical industry. OR Spectrum, v. 24, n. 3, p. 281-314, 2002.

GÜNTHER, H. Planning lot sizes and capacity requirements in a single stage production system. European Journal of Operational Research, v. 31, n. 2, p. 223 - 231, 1987.

HARRIS, F. W. How many parts to make at once. Factory, The Magazine of Management, v. 10, n. 2, p. 135-136, 152, 1913.

HARRISON, T. P.; LEWIS, H. S. Lot sizing in serial assembly systems with multiple constrained resources. Management Science, v. 42, n. 1, p. 19-36, 1996.

HEINRICH, C. Mehrstufige Losgrössenplanung in Hierarchisch Strukturierten Produktionsplanungssystemen. [S.1.]: Springer-Verlag, Berlin, 1987 (in german). apud (TEMPELMEIER; HELBER, 1994).

HELBER, S. Lot sizing in capacitated production planning and control systems. OperationsResearch-Spektrum, v. 17, n. 1, p. 5-18, 1995.

HELBER, S.; SAHLING, F. A fix-and-optimize approach for the multi-level capacitated lot sizing problem. International Journal of Production Economics, v. 123, n. 2, p. 247 - 256, 2010 . 
HEUTS, R.; SEIDEL, H.; SELEN, W. A comparison of two lot sizing-sequencing heuristics for the process industry. European Journal of Operational Research, v. 59, n. 3, p. 413 - 424, 1992.

JAMES, R. J.; ALMADA-LOBO, B. Single and parallel machine capacitated lotsizing and scheduling: New iterative mip-based neighborhood search heuristics. Computers \& Operations Research, v. 38, n. 12, p. $1816-1825,2011$.

JENSEN, P.; BARNES, J. Network flow programming. [S.1.]: Johy Wiley \& Sons, New York, 1980.

KALLRATH, J. Planning and scheduling in the process industry. OR Spectrum, v. 24, n. 3, p. 219-250, 2002.

KARIMI, B.; GHOMI, S. F; WILSON, J. The capacitated lot sizing problem: a review of models and algorithms. Omega, v. 31, n. 5, p. 365 - 378, 2003.

KATOK, E.; LEWIS, H. S.; HARRISON, T. P. Lot sizing in general assembly systems with setup costs, setup times, and multiple constrained resources. Management Science, v. 44, n. 6, p. 859-877, 1998.

KIRCA, O.; KÖKTEN, M. A new heuristic approach for the multi-item dynamic lot sizing problem. European Journal of Operational Research, v. 75, n. 2, p. 332 - 341, 1994.

KUIK, R.; SALOMON, M.; WASSENHOVE, L. N. V.; MAES, J. Linear programming, simulated annealing and tabu search heuristics for lotsizing in bottleneck assembly systems. IIE Transactions, v. 25, n. 1, p. 62-72, 1993.

LAMBRECHT, M. R.; VANDERVEKEN, H. Heuristic procedures for the single operation, multi-item loading problem. A IIE Transactions, v. 11, n. 4, p. 319-326, 1979.

LAND, A. H.; DOIG, A. G. An automatic method of solving discrete programming problems. Econometrica, The Econometric Society, v. 28, n. 3, p. 497-520, 1960.

LANG, J. C.; SHEN, Z.-J. M. Fix-and-optimize heuristics for capacitated lot-sizing with sequence-dependent setups and substitutions. European Journal of Operational Research, v. 214, n. 3 , p. $595-605,2011$.

LEISERSON, C. E.; STEIN, C.; RIVEST, R. L.; CORMEN, T. H. Algoritmos: Teoria e Prática. [S.1.]: Campus, 2002.936 p.

LOZANO, S. Planificación de la producción con costes fijos. soluciones heuristicas de tipo primal-dual. Unpublished Ph.D. dissertation, Universidad de Sevilla. 1987.

LOZANO, S.; LARRANETA, J.; ONIEVA, L. Primal-dual approach to the single level capacitated lot-sizing problem. European Journal of Operational Research, v. 51, n. 3, p. 354 - 366, 1991.

LUCHE, J. R. D.; MORABITO, R.; PUREZA, V. Combining process selection and lot sizing models for production scheduling of electrofused grains. Asia-Pacific Journal of Operational Research, v. 26, n. 03, p. 421-443, 2009. 
MAES, J.; MCCLAIN, J. O.; WASSENHOVE, L. N. V. Multilevel capacitated lotsizing complexity and lp-based heuristics. European Journal of Operational Research, v. 53, n. 2, p. 131 $-148,1991$.

MAES, J.; WASSENHOVE, L. N. V. A simple heuristic for the multi item single level capacitated lotsizing problem. Operations Research Letters, v. 4, n. 6, p. 265 - 273, 1986.

MANNE, A. S. Programming of economic lot sizes. Management Science, v. 4, n. 2, p. 115$135,1958$.

MAUDERLI, A.; RIPPIN, D. Production planning and scheduling for multi-purpose batch chemical plants. Computers \& Chemical Engineering, v. 3, n. 1-4, p. 199 - 206, 1979.

MÉNDEZ, C. A.; CERDÁ, J.; GROSSMANN, I. E.; HARJUNKOSKI, I.; FAHL, M. State-ofthe-art review of optimization methods for short-term scheduling of batch processes. Computers \& Chemical Engineering, v. 30, n. 6-7, p. 913 - 946, 2006.

MERCÉ, C.; FONTAN, G. Mip-based heuristics for capacitated lotsizing problems. International Journal of Production Economics, v. 85, n. 1, p. 97 - 111, 2003.

POCHET, Y.; WOLSEY, L. A. Production planning by mixed integer programming. [S.1.]: Springer Verlag, 2006.

RUSSELL, T. W. F.; ROBINSON, A. S.; WAGNER, N. J. Mass and Heat Transfer. [S.1.]: Cambridge University Press, 2008.

SABBAG, Z. Planejamento da Produção em Máquinas Paralelas Sob Restrições de Capacidade. Dissertação (Mestrado) — Universidade Estadual de Campinas, UNICAMP, Brasil, 1993.

SAHINIDIS, N.; GROSSMANN, I. Reformulation of multiperiod MILP models for planning and scheduling of chemical processes. Computers \& Chemical Engineering, v. 15, n. 4, p. 255 $-272,1991$.

SAHLING, F.; BUSCHKÜHL, L.; TEMPELMEIER, H.; HELBER, S. Solving a multi-level capacitated lot sizing problem with multi-period setup carry-over via a fix-and-optimize heuristic. Computers \& Operations Research, v. 36, n. 9, p. 2546 - 2553, 2009.

SALOMON, M.; KROON, L. G.; KUIK, R.; WASSENHOVE, L. N. V. Some extensions of the discrete lotsizing and scheduling problem. Management Science, v. 37, n. 7, p. 801-812, 1991.

SANTOS, M. O.; ALMADA-LOBO, B. Integrated pulp and paper mill planning and scheduling. Computers \& Industrial Engineering, v. 63, n. 1, p. 1 - 12, 2012.

SCHMIDT, L. The Engineering of Chemical Reactions. [S.1.]: Oxford University Press, 1998.

SELEN, W.; HEUTS, R. A modified priority index for Günther's lot-sizing heuristic under capacitated single stage production. European Journal of Operational Research, v. 41, n. 2, p. $181-185,1989$.

SELEN, W.; HEUTS, R. Operational production planning in a chemical manufacturing environment. European Journal of Operational Research, v. 45, n. 1, p. 38 - 46, 1990. 
STADTLER, H. Multilevel lot sizing with setup times and multiple constrained resources: Internally rolling schedules with lot-sizing windows. Operations Research, v. 51, n. 3, p. 487-502, 2003.

SUSARLA, N.; KARIMI, I. Integrated campaign planning and resource allocation in batch plants. In: PIERUCCI, S.; FERRARIS, G. B. (Ed.). 20th European Symposium on Computer Aided Process Engineering. [S.1.]: Elsevier, 2010. v. 28, p. 1183 - 1188.

TEMPELMEIER, H.; DERSTROFF, M. Mehrstufige mehrprodukt-losgrößenplanung bei beschränkten ressourcen und genereller erzeugnisstruktur. Operations-Research-Spektrum, v. 15, n. 2, p. 63-73, 1993.

TEMPELMEIER, H.; DERSTROFF, M. A lagrangean-based heuristic for dynamic multilevel multiitem constrained lotsizing with setup times. Management Science, v. 42, n. 5, p. 738-757, 1996.

TEMPELMEIER, H.; HELBER, S. A heuristic for dynamic multi-item multi-level capacitated lotsizing for general product structures. European Journal of Operational Research, v. 75, n. 2, p. $296-311,1994$.

TOLEDO, F. M. B. Dimensionamento de lotes em máquinas paralelas. Tese (Doutorado) Universidade Estadual de Campinas, UNICAMP, Brasil, 1998.

TOLEDO, F. M. B.; ARMENTANO, V. A. A lagrangian-based heuristic for the capacitated lotsizing problem in parallel machines. European Journal of Operational Research, v. 175, n. 2, p. $1070-1083,2006$.

TRIGEIRO, W. W.; THOMAS, L. J.; MCCLAIN, J. O. Capacitated lot sizing with setup times. Management Science, v. 35, n. 3, p. 353-366, 1989.

WAGELMANS, A.; HOESEL, S. van; KOLEN, A. Economic lot sizing: An O(n log n) algorithm that runs in linear time in the wagner-whitin case. Operations Research, v. 40, n. 1Supplement-1, p. 145-156, 1992.

WAGNER, H. M.; WHITIN, T. M. Dynamic version of the economic lot size model. Management Science, v. 5, n. 1, p. 89-96, 1958.

XIE, J.; DONG, J. Heuristic genetic algorithms for general capacitated lot-sizing problems. Computers \& Mathematics with Applications, v. 44, n. 1-2, p. 263 - 276, 2002. 